\title{
Land as a Renewable Resource: Integrating Climate, Energy, and Profitability Goals using an Agent-Based NetLogo Model
}

Inocencio Rodriguez

West Virginia University

Follow this and additional works at: https://researchrepository.wvu.edu/etd

\section{Recommended Citation}

Rodriguez, Inocencio, "Land as a Renewable Resource: Integrating Climate, Energy, and Profitability Goals using an Agent-Based NetLogo Model" (2012). Graduate Theses, Dissertations, and Problem Reports.

3547.

https://researchrepository.wvu.edu/etd/3547

This Dissertation is protected by copyright and/or related rights. It has been brought to you by the The Research Repository @ WVU with permission from the rights-holder(s). You are free to use this Dissertation in any way that is permitted by the copyright and related rights legislation that applies to your use. For other uses you must obtain permission from the rights-holder(s) directly, unless additional rights are indicated by a Creative Commons license in the record and/ or on the work itself. This Dissertation has been accepted for inclusion in WVU Graduate Theses, Dissertations, and Problem Reports collection by an authorized administrator of The Research Repository @ WVU.

For more information, please contact researchrepository@mail.wvu.edu. 
Land as a Renewable Resource: Integrating Climate, Energy, and Profitability Goals using an Agent-Based NetLogo Model

\title{
Inocencio Rodríguez
}

Dissertation Submitted to the Davis College of Agriculture, Natural Resources and Design at West Virginia University

in Partial Fulfillment of the Requirements

for the Degree of

\author{
Doctor of Philosophy \\ in \\ Natural Resource Economics
}

Gerard E. D’Souza, Ph.D., Chair

Alan Collins, Ph.D.

Thomas Griggs, Ph.D.

Donald Lacombe, Ph.D.

Timothy Phipps, Ph.D.

Agricultural and Resource Economics Program
Division of Resource Management
West Virginia University

Morgantown, WV

2012

Keywords: Multifunctional Land Use; Spatial; Renewable Resources; Climate; Pasture-Based Beef; NetLogo

Copyright 2012 Inocencio Rodríguez 


\section{ABSTRACT \\ Land as a Renewable Resource: Integrating Climate, Energy, and Profitability Goals Using an Agent-Based NetLogo Model}

\section{Inocencio Rodríguez}

Product innovations and new production configurations are a growing part of the economy. In the case of agriculture, this product development is driven mainly by the increased demand for more healthful, nutritious, fresh and locally grown food products as well as the growing recognition that agriculture can provide more than just food. There is obviously a potential increase in private benefits to producers/landowners as a result of increased production of established and niche crops to satisfy this demand. What is less obvious is the potential to also generate increased social benefits, particularly as they relate to energy conservation, alternative energy development and carbon offsets. Overall, the objective of this analysis is to develop a conceptual framework and an associated model to illustrate the conditions under which it is feasible for a farm to produce multiple products. Our approach includes the production of food, energy, and carbon offsets in a way that enhances profitability at the farm-level while enabling surrounding communities to benefit from high quality food products, environmental improvement, economic development and, ultimately, quality of life. Using an optimal control framework and an agent-based simulation model, we apply this analysis to the case of pasturebased beef (PBB) in West Virginia.

The objectives of this study center over the course of the beef production life cycle as a management strategy to optimize the financial and natural resource endowment on farms at the county level based on the data available. Although the application is to West Virginia, implications can be derived for other areas with similar resource endowments. The beef farms located in adjacent locations within a county are identified as suppliers of inputs to the farm of interest (or contracting farm) in order to provide the basic foundation for agglomeration economies. The idea is to interconnect the farmer, society, and the ecosystem in ways that meet both private and social goals. Obviously, the production configuration envisioned here is somewhat forward looking and futuristic, but one that is based on emerging trends and societal priorities. It involves decision-making at the individual farm-level, as with current operations, but greater cooperation and/or contracting with surrounding farms in a way that enhances the ability of the farm to reap benefits associated with clustering or agglomeration, as with other industries.

Both an intertemporal component and a spatial component are involved since clustering systems are enhanced when key players are interconnected over space. This is accomplished by using an optimal control framework as the basis of a NetLogo agent-based model (ABM) that explicitly includes a spatial component. This model is intended to provide a foundation for developing agglomeration economies in which other locations are able to supply resources to given locations - or to serve as input markets - by taking advantage of the spatially integrated nature of the agriculture industry. The spatial component provides the basis for regional economic development through clustering among the agricultural and other sectors since they might share locally produced inputs/outputs in the supply chain, thereby enhancing both scope economies and agglomeration economies. Thus, the integration of environmentally friendly technologies that enhance diversified products for the area such as renewable energy as well as 
digested manure along with high quality beef products and carbon offsets would create new markets which expand market channels and spur economic development, of interest to policy makers at all levels. As a result, farmers would be able not only to produce essential inputs for their own farms but, given appropriate incentives, would also supply them to adjacent farms boosting the local economy. Furthermore, a comparison with conventional, confined animal feeding operations (CAFOs), is briefly provided for perspective as well as the basis for environmental improvement through PBB techniques. Our intention is to replicate a diversified PBB industry and its interaction with surrounding communities in order to identify the optimized paths of the farmer and society in an intertemporal setting. The design of policy instruments is based on the results from the ABM wherein maximizing farm-level profitability that is able to bring benefits to society in which clustering among locations contributes in intensifying the benefits from the adoption of sustainable best management practices (BMPs). Thus, the explicit recognition and use of multifunctional land attributes enables us to address bio-fuel production and climate-related issues such as carbon offsets as well as to expand adoption of sustainable BMPs across space and time. In order to determine policy instruments, we ran our ABM with the absence of carbon prices and cost-share programs as well as different carbon prices and costshare percentages under different clustering systems along a planning horizon of 15 years. We also compared the profitability between a diversified entrepreneur with a specialized business as an approach to identify the financial motivation to establish our proposed business concept. Results indicate that in order to observe environmental and social benefits as well as economic development in Appalachia through the introduction of a diversified PBB industry, a combination of cost-share policies and carbon prices must be considered. Our results imply that for an average grass-fed beef enterprise with 93 acres of pastureland (as is typical of Appalachia) as the primary resource surrounded by nearby cow/calf farms within an approximate 20 mile radius, will need to rely on a minimum of $\$ 13$ per ton $\mathrm{CO}_{2} \mathrm{e}$ reduced along with a cost share program willing to share the risk of no less than half of the capital investment associated with an anaerobic digester within a clustering system of up to two participants to successfully diversify its business bringing environmental and economic development to the region. Alternatively, a policy combination of 50 percent cost share with a \$26 carbon price not only will enhance environmental improvement but also profitability under unexpected as well as certain weather conditions. We also found that more renewable energy can be generated when more farms join a regional cluster, implying a synergistic effect through clustering. We estimate results under both deterministic and stochastic situations. The latter relate primarily to weather uncertainty and animal death loss, since those are the variables for which data is available.

The results have implications for producers, the industry and policy makers in Appalachia and possibly other regions where niche products have the potential to enhance farm income while also contributing to societal objectives. Our approach illustrates one way in which a given sector such as farming can potentially contribute to the solution of "wicked problems" relating to energy, obesity, and quality of life. 


\section{ACKNOWLEDGEMENTS}

I would like to express my genuine thanks to Dr. Gerard D’Souza, my major advisor and committee chair, for his direction and encouragement throughout this once in a lifetime journey and giving me the privilege to work with him on this project. I also want to thank him for sharing his expertise and vision toward innovation. My gratitude also goes to my committee members, Dr. Alan Collins, Dr. Tim Phipps, Dr. Thomas Griggs and Dr. Donald Lacombe, for their constant insightful comments and knowledge within the context of my dissertation, courses and beyond the classroom.

Furthermore, I wish to express my gratitude to Dr. Edward Rayburn not only for his publications and sharing his expertise from past work but also for his availability and guidance. I also would like to thank Dr. Jan Thiele, Professor in the Ecoinformatics, Biometrics and Forest Growth Department at University of Goettingen, Germany and NetLogo-R-Extension designer, for his support during the NetLogo-R-Extension installation to be used in the ABM NetLogo model developed here.

In addition, I must thank the administrative staff including Dr. Jerald Fletcher, Dr. Dennis Smith, Dr. Peter Schaeffer, Mrs. Lisa Lewis, Mrs. Ellen Hartley-Smith and Mrs. Melanie Jimmie from their constant help and care during my graduate studies at WVU. Moreover, I wish to express my gratitude to the USDA, ARS-funded pasture-beef project for providing the funding to undertake this research project.

My special thanks also goes to my devoted wife, Rosamary, and to my two loving sons, Esteban and Sebastian, for their support, care and patience inspiring me to do my best and work hard. I also would like to thank my family in Puerto Rico that constantly sees me as an inspiration to my family members and close friends, especially the younger generations. 


\section{TABLE OF CONTENTS}

Abstract

ii

Acknowledgements

iv

List of Tables

vii

List of Figures

viii

CHAPTER I: INTRODUCTION

1.1 PROBLEM STATEMENT

8

1.2 SIGNIFICANCE OF THE STUDY

8

1.3 RESEARCH OBJECTIVES

CHAPTER II: REVIEW OF PREVIOUS WORK

2.1 THE STUDY AREA

2.2 TECHNOLOGY

2.3 PASTURE AS A PRIMARY INPUT

2.3.1 ANIMAL WELFARE

2.3.2 HUMAN HEALTH

2.3.3 ENERGY INPUT

2.3.4 RENEWABLE ENERGY

2.3.5 NATURAL FERTILIZER

2.3.6 CARBON SEQUESTRATION/OFFSET

2.4 OPTIMAL CONTROL MODEL

2.4.1 DYNAMIC OPTIMIZATION

2.4.2 OPTIMAL CONTROL APPROACHES

2.5 CLUSTERING SYSTEMS

2.5.1 AGGLOMERATION ECONOMIES

2.6 AGENT BASED MODELS

2.6.1 MODEL DEVELOPMENT

2.6.2 LANGUAGE PROGRAMMING

2.6.3 MODEL CONSIDERED

2.7 POLICY INSTRUMENTS

CHAPTER III: CONCEPTUAL FRAMEWORK

3.1 OBJECTIVE

27

3.2 MODEL AND EXPECTED RESULTS

CHAPTER IV: METHODOLOGY

4.1 OBJECTIVE

51

4.2 BEFERGYONET MODEL: AN OVERVIEW

53

4.3 EXPERIMENTAL MODEL: AGENTS, SYSTEM AND INTERACTIONS

60 
4.4 SELECTIONS: BUTTONS, CHOOSERS, SWITCHES AND MONITORS

4.5 OUTCOME FROM EMERGING PATTERNS: RESULTS GENERATION 69

4.6 SIMULATED EQUATIONS AND ASSUMPTIONS

$\begin{array}{ll}\text { CHAPTER V: RESULTS AND DISCUSSION } & 87\end{array}$

$\begin{array}{ll}\text { 5.1 RESULTS AND DISCUSSION } & 87\end{array}$

5.1.1 WORLD INTERACTION

5.1.2 BET MODEL AND OUTCOMES $\quad 92$

$\begin{array}{lr}\text { 5.1.3 SENSITIVITY ANALYSIS } & 105\end{array}$

5.1.3.1 ZERO CARBON PRICE, NO COST-SHARE PROGRAM 106

5.1.3.2 CARBON PRICES WITH NO COST-SHARE PROGRAM 108

5.1.3.3 CARBON PRICE (\$13) WITH COST-SHARE PROGRAM 109

5.1.3.4 CARBON PRICE (\$26) WITH COST-SHARE PROGRAM 110

CHAPTER VI: POLICY RECOMMENDATIONS 115

6.1 POLICY RECOMMENDATIONS 115

CHAPTER VII: SUMMARY AND CONCLUSIONS 120

7.1 SUMMARY AND CONCLUSIONS 120

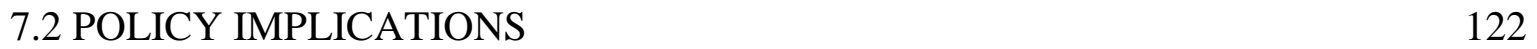

7.3 MODEL LIMITATIONS AND FUTURE RESEARCH 123

$\begin{array}{ll}\text { REFERENCES } & 127\end{array}$

$\begin{array}{ll}\text { APPENDIX } & 145\end{array}$ 


\section{LIST OF TABLES}

Page

Table 3.1: Definition of Variables 30

Table 4.1: Assumptions 53

Table 4.2: Scenarios 55

Table 5.1: Annual stocking rate in the farm of interest (stocker) over 15 years 100

Table 5.2: Annual stocking rate for adjacent cow/calf farms over 15 years 101

Table 5.3: Investment costs associated with anaerobic digester 105

Table A-1: Energy Data $\quad 145$

Table A-2: Climatological and WV County Data 145

Table A-3: Carbon Offset Market, Costs and Prices $\quad 145$

Table A-4: Steer Sold Price (\$ per cwt) 146

Table A-5: Other Beef Production Costs per Head 146

Table A-6: Energy Prices in Cents 147

Table A-7: Steer Purchasing Price (\$ per cwt) 147

Table A-8: Hauling Manure Costs Ton Per Mile 148

Table A-9: Manure Base Charge per Ton 148

Table A-10: Costs of Manure per Ton 149

Table A-11: Capital Costs Estimates of Anaerobic Digester 149

Table A-12: Annual Costs Associated with Forage Production 149 


\section{LIST OF FIGURES}

Figure 1.1: Grain-Fed Beef Concept 4

Figure 1.2: Pasture-Fed Beef Concept $\quad 7$

Figure 3.1: Paths of Soil Organic Matter and Pasture Mass 35

Figure 3.2: Effects of Soil Organic Matter on Pasture Mass and Beef Production 38

Figure 3.3: Effects of Stocking Rate on Forage Growth and Soil Organic Matter 39

Figure 3.4: Effects of Stocking Rate on Soil Organic Matter and Energy 42

Figure 3.5: Effects of Energy Production on $\mathrm{CO}_{2}$ Emissions 43

Figure 4.1: NetLogo-System Dynamics Modeler used for Simulation 58

Figure 4.2: NetLogo-System Dynamics Modeler: A Segment 59

Figure 4.3: NetLogo-Programming Language in Java 59

Figure 4.4: NetLogo-World Setting 60

Figure 4.5: Interactive World in NetLogo 62

Figure 4.6: NetLogo-Simulation Control Panel 68

Figure 5.1: Interaction between Farm of Interest and Cow/Calf Farms 88

Figure 5.2: Interaction among Agents within the System 89

Figure 5.3: Cattle Interaction during Grazing $\quad 89$

Figure 5.4: Interaction between Farm of Interest and Silage Business 90

Figure 5.5: Manure Collection during Winter Season 91

Figure 5.6: Estimates Illustrated in Interacting World 92

Figure 5.7: Simulation Results depicted in the Interface View 93

Figure 5.8: Instructions for Exporting Results 93

Figure 5.9: Outcome in a Spreadsheet Format $\quad 94$

Figure 5.10: Daily Pasture Growth in Pounds per Acre over One Year 95

Figure 5.11: Daily Pasture Growth in Pounds per Acre (15 years) 95

Figure 5.12: Daily Precipitations for One Year 96

Figure 5.13: Daily Precipitations for the Planning Horizon 96

Figure 5.14: Daily Temperature Fluctuations for One Year 97

Figure 5.15: Daily Temperature over the Planning Horizon 97

Figure 5.16: Total Annual Forage Yield per Acre over 98

Figure 5.17: NetLogo: Stocking Rate 99

Figure 5.18: NetLogo: Carbon Offset compared to $\mathrm{CO}_{2} \mathrm{e}$ baseline 102

Figure 5.19: Carbon Offset under 0, 3 and 5 Clustering Systems 102

Figure 5.20: NetLogo: Energy Generation during Winter Season 103

Figure 5.21: Energy Production under 0, 3 and 5 Clustering Systems 103

Figure 5.22: NetLogo: Beef Production 104

Figure 5.23 Annual Beef Production during System Interaction 104

Figure 5.24: NPV: Carbon Price Zero and No Cost-Share Program 107 
Figure 5.25: NetLogo: Unprofitable Notice is Prompted to Users 107

Figure 5.26: NetLogo: Unprofitability Notification in the Interacting World 108

Figure 5.27: NPV under Different Carbon Prices and No Cost-Share Program 109

Figure 5.28: NPV under \$13 Carbon Price and Cost-Share (20 and 50 percent) 110

Figure 5.29: NPV under \$26 Carbon Price and Cost-Share (20 and 50 percent) 111

Figure 5.30: NetLogo: Profitable Notice is Prompted to Users 111

Figure 5.31: NetLogo: Profitability Notification in the Interacting World 112

Figure A-1: Language Programming: Measuring Distance among Agents 150

Figure A-2: Language Programming: Parameter Estimations 150

Figure A-3: Language Programming: Coding Plots for the Interface View 151

Figure A-4: Language Programming: Coding Pasture Interaction 152 


\section{CHAPTER I: INTRODUCTION}

\section{Introduction}

The quality of land for current and future uses is a key factor influencing the sustainability of the pasture-based livestock industry. According to Perman et al. (2003), renewable resources are stock resources with the capability of regeneration over time such as plant and animal populations among others. However, these resources can also be exhaustible when their harvesting rate is higher than regeneration capabilities at the point of depleting the resources (Perman et al., 2003). Thus, land as a renewable resource can be used for farming over and over again as long as the resource continues to be productive. This occurs when appropriate farming techniques such as pasturelands for beef production take place; otherwise, farming would no longer be viable since land would be depleted. The more land we use for crop production, the fewer nutrients are available for future yield which will require higher amounts of fertilizers to satisfy the demand. Agricultural land could be a renewable resource if well-managed and sustainable practices are taken into account. The term "sustainable practices" is based on the definition of sustainability expressed in "Our Common Future” or the Brundland Report as “...development that meets the needs of the present without compromising the ability of future generations to meet their own needs” (WCED, 1987). The introduction of such sustainable practices as a PBB system and waste management for electricity production not only would bring benefits to farmers but also to society since they could result in economic development in the area while protecting natural resources for future needs. Nowadays, the use of BMPs in agricultural lands has become an essential component in food production in order to enhance high quality output as well as a better environment. In fact, BMPs is defined as "methods or techniques found to be the most effective and practical means in achieving an objective (such as 
preventing or minimizing pollution) while making the optimum use of the firm's resources.” (BDC, 2012).

Land quality is an essential component of the pasture-based industry since grass is the main ingredient in order to have more sustainable beef production. The increased use of pasture as the primary diet for cattle in the beef industry has been attributed to positive effects not only in terms of animal welfare but also to human health, land, and the ecosystem. In fact, lands characterized by having topographical constraints, limited soil fertility or erosion are able to be converted into more productive uses when pasture practices are implemented (Evans et at., 2007). A marketing claim that livestock is “pasture-raised” means animals have had "continuous and unconfined access to pasture throughout their life cycle” (Paine, et al., 2009). The American Gras-Fed Association, defines the closely related "grass-fed" concept as "food products from animals that have eaten nothing but their mother's milk and fresh grass or grass-type hay from birth to harvest-all their lives.” (AGA, 2011).

In addition, studies have demonstrated that the waste produced from livestock can be used as natural fertilizer as well as a source of alternative energy which eventually maintains land quality and provides renewable fuels to farmers, in the process reducing dependency on products derived from fossil fuels (Fulhage, et al., 1993, Pimentel and Pimentel, 2008). These practices make this industry more attractive since it becomes more self-reliant while maintaining agricultural lands for future production as well as protecting the environment with attendant societal benefits.

However, land might also be exhausted if it is not managed appropriately. History has shown that row crop production, along with intensive fertilizer applications and accompanying land tillage practices due to specialization has provoked land compaction, increased erosion as 
well as breakdown of the soil structure in regions such as Eastern Canada (StoneHouse and Bohl, 1990 ). Also, unlike pasture-based beef (PBB) practices in which some grass varieties do not require seeding for years, annual crop production such as corn requires tillage which diminishes water conservation as well as organic matter in the soil. In fact, the movement of soil particles, inorganic fertilizers and other chemical residues from farmland to downstream water bodies such as reservoirs and rivers at lower elevations leads to water degradation (StoneHouse and Bohl, 1990).

McConnell (1983) established that land degradation leads to two main externalities: the degradation of downstream bodies of water as well as a reduction of future food production as the two main externalities affecting the ecosystem (McConnell, 1983).

Figure 1.1 provides a description of the potential negative impacts of particular grain-fed beef practices, known also as conventional techniques, to farmers and surrounding communities which also represent the environmental conditions that would be targeted improvement by introducing the PBB industry. This figure represents a grain-fed beef farm in which animals tends to live in a confined environment or CAFOs. Confined conditions as well as a high diet on grain such as corn impact farmers as well as society in the following manner:

- Under these operational conditions, there are situations in which animals get sick because their diet (grain) gets contaminated with manure. Moreover, the use of grain as the primary diet for beef production causes acid-resistant conditions in the animals' intestines that motivate the reproduction of E. Coli counts in their stomach. Furthermore, confined conditions not only cause stress to animals which eventually will be reflected in diminished quality of the final product but also are directly exposed to other animals that might be ill so diseases are easily spread among the animals. This operational condition 
requires farmers to incur additional costs associated with antibiotics in order to improve animals' health.

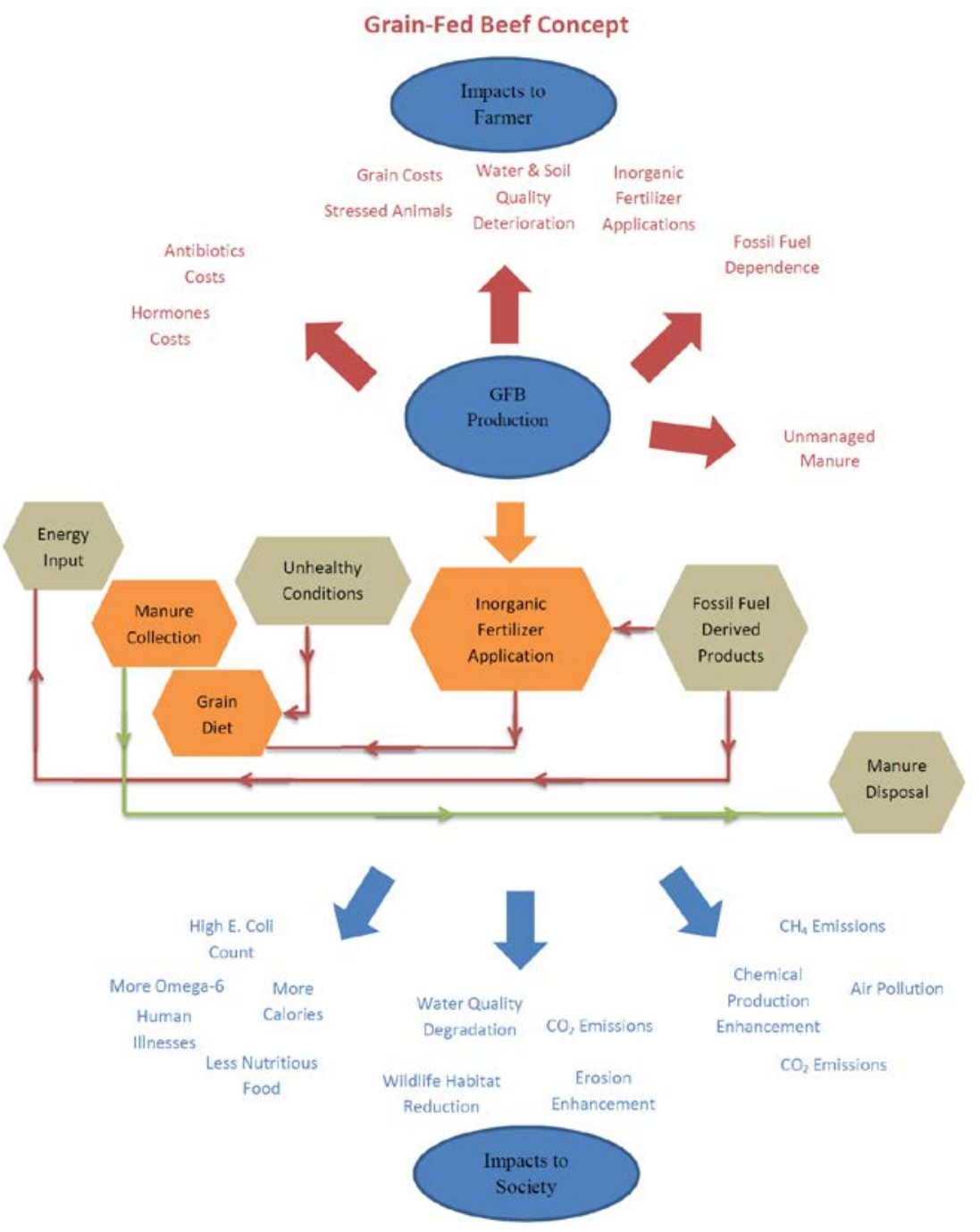

Figure 1.1: Grain-Fed Beef Concept

Also, beef farms that use grains such as corn as part of the livestock diet not only absorb the costs associated with these inputs regardless of whether they are grain growers or grain buyers but also contributes to the tillage and fertilizer application needed. Also, as a technique to boost animals' weight, farmers provide hormones to cattle which imply an increase on input costs. On the other hand, manure is usually deposited into lagoons or ponds that release methane to the 
atmosphere contributing to GHG emissions. Thus, the lack of appropriate manure management practices would increase greenhouse effects. Under this scenario, farmers rely on fossil fuel sources to satisfy their energy needs which also generate GHG emissions.

- Farmers' decisions obviously have an impact on society. The quality of the product might be negatively affected. For instance, E. Coli counts stored in the beef are transferred to humans through consumption as well as high levels of Omega-6 proving a less nutritious food that threatens human health. Also, due to the fact that grain production requires certain cultivating stages that lead to a decrease of water quality and wildlife habitat reduction through land tilling as well as erosion impacting the natural resources of the area. It also generates GHG emissions through the production of inorganic fertilizer required to satisfy grain yield as well as the use of the machinery required for growing grain, besides other energy inputs needed to operate the farm. GHG emissions would be also positively affected by methane emissions from the manure lagoons. The concentration of all these GHG emissions would cause air pollution and warming effects that would negatively affect nearby communities through drought, decay of vegetation, and asthma among other social problems. As a result, society would be impacted by grain-fed practices under confined operations.

If indeed the PBB industry has the potential for higher profitability and reduction in the negative externalities caused by conventional practices while contributing to the local and regional economy, transitioning to this type of system would be beneficial to society. Approximately 26 billion pounds of beef were consumed in the U.S. in 2010, most of which was produced domestically. This amount of beef had a market value of $\$ 74$ billion (Mathews and McConnell, 2011). In 2005, approximately $\$ 230$ was spent on beef products per U.S. household 
(Evans, et al., 2007). The economic value of this sector to the US is clearly large and well documented. What is less obvious is the ecosystem value of this production, and its associated contribution (or detraction) to the multi-attribute functions increasingly expected by society and policymakers from the land resource.

Figure 1.2 illustrates the PBB concept proposed in this research. It basically represents a diversified pasture-fed beef farm that integrates the collection of manure to produce renewable energy and natural fertilizer, a by-product from alternative energy production, as environmentally friendly as well as managerial strategies to enhance farm and social benefits. As we can observe, the integration of these sustainable practices not only provides natural conditions for animals by enhancing healthy diets and stress reduction that eventually is reflected in the quality of the beef but also more energy and fertilizer independence through improved waste management practices since manure is utilized and not deposited into lagoons or ponds. These techniques would bring the following benefits to farmers as well as society:

- Farmers benefit from the proposed concept since they do not incur costs associated with antibiotics, hormones and grains on a regular basis since animals are exposed to a healthy diet and natural environment which make them more resistant to diseases. Moreover, the use of digested manure, a by-product from renewable energy production, as a fertilizer reduces the costs associated with inorganic fertilizer purchases to be applied on pasturelands providing the nutrients required for pasture production while any excess can be sold to nearby farms. In addition, the electricity produced from manure can either be used to satisfy the farm’s energy needs or sold to utility companies as a source of income.

- Society would also benefit when these management practices are taken into account. The production of pasture as the primary input in the animals' diet contributes to low E. Coli 
counts and healthy essential nutrients through beef consumption. Furthermore, grasslands reduce land erosion (StoneHouse and Bohl, 1990 ) that otherwise would decrease water quality (Saliba, 1985), as well as enhance wildlife diversification and $\mathrm{CO}_{2}$ sequestration improving the attractiveness of the area and human health conditions associated with greenhouse emissions. Society also benefits from alternative energy production and its by-product since it not only provides cleaner energy sources but also reduces the need of inorganic fertilizer production offsetting $\mathrm{CO}_{2}$ emissions.

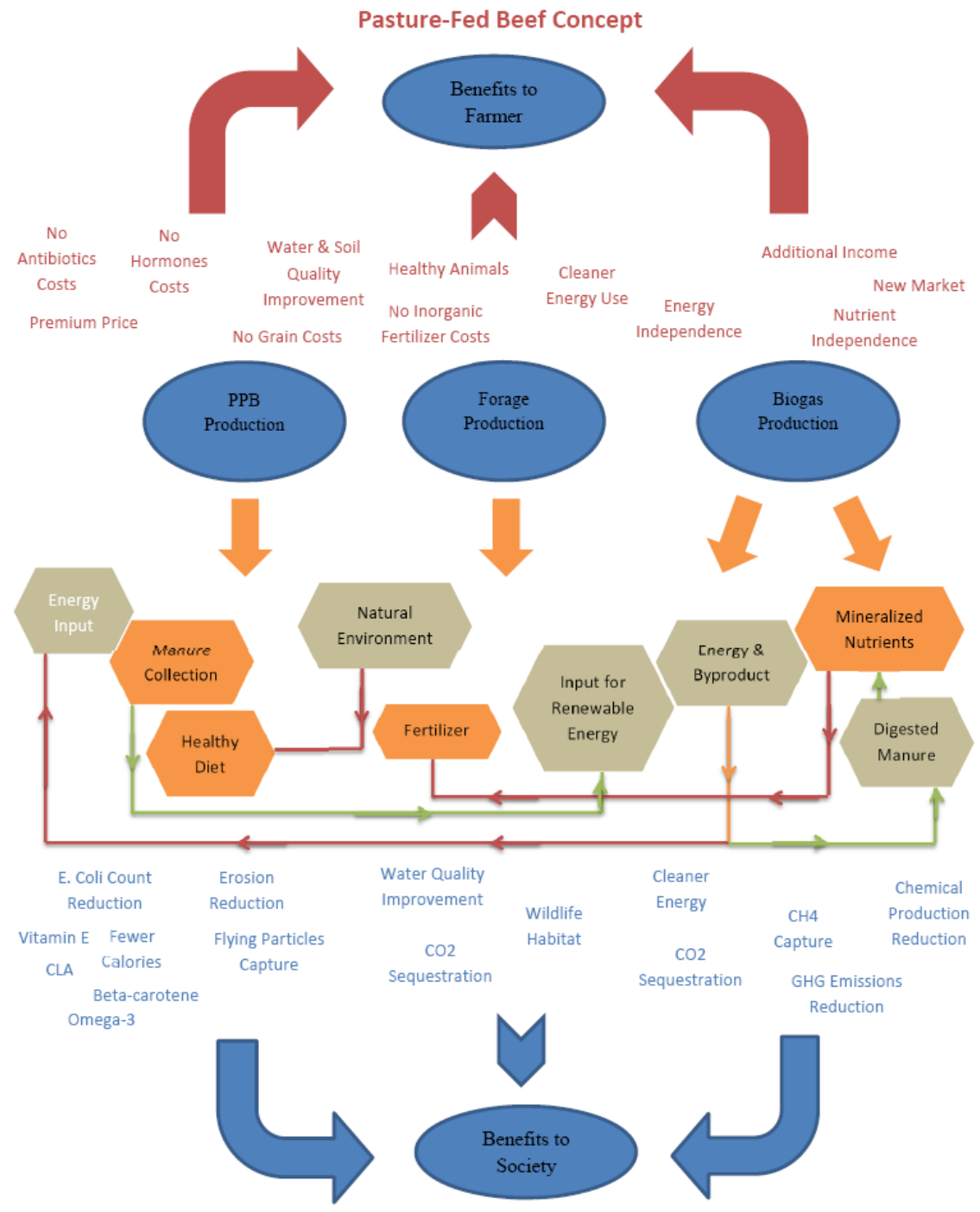

Figure 1.2: Pasture-Fed Beef Concept 
This study is part of a larger, interdisciplinary multi-institutional research project funded by USDA, ARS, focusing on the development of sustainable PBB systems for Appalachia.

\subsection{Problem Statement}

The study area is West Virginia (WV), characteristic of Appalachia in general. The latter is an interesting study area because of the close relationship among natural resources, economic development and quality of life. Although efforts to improve the well-documented economic malaise in the Appalachian region have been conducted by governmental agencies through educational programs, heath care accessibility and, more recently, obesity-reduction programs, economic stagnation persists in the study area (Shubert, 2010). The Appalachian area has been identified as the "most economically distressed” region in the U.S. (D'Souza, 2010). Furthermore, land use in the central Appalachian coal region is limited due to its steep slopes. This restricts its potential use for practices other than developing industrial, residential and commercial enterprises (Zipper and Skousen, Undated). In addition, mining has an impact on Appalachian soils. There are more than 190,000 acres of surface-mined lands in WV that are considered as being “severely disturbed” by the industry (BRMGL, 2007, MATRIC, 2010). Given the fact that Appalachia faces resource limitations for economic development, production systems in which resources are optimized must be evaluated. One such system could be pasturebased beef.

\subsection{Significance of the Study}

This study can contribute to the sustainable growth and development of Appalachia and specifically the PBB industry. By linking the pasture resource to landowner objectives

(increased productivity, profitability and income opportunities while better managing risk) as well as to societal objectives (sustainable land use, enhanced water quality, alternative energy 
and climate change mitigation), this study can provide knowledge and recommendations to enhance socio-economic and environmental conditions in Appalachia. Furthermore, this study advances the literature by examining a new approach, agent-based models, to sustainable land use management.

\subsection{Research Objectives}

The fact that the Appalachian region provides the natural resources needed to develop a diversified PPB system, the introduction of this industry through the application of economic theory would lead us to identify solutions to "wicked problems" in the area. We define wicked problems: "A wicked problem is one for which each attempt to create a solution changes the understanding of the problem. Wicked problems cannot be solved in a traditional linear fashion, because the problem definition evolves as new possible solutions are considered and/or implemented." (Rith and Dubberly, 2006). The approaches developed in this research offer alternative solutions to such issues as the lack of economic development and quality of life encountered in the region. Our research objectives are defined as follow. First, we design a conceptual framework based on optimal control theory that integrates a spatial component in which the production of pasture-based beef (PBB), renewable energy as well as carbon offsets enhance profitability and social welfare. The development of an optimal control model allows for better visualizing the proposed sustainable concept from two perspectives (farmer and surrounding society) in a spatial context in order to intensify the benefits from sustainable practices in the area. In addition, the application of the conceptual model developed in this paper could be applicable to the sustainable development of other production systems. Second, we develop a dynamic, agent-based model (ABM) that replicates the complexities associated with the introduction of the PBB concept proposed in order to analyze the interaction among agents 
and surrounding environment. The use of an ABM (using a program such as NetLogo) to simulate the introduction of this industry based on available (secondary) data could help identify the potential optimal paths for farmers and for society, providing the basis for recommendations. Third, we develop policy instruments to enhance the implementation of the proposed sustainable techniques to improve local economic growth and social welfare. Thus, the simulation results could lead to the development of policy instruments associated with pasture-based, carbon offset production as well as renewable energy sources that can be utilized by policymakers to enhance local economic growth and social welfare. 


\section{CHAPTER II: REVIEW OF THE LITERATURE}

\subsection{The Study Area}

There are underlying and persistent economic, social and environmental concerns that have kept the Appalachian region stagnant for decades. This region consistently ranks below the U.S. average in per capita income and other socioeconomic measures (Stevens and Deal, 2010). Based on Appalachian Regional Commission data (2002), only 17 percent of rural counties nationwide are identified as distressed areas while 33 percent of rural counties in Appalachia are so categorized. In addition, the mountainous topography dampens business opportunities in the region because it increases the expected costs of production, operation, and transportation (Bagi, et al., 2002). In 1990, the poverty rate was 13 percent at the national level while Appalachia experienced a 15 percent poverty rate. A large proportion (77 percent) of all counties in the region are considered poor (Cushing and Rogers, Undated).

Environmental contamination and health issues have also been a big concern in the region. For instance, the Washington Moment used to be seen from a distance of 75 miles away along the Appalachian Trail. However, the pollution caused by congestion today is so persistent that this national monument is no longer observed as used to happen until about 40 years ago (Chidester, 2010). In fact, Chattanooga, an Appalachian city, was ranked number 4 out of 100 U.S. cities as one of the worst cities to live in with asthma (AAFA, 2011). In addition, several locations, like for example, the Chesapeake Bay have identified inorganic fertilizers and pesticide use as being of vital concern in the Appalachian catchment areas (CBSG, 2008). In addition, the state of $\mathrm{WV}$, the only one contained wholly within the Appalachian region, has an obesity rate that consistently ranks in the top three among US states (D'Souza, 2010). People’s health has been affected by professions such as farming, coal mining and chemical 
manufacturing which tend to be prominent in the area, and which increase exposure to hazardous substances (Stevens and Deal, 2010).

Although Appalachia experiences challenging issues in need of alleviation, the introduction of PBB seems to offer potential solutions. In fact, the combination of a highly mountainous terrain and existing farm resource endowments (a WV farm is 194 acres on average, of which 48 percent is devoted to pasture) makes grass-fed cattle production well suited to WV (Evans, et al., 2007). According to the West Virginia Department of Agriculture, a total of 10,700 farmers generated more than \$100 million from approximately 150 million pounds of beef sales with a resource base of 200,000 beef cattle in 2010 (WVDA, 2012).

\subsection{Technology}

Technological innovation plays an essential role when considering the integration of biofuel production and climate change within the PBB industry. The anaerobic digester is becoming one such popular, environmentally friendly technology. It is basically on an enclosed chamber with the absence of oxygen in which manure is broken down by bacteria as part of a natural biological process. After the manure is collected, it enters into the digester where a decomposition process takes place under temperatures of $95^{0}$ to $105^{\circ} \mathrm{F}$ while releasing the biogas (composed of 55-70\% methane) which is used for electricity generation. For optimal digestion, this procedure might take approximately 15 to 20 days for the biogas release and it is trapped in a permeable and flexible cover (Pillars, 2003). The methane is captured and utilized as a renewable energy source to generate heat or electricity as well as for reducing potential environmental pollution such as surface water contamination, manure odor and GHG emissions (Key and Sneeringer, 2011).

Once the anaerobic digestion is complete, the remained biosolids possess higher concentration of 
potassium, nitrogen and phosphorus than undigested manure in a mineralized form which makes it more readily accessible to crops just like commercial fertilizers (Pillars, 2003).

\subsection{Pasture as a Primary Input and its Implications}

The use of grass as the primary diet for cattle in the beef industry has the potential to generate positive benefits in terms of animal welfare, human health, energy and fertilizer independence as well as environmental conditions, as outlined below.

2.3.1 Animal Welfare. Management-intensive grazing such as rotational grazing (upon which PBB is based) contributes to improving cattle immune systems and decreasing animal stress. Heckman et. al (2007) defines management-intensive grazing as a system in which livestock is moved between paddocks. Through this way, this system "can provide the highest forage production and use per acre, control weeds ... and allow paddocks to rest and regrow completely.” Under PBB, cattle are exposed to a more natural diet that facilitates digestibility, in the process substantially reducing the chances of disruption in rumen function as often occurs with animals under conventional or feedlot practices (Evans, et al., 2007). Although conventional practices might result in economies of scale through feedlot methods, the crowded conditions in which steers are raised enhance "stress-induced immunological deficiencies" sometimes leading to death and morbidity through acquired illness (Evans et al., 2007, Hennessy, Roosen, and Jensen, 2005).

2.3.2 Human Health. Management-intensive grazing techniques are beneficial to human health through green space and healthier end products. Recent literature confirms that grass-fed meat provides greater health benefits to humans than grain-fed beef (Evans, et al., 2007). Studies have proven that a 6-ounce steak produced from a pasture-fed animal can provide 100 fewer calories, up to 6 times more Omega-3s (a nutrient for obesity and other diseases prevention) and 
conjugated linoleic acid (a cancer fighter) than a comparable 6-ounce steak from a grain-fed steer. This would result in the consumption of 17,733 calories less per year for a typical beef consumer without impacting the normal intake routine (Robinson, 2002). PBB is also an excellent source of vitamin E which contributes to the prevention of immune disorders, lung disease, diabetes and eye illnesses (Portelli, 2008).

2.3.3 Energy Input. The use of pasture based production techniques also consumes potentially less energy input than confined animal feeding operations (CAFOs). It is estimated that one cattle unit requires around 74 gallons of crude oil if it is pasture-fed while a grain-fed cow consumes 208 gallons of crude oil from conception to the finish phase before slaughtering (Lee, et al., 2005). In general, a total of 930 gallons of gasoline per year is needed for the process of cultivating, processing and distributing the amount of food required for a four- member family (Hemert and Holmes, 2008).

2.3.4 Renewable Energy. Today, most of the farms that use livestock manure for energy production are under CAFOs since their infrastructure design makes it easier to collect animal wastes than under pastured-fed methods. However, if pasture-based systems are able to develop effective manure collection techniques, farmers could produce alternative energy, leading to the development of an additional, renewable, energy source. For example, New Zealand is considering adopting the cap and trade system for livestock, where it has been proposed that all livestock be fitted with manure catchers similar to the horse bun bag. In addition, to capture the belching, responsible for more than half of the methane emissions, it is suggested that livestock be fitted with carbon filter gas masks. According to Peter (2011), a series of balances allow the mask to open when in the feeding position and close when in "chewing the cud" mode. 
There are environmentally-friendly technologies, like for example, anaerobic digesters which convert animal waste (methane) into electricity making it appealing to farmers, the environment and utility companies (Key and Sneeringer, 2011). In fact, methane is approximately 25 times more harmful than $\mathrm{CO}_{2}$, and is one of the major contributors of greenhouse gas emissions (Baylis and Paulson, 2011, EPA, 2004, Key and Sneeringer, 2011, Forster et. al, 2007, EPA, 1999). Thus, when it is captured and utilized as a renewable energy source, it contributes significantly to reducing the greenhouse effect. Additionally, the electricity generated through "engine-generator" attached to the anaerobic digestion systems can be purchased by utility companies (Leuer, Hyde and Richard, 2008). The amount of manure produced by one 1,000 pound-cattle unit per day might generate approximately 10,239 BTUs or 3 KWh (Fulhage, et al., 1993). Moreover, methane, the major element of natural gas, can be carried by pipeline to be sold to the local power grid in order to be used in electric generators (S.E.C.O., Undated). This practice also potentially helps in reducing costs to farmers by providing their own energy as well as decreasing human health problems associated with the use of conventional fuels. In addition, previous studies have shown that large livestock farms are likely to profit from anaerobic digesters due to their level of manure production that offset the costs of technology. For instance, Shih et. al (2006) found out that anaerobic digesters might be lucrative on livestock farms equal or greater than 400 heads. On the other hand, Ghafoori and Flynn (2006) identified that a centralized anaerobic digestion system like the one located in the Red Deer County, Alberta is more profitable than any combination of systems based on multiple plants due to the fact that its manure source shipped from a 7500 beef cattle feedlot to the system allows for low "capital cost per unit of input/output". 
2.3.5 Natural Fertilizer. The use of manure to maintain the required nutrients for soil fertility is essential not only to support sustainable practices that reduce input costs associated with crop production but also to keep potential pollutants away from the atmosphere, water streams and the nearby farm population. When manure is used for the production of alternative energy, its nutrient content is not affected, enabling retention of nitrogen, potassium and phosphorus with their valuable characteristics (Pimentel and Pimentel, 2008). In fact, this manure, known as digested slurry or digested manure, is very effective in enhancing porosity and fertility as well as providing humus to the soil (TaTEDO, Undated). However, manure generated in conventional beef production practices can also destroy crops due to its high content of heavy metals, hormone remains, nitrogen and phosphorus (Portelli, 2008). Furthermore, studies suggest that moderate nitrogen applications contribute in building up carbon availability in the soil (FAO, 2010).

2.3.6 Carbon Sequestration/Offset. Despite the uncertainty regarding the amount of carbon sequestered in the soil by the pasturelands, it might contribute reducing $\mathrm{CO}_{2}$ emissions suspended in the atmosphere (FAO, 2010). In fact, this emerging and sustainable farming technique has also been known as carbon farming since it helps building up carbon sequestration into the soil. This strategy takes place when pasture-based production systems and reduced tillage intensity is considered. These farming practices are also known as carbon farming since it contributes addressing climate change by sequestrating $\mathrm{CO}_{2}$ from the atmosphere and convert it into carbon in the soil (Keating and Carberry, 2008). Although the literature examined seems to differ in terms of the size and distribution of the $\mathrm{CO}_{2}$ sequestered from the atmosphere done by pasturelands, most sources agree on the potential environmental and soil nutrient improvements. For instance, LaSalle (2009) points out that grassland soils have the capability of sequestrating 
approximately 5.5 tons of $\mathrm{CO}_{2}$ annually per acre which is equivalent to 1.5 tons of carbon in the soil that are not released into the air. Moreover, a reduction of an estimated 14 billion pounds of $\mathrm{CO}_{2}$ from the atmosphere would take place if all the (16 million) acres of land devoted to grow corn for cattle feedlot in U.S. were to be used for forage (Portelli, 2008). On the other hand, FAO (2010) expresses that around 3.67 tons of $\mathrm{CO}_{2}$ sequestered from the atmosphere would bring 1 ton of carbon into the soil. Furthermore, Follett, Kimble and Lal (2001) indicate that U.S. pasturelands are likely to sequester approximately over 190 million tons of $\mathrm{CO}_{2}$ at the yearly basis for thirty years. Moreover, the combination of water from the soil, carbon dioxide from the air and energy from the sunlight enables crops to produce organic compounds leading carbon to become an important component in soil organic matter (Sundermeier, et al., 2005). Thus, the adoption of some grazing management techniques such as rotational grazing and reasonable livestock might help increasing carbon available in soils where pasturelands have been degraded (FAO, 2010). Also, $0.2 \mathrm{~kg}$ of flying particulates can be absorbed by $1 \mathrm{~m}^{2}$ of grass in addition to supplying the amount of oxygen that one person needs for a year through the process of photosynthesis (Mazereeuw, 2005). Furthermore, it was determined that the use of biogas produced from cattle manure in a year would contribute to reducing about 4 percent (99 million tons) of the greenhouse gas (GHG) emission emitted in the U.S. (Cuellar and Webber, 2008).

Livestock operations also can contribute to reduced GHG emissions when manure management techniques are employed. For instance, livestock farmers who reduce methane emissions through methane digesters can sell "carbon offsets" in the carbon offset market to other GHG emitters that might face emission caps. This allows livestock producers to generate additional income in which their profitability will depend on emissions sold in a carbon offset market, energy sales as well as energy savings (Key and Sneeringer, 2011). This makes the use 
of anaerobic digesters attractive for entrepreneurs as well as society through environmental improvements.

\subsection{Optimal Control Model}

Optimal control theory allows us to illustrate the integrated PBB concept proposed as a way of optimizing a farm's resources in an environment in which dynamic optimization is applied. Through this theory, we are able to maximize the farmer's profitability while enhancing social welfare when sustainable practices are taken into consideration.

\subsubsection{Dynamic Optimization. Dynamic optimization models have increasingly been} applied in the agricultural and resource economics area in recent years (Cacho, 1998). Chiang (2000) describes the fundamental components of an optimal control (OC) model. The author establishes that a control variable can be seen as a policy tool that is able to impact state variables which means that any selected control path involves a linked state path (Chiang, 2000). On the other hand, Perman et al. (2003) establish that an optimal control model does not necessarily need to have the state and control variables present in the objective functions. In addition, they state that what makes dynamic optimization important is to obtain the values of these variables at each point in time up to the planning horizon as the solution to the problem. The initial values of state variables and their evolution over time are based on some physical, economic and biological system that is captured through a set of differential equations or state equations. Moreover, control variables represent instruments in which their values can be chosen by the decision maker with the purpose of steering the evolution of the state variables through the pass of time in a desired way. Another essential variable in the optimal control model is the co-state variable which is commonly known as the price shadow. This variable basically denotes 
the marginal valuation of the state variable at each point in time which varies over time (Perman, et al., 2003).

2.4.2 Optimal Control Approaches. Cacho (1998) employs an OC model using a meat production function in which grass is the primary input while stocking rate and fertilizer applications have an indirect control over production. The author considers four state variables such as soil depth and animal weight, and control variables such as the stocking rate to capture seasonal variations on an annual basis (Cacho, 1998).

Saliba (1985) explores the interactions among management choices, soil loss through erosion, and farmland productivity. The author analyzes four models developed by other researchers and concludes that none of them directly addresses the relationship between soil erosion and soil productivity. In addition, tradeoffs among intensity of crop rotation, soil conservation practices and production inputs are not sufficiently explained, limitations that the author seeks to overcome. She addresses the tradeoffs among intensity of crop rotation, soil conservation practices and production inputs through her model. The optimization model developed considers a profit maximizing farmer in which the contributions and costs of soil among other inputs in crop yield are analyzed when making decisions with regard to input use and conservation methods. The objective function takes into account crop rotation, output price and other variables in which the marginal value soil depth is categorized as the costate variable and five necessary conditions are developed. Entrepreneurs have two alternatives to maintain crop production by either: i) substituting a better variety of plants, or commercial fertilizers among other inputs; or ii) implementing conservational techniques such as conservation tillage instead of conventional tillage (Saliba, 1985). Similarly, McConnell (1983) develops an economic model where the use of soil can be optimized from a social and private point of view. 
He builds up a production function in which explanatory variables such as technological change, soil loss, and soil depth are considered to express the effect on output. The model also establishes that farmers' behavior toward soil is influenced by the soil's effect on profits in which the farmer makes use of the land in order to maximize the value of the farm plus the present value of the profit stream at the end of the planning horizon. This implies setting up an objective function as well as the Hamiltonian equation and derives the Pontryagin necessary conditions (first order conditions of each variable) to find the optimal path of each variable considered (McConnell, 1983).

Furthermore, Torell, Lyon and Godfrey (1991) construct a dynamic OC model in which the stocking rate is the instrumental variable while the average herbage production represents the state variable with the purpose of maximizing the discounted net present value from grazing over future years specifically applied in eastern Colorado. The stocking rate model developed employs a deterministic approach where forage conditions, costs and prices are foreseen at the time the stocking rate choice is made (Torell, et al., 1991). On the other hand, Standiford and Howitt (1992) utilize the stocks of livestock and oak trees as state variables while the amount of oak firewood cut and livestock density as control variables. The objective is to maximize the net present value of profits based on firewood, hunting and livestock revenues. Under these circumstances, the farm manager has to make decisions on a yearly basis since oak trees negatively impact livestock revenue but positively impact hunting returns. Thus, ranch managers select optimal hunting levels by controlling livestock density and firewood harvesting. The authors evaluate the optimal trajectory for each control variable under different scenarios for a policy analysis, specifically in the Californian hardwood rangeland region due to the dynamic interaction among the resources available in the area (Standiford and Howitt, 1992). 
Other approaches integrate a spatial component into OC theory. For instance, Brock and Xepapadeas (2009) propose an OC model in which spatial effects of accumulated state variables in other locations are considered as influencing given sites in an abstract format in which specific locations are not specified, allowing for broad applications. They establish that the integration of the model kernel expressions is an appropriate tool for dynamic economics when spatial effects are taken into account (Brock and Xepapadeas, 2009).

\subsection{Clustering System}

The integration of a PBB industry into this region would also provide the basis for regional economic development through clustering among the agricultural and other sectors surrounding the area of interest.

2.5.1 Agglomeration Economies. Agglomeration economies play a crucial role not only in the development of emerging companies but also as a mechanism to enhance economic growth in the geographic area of interest (Porter, 1990). Porter (1990) establishes that clusters contribute to: i) rising productivity among the businesses in the clustering system, ii) encouraging new companies in the field, and iii) increasing innovation in the field. The optimal use of the resources available within the beef industry in the Appalachian region would enhance the local economy. Pastureland is an abundant resource in the area as well as cattle farming. Moreover, the use of state-of-the-art technology motivates the development of new products, services, production procedures and innovative ways of organizing economic activity as a way of establishing new markets (Dearlove, 2001). Thus, the integration of environmentally friendly technologies that enhance diversified products for the area such as alternative energy as well as digested manure along with high quality beef products and carbon offsets would create new markets which expand market channels and create new economic conditions locally. Therefore, 
innovation would contribute to extending the lifespan of inputs and bringing more products when resources are maximized. Since firms are capable of motivating and supporting local suppliers of essential inputs, they have an incentive to play an energetic role in developing clusters that enhance coordination with local channels, suppliers and buyers to help them improve and extend their own competitive advantage (Porter, 1990). In fact, the integration of a carbon market within a region when methane digesters are employed could stimulate existing economies and concentration of production on large scale operations. On the other hand, smaller operations could be able to attain more efficient methane scale when digesters are shared with other small operations. Actually, the use of anaerobic digesters can be motivated through instruments such as tax incentives or cost-sharing subsidies when the adoption of this innovation by small operators is a policy goal (Key and Sneeringer, 2011). Thus, clustering among small operations as well as the introduction of a carbon market would allow for more efficient business development even in smaller scale operations. In addition, farmers would be able not only to produce natural fertilizers, hay, energy, and calves among other things for their own farms but also to supply them to adjacent farms boosting the local economy. This clustering would also connect farmers' production with energy utility companies through renewable energy which eventually stimulates GHG emissions reduction through methane capture.

\subsection{Agent-Based Models}

In order to simulate the economic, environmental and social complexities of the examined PBB industry within a region, the application of agent-based modeling is considered in this study since computer simulations have been categorized as a useful tool to evaluate the complexity of ecological and economic systems. In fact, an ABM is considered a new method to model complex systems characterized by the role of independent and interrelating agents (Macal 
and North, 2010). They tend to be easier, quicker and less expensive than ordinary experiments (Chi, 2000). In addition, some simulation programs not only provide figures and values as outputs to illustrate the system interaction but also graphical illustrations of the system behavior as a close approach to the reality. Furthermore, ABMs, also known as individual-based simulations, are used to replicate certain scenarios in which individuals interact based on their actions or procedural regulations and distinctive parameters where their acts are tracked through time (Reynolds, 1999). Simulations contribute in estimating and comprehending emerging behaviors that require the development of new regulations for local agents that would make improvements to the system. In other words, the performance of a system is highly probable to get better when agents' activities are optimized at a local level (Anthes, 2003). Thus, the outcomes derived from the agent-based platform such as NetLogo would have the basis to address policy instruments based on system behavior and outcomes.

2.6.1 Model Development. Different simulation models have been developed through computer networks to evaluate real world problems under specific scenarios in order to approach the potential solutions that can be used by educational institutions and policymakers among other interested parties. Planners must develop systems that function harmoniously not only internally but also with the environment that they are projected to match. A system can be described as a region, individual, a herd of animals or a nation while a subsystem is expressed as explanatory variables which might be common to some subsystems or restricted to a subsystem. It is also crucial that models do not violate the assumptions under consideration. In order to simulate management systems for a particular set of social, economic and production scenarios, maximization skills can be taken into account (Joandet and Cartwright, 1975). When developing the model, it is important to identify first the calculations under consideration since they will be 
used by the computerized system. Also, theory, data and program are fundamental in agent-based computer simulation models (Chi, 2000). Moreover, the extendibility of the model is essential for future research purposes since potential users are willing to adapt the model for new applications. Through this way, an investigator would be able to use the model already published to add a new characteristic in order to find an answer while others may want to explore new variants of the model (Axelrod, 1997).

2.6.2 Language Programming. When considering agent-based modeling, it is essential to keep in mind that procedural languages might be involved. For example, Visual Basic is accessible for spreadsheet programs making it suitable to be jointly used with Excel while having full control of a procedural language using the framework of a simple spreadsheet. This program is very useful when simple ideas need to be tested (Axelrod, 1997). Other computer programs such as Stella and ModelMaker do not require programming languages which helps in saving time that might be spent on programming (Chi, 2000). Others such as StarLogo (a programmable environmental ABM), Pascual, C, Basic and FORTRAN are among the most common programming languages (Axelrod, 1997). Another AMB is NetLogo which is based on the language programming known as Java. Furthermore, once the system is conceptualized, it can be described either through equations or verbally. In order to describe cause and effect relationships, mathematical models are applied by animal scientists. Let’s say, "phenotype of progeny" is a function of dietary requirements as a function of carcass measurements. Other models describe pasture production based on a particular species while still others consider different species, and the consequences of foraging. Since simulation results are the end point of the functions developed for the model, they must be cautiously interpreted. The necessity of conducting production research can be replaced by effective models that simulate production 
(Joandet and Cartwright, 1975). For instance, Carter, along with the U.S. Geological Survey, developed a spatially-explicit model of animal behavior, in which pasture consumption and animal movement were jointly analyzed (Reynolds, 1999).

2.6.3 Model Considered. Since the focus of this study is on simulations using an ABM known as NetLogo, it is significant to point out some of its features for a basic understating of the program. This is a free of charge model developed by Northwestern University and suitable for developing complex systems. It provides manuals, dictionary, tutorial and other mechanisms to help users in the development process. NetLogo provides different alternatives in which the system that needs to be explained can be built up. For instance, the simulation can be performed by adding the codes in the procedures tap and linking them to functional features such as buttons, sliders, monitors, and switches among others available in the interface tab which allow the simulation to begin and stop as well as to modify the conditions or parameters of the system. Simulations can also be done by interconnecting a system dynamic diagram with the codes developed in the procedures tab and with the interface functional features. Depending on the programmer's approach, the system behavior could also be graphically illustrated or viewed in what is called the "view or world window" that is based on coordinates and the codes expressed in the procedures tab in which the boundaries and topology of the world are defined.

\subsection{Policy Instruments}

The extent of adoption of diversified PBB systems will probably hinge on policy changes and instruments that account for both private and social benefits. Policy instruments, like for example, “Oil for Food” are appropriate for the Appalachian region (Lee, et al., 2005). This particular policy tool could be employed, for instance, when non-renewable energy producers compensate the public for the removal of oil, natural gas and coal from public lands. In the 
context of this study, for example, a policy instrument can be devised whereby firms that lease public areas for conventional energy production would be mandated to lease equivalent areas for pasture-based livestock or similar types of production.

Carbon credits are another alternative to enhance pasture-fed practices since they stimulate the development of sustainable practices to decrease GHG emissions. Carbon credit programs have become popular since they are a promising source of income in GHG markets (E.P.A., Undated). The use of carbon credits to address climate change enhances practices that reduce carbon emissions in the atmosphere. Moreover, non-profit organizations, like for example, Greenhouse Emissions Management Consortium has bought carbon emission reduction credits from farmers that reduce methane emissions from livestock waste, power production from biomass and no-till farming techniques (BELC, Undated). Moreover, the cap and trade system enhances agricultural mitigation for offset credits through improved agricultural techniques (Horowitz and Gottlieb, 2010), as exemplified recently for cattle in the case of New Zealand for example. In fact, these reductions on methane emissions can be sold to greenhouse emitters who might either willingly desire to reduce their own emissions or encounter emissions caps (Key and Sneeringer, 2011, Subler, 2006). 


\section{CHAPTER III: CONCEPTUAL FRAMEWORK}

\subsection{Objective 1: Conceptual Framework}

The objective is to develop a conceptual framework based on OC theory that integrates a spatial component in which the production of PBB and alternative energy as well as GHG emission reduction enhances profitability. Although our analysis is mostly focused on the supply side, WV is used as the given location in which surrounding communities would benefit from high quality food products, environmental improvement, and economic development. This model is intended to provide a basic foundation for developing agglomeration economies in which other locations are able to supply resources to given locations as a way of impacting the economic and environmental conditions of the Appalachian region through a spatially dependent industry.

\subsection{Model and Expected Results:}

An OC framework is proposed to examine how a niche product such as PBB can benefit the farmer and society by integrating current climate, energy and production challenges. As Saliba (1985) and Chiang (2000) propose, the OC framework allows decision variables to respond over time to accrued influences of previous control management choices on state variables and crop production. This model is intended to capture the dynamic effects that take place in three interconnected production functions that eventually determine farm-level profitability. Management-intensive grazing practices allow farmers to identify the optimal choice between grass production and cattle consumption in the production of beef wherein benefits are dispersed across locations.

This model is projected to integrate the OC approaches proposed by McConnell (1983), Saliba (1985) and Cacho (1998) as well as to incorporate a spatial component based on Brock 
and Xepapadeas (2009). In addition to the explicit integration of a spatial component, this study is unique in that it also includes potential ecosystem benefits of the PBB industry, vis-à-vis electricity production, digested manure as well as GHG emission reductions. In addition to farmlevel profitability, this model also provides the basis for agglomeration economies to enhance economic and environmental development in the Appalachian region. This can be achieved when the optimal private path equals the socially optimal path.

It is essential to mention that the following conceptual framework tends to differ from our experimental ABM simulation in certain ways which will be discussed in details in Chapter IV. In fact, our ABM is an optimization model in which the resources available across space are optimized bringing some economic benefits to society and entrepreneurs over a planning horizon. Optimization procedures have been a favorite approach to model programmers when topics involving a wide number of schemes are evaluated against numerous criteria (Wang, 2001) allowing our main concept to be simulated from an optimization perspective in NetLogo. In fact, simulation models are able to replicate complex systems through the use of computerized methods making it suited to the topic as well as feasible (Wang, 2001). Furthermore, the use of dynamic optimization through simulation models permits parameters to change over time intervals when applying diverse economic and natural circumstances (Costanza and Neuman, 1997). This would allow modelers to experiment the emerging development of the system simulated under economic and environmental conditions obtaining optimized results. Literally, given some initial conditions and the dynamics involved in a computerized platform is what a programmer needs to conduct a simulation. In addition, it requires the capability to change the initial conditions and run the model several times in order to experiment new outcomes (Costanza and Neuman, 1997). In our experimental approach, we intent to estimate an 
optimization model (BET) using some of the basis of our conceptual framework. Table 3.1 contains a description of all variables used in our OC model.

Farmer's Perspective:

As a starting point, we developed Equation (1) with the main purpose of illustrating the objective function without considering the spatial component in contrast to Equation (4) which captures the spatial influences. However, it is essential to point out that our conceptual model is derived from Equation (2) to Equation (28). Assuming that the value of the land at the end of the planning horizon $T$ is not considered (Standiford and Howitt, 1992, Cacho, 1998) since the resale of the farm is not an argument, the objective function in which the entrepreneur maximizes the present value of the profit stream or discounted accumulated profits over the planning horizon (McConnell, 1983, Saliba, 1985) is:

$$
\underset{\gamma}{\operatorname{Max}} J=\int_{0}^{T} e^{-r t}\left[p_{\alpha} f_{\alpha}\left(\gamma_{\gamma}\right)+p_{\xi} f_{\xi}\left(\omega_{t}(\gamma)+p_{\psi} f_{\psi}\left(\xi_{t}\right)\right)-c_{\alpha} \gamma-c_{\xi} \omega-c s\right] d t
$$


Table 3.1: Definition of Variables

\begin{tabular}{|c|c|c|c|}
\hline $\begin{array}{c}\text { Variable } \\
\text { Type/Function }\end{array}$ & Variable Symbol & Description & Units \\
\hline \multicolumn{4}{|l|}{ Control } \\
\hline & $\gamma$ & Stocking Rate & head/acre \\
\hline \multirow[t]{3}{*}{ State } & & & \\
\hline & $\rho$ & Pasture Mass & lbs./acre \\
\hline & $\eta$ & Soil Organic Matter & lbs./acre \\
\hline \multicolumn{4}{|l|}{ Prices } \\
\hline & $p_{\alpha}$ & Price of Beef & \$/lbs. \\
\hline & $p_{\xi}$ & Price of Electricity & $\$ / \mathrm{KWh}$ \\
\hline & $p_{\psi}$ & Carbon Price & $\$ / \mathrm{CO}_{2 \mathrm{e}}$ ton \\
\hline \multicolumn{4}{|l|}{ Costs } \\
\hline & $C_{\alpha}$ & Beef Production Costs & \$/lbs. \\
\hline & $C_{\xi}$ & Electricity Production Costs & $\$ / \mathrm{kWh}$ \\
\hline & $C S$ & Fixed Costs & $\$$ \\
\hline \multirow[t]{17}{*}{ Others } & & & \\
\hline & $\alpha$ & Beef Production & lbs./acre \\
\hline & $\xi$ & Electricity Production & KWh/head \\
\hline & $\psi$ & GHG Emission Reduction Function & $\$ / \mathrm{CO}_{2 \mathrm{e}}$ ton \\
\hline & $\mu$ & Harvested Forage by Stocking & lbs./acre \\
\hline & $\beta$ & Digested Manure Application & lbs./acre \\
\hline & $\phi$ & Forage Growth & lbs./acre \\
\hline & $\theta$ & Hay for Winter Feed & lbs./acre \\
\hline & $\varsigma$ & Nutrients Accumulation & lbs./acre \\
\hline & $\begin{array}{c}\omega \\
v\end{array}$ & $\begin{array}{l}\text { Amount of Manure Collected } \\
\text { Precipitation }\end{array}$ & $\begin{array}{l}\text { lbs./head } \\
\text { inches }\end{array}$ \\
\hline & $\kappa \rho_{t+1}$ & $\begin{array}{l}\text { Pasture Mass at the End of } \\
\text { the Feeding Season }\end{array}$ & $\%$ \\
\hline & $e^{-r t}$ & Continuous Time Discount Factor & \\
\hline & $e^{-\delta t}$ & Continuous Time Welfare Factor & \\
\hline & $\delta$ & Welfare Value of Future Generations & \\
\hline & $r$ & Private Discount Rate & \\
\hline & $t$ & Specific Time Period & \\
\hline & $T$ & End of the Planning Horizon & \\
\hline \multirow[t]{5}{*}{ Spatial } & $Z$ & Given Locations & \\
\hline & $Z^{\prime}$ & Other Locations & \\
\hline & $Z$ & Entire Spatial Domain & \\
\hline & $\mathrm{P}$ & Concentrations of Pasture Mass from z' & lbs. \\
\hline & $\mathrm{N}$ & $\begin{array}{l}\text { Accumulated Soil Organic Matter } \\
\text { from z' }\end{array}$ & lbs. \\
\hline
\end{tabular}

Equation (1) represents the objective function of the farmer which is to maximize the discounted 
accumulated profits over the planning horizon $T$ within a non-spatial context. Notice that Equation (1) is only used to illustrate our starting point; but our main objective function is presented in Equation (4) since it is the one integrating the spatial component. In order to integrate the spatial components in our objective function, the following procedures and assumptions have been considered.

As part of the integration of the spatial component in our OC model, we created the following five assumptions.

Since the farm of interest might be surrounded by a diverse group of businesses throughout the entire spatial domain, their spatial influences toward its production functions might differ depending on the operational nature of every nearby farm. This implies that besides the farm of interest, other businesses in the surrounding area might be producers of beef, hay among other agricultural products. Therefore, we need to consider the spatial influences in our objective function which is represented in Equation (4). This spatial diversity leads us to the assumption number 1.

Assumption 1: Locations z' are adjacent forage-based farms in which the spatial effects are heterogeneous across locations.

The slope of the pastureland available in an area has an impact on land use, especially for grazing as well as fertilizer applications. In fact, the steeper the slope the less pasture in the site is consumed by cattle since animals tend to gather and graze more in flat or less steep slopes. This might have a negative effect on the grazable land area available for beef production (Laca, 2000, Holechek, 1988). Since land use in Appalachia is limited due to its steep slopes, it might restrict its potential use for agricultural production among others (Zipper and Skousen, Undated). This leads us to the assumption number 2 . 
Assumption 2: The slope of farms in location $\mathrm{z}$ is flat while land slope in location $\mathrm{z}$ ' might be steeper which is a limiting factor for machinery use as well as grazing.

P and N represent inputs (Brock and Xepapadeas, 2009) in the production functions presented in the objective function (4), the amount of $\mathrm{P}$ and $\mathrm{N}$ would have different interpretations. In our model, these quantities could be captured in the amount of undigested manure available and in hay production. This is true not only because the change on state variables is influenced by these variables in some way but also due to the fact that they play an essential role in energy and beef production as well as in GHG emission reductions eventually. Since these variables are mobile across locations, this allows for clustering among locations as a wisely planned strategy of optimizing resources available in the entire spatial domain in order to maximize profits. The development of interconnected businesses and suppliers in a geographic region enhances the ability for firms to cluster together in a way that creates economic activity as well as concentration of knowledge (Dearlove, 2001). Due to the fact that manure is collected during winter season and transported from adjacent farms to the farm of interest, we define assumption 3 and 4. Since hay is also transported from nearby hay farms to the farm of interest, we define it as a mobile input.

Assumption 3: Manure is collected during the winter season in the barn.

Assumption 4: Undigested manure and hay are completely mobile.

As an approach of presenting the reality of the production cycle and a well performed economic functions, we assume that production functions are differently concave (Brock and Xepapadeas, 2009, Cacho, 1998). This allows us to observe diminishing returns over as a typical economic behavior in business of how the rate of output changes when inputs of production vary. This provides the basis for assumption 5 . 
Assumption 5: Production functions are differentiable AND concave which presents diminishing returns over time. Due to the fact that spatial distributions are not uniform across locations or are spatially heterogeneous, this allows for the emergence of agglomeration economies or clustering through resource optimization which could turn out to be persistent in a heterogeneous steady state among locations (Brock and Xepapadeas, 2009). In other words, state variables are optimized when management decisions are manifested wisely through sustainable practices considering the entire space domain. However, the land endowment for each enterprise in the entire spatial domain is constant, which implies that every farm has the same number of acres on average for simplification purposes. This provides the fundamentals for assumption 6 .

Assumption 6: Pastureland in the PBB industry is predetermined.

Furthermore, mathematical expressions have been designed to illustrate the effects of variables developed in adjacent locations on the production functions in a given location. In order to integrate the spatial effects in locations $Z$ (the given locations) caused by the accumulated state variables in other locations identified as $Z^{\prime}$, it is essential to consider the kernel formulation which basically measures the influences of sites $Z^{\prime}$ on location $Z$ developed by Brock and Xepapadeas, 2009. For instance, variables such as pasture mass and soil organic matter (our state variables) identified in nearby locations can be expressed as part of the production functions of the farm of interest by integrating the kernel function. Following Brock and Xepapadeas (2009), the spatial influences of the concentrated state variables $\rho\left(t, z^{\prime}\right)$ and $\eta\left(t, z^{\prime}\right)$ in locations $z^{\prime}$ (adjacent locations) on the state variables $\rho(t, z)$ and $\eta(t, z)$ in locations $Z$ (locations or areas of interest) are represented in equations (2) and (3), respectively:

$$
\mathrm{P}(t, z)=\int_{z^{\prime} \in Z} w\left(z-z^{\prime}\right) \rho\left(t, z^{\prime}\right) d z^{\prime}
$$




$$
\mathrm{N}(t, z)=\int_{z^{\prime} \in Z} w\left(z-z^{\prime}\right) \eta\left(t, z^{\prime}\right) d z^{\prime}
$$

The integration of these state variables into the production functions at locations of interest is an approach to illustrate the spatial interaction when the kernel function is employed. In fact, the application of the kernel influence function, $w($.$) , as described by Brock and$ Xepapadeas (2009) allows us to describe explicitly the impact of state variables located at spatial locations $Z^{\prime}$ on state variables at particular sites $Z$ in which the entire spatial domain is represented as $Z\left(z, z^{\prime} \in Z\right)$. In other words, $P($.$) (accumulated pasture mass) and N($.$) (soil$ organic matter) from locations $z^{\prime}$ (adjacent locations) reflect spatial spillovers on the beef, $f_{\alpha}$ and electricity, $f_{\xi}$, production functions on $\mathrm{z}$ locations. The integration of these adjacent state variables into the objective function on the entrepreneurs in the given locations allows the development of "dynamic system forces” that leads to agglomeration economies in the region (Brock and Xepapadeas, 2009).

$$
\begin{aligned}
& \underset{\gamma}{\operatorname{Max}}: J= \\
& \int_{z \in Z} \int_{0}^{T} e^{-r t}\left[p_{\alpha} f_{\alpha}\left(\gamma_{t, z}, \mathrm{P}_{t, z}, \mathrm{~N}_{t, z}\right)+p_{\xi} f_{\xi}\left(\omega_{t, z}(\gamma), \mathrm{P}_{t, z}, \mathrm{~N}_{t, z}\right)+p_{\psi} f_{\psi}\left(\xi_{t, z}\right)-c_{\alpha} \gamma_{t, z}-c_{\xi} \omega_{t, z}-c S_{t, z}\right] d t d z
\end{aligned}
$$

Equation (4) denotes our intended objective function that maximizes the discounted accumulated profits over the planning horizon $T$ when spatial spillovers are internalized while the value of the land at the end of the planning horizon $T$ is not considered since it is not an argument. Figure 3.1 provides a simplified overview of the state variables paths when decision variables are taken into account. 


\section{Paths of $\eta_{t, z}$ and $\rho_{t, z}$ in Locations z}

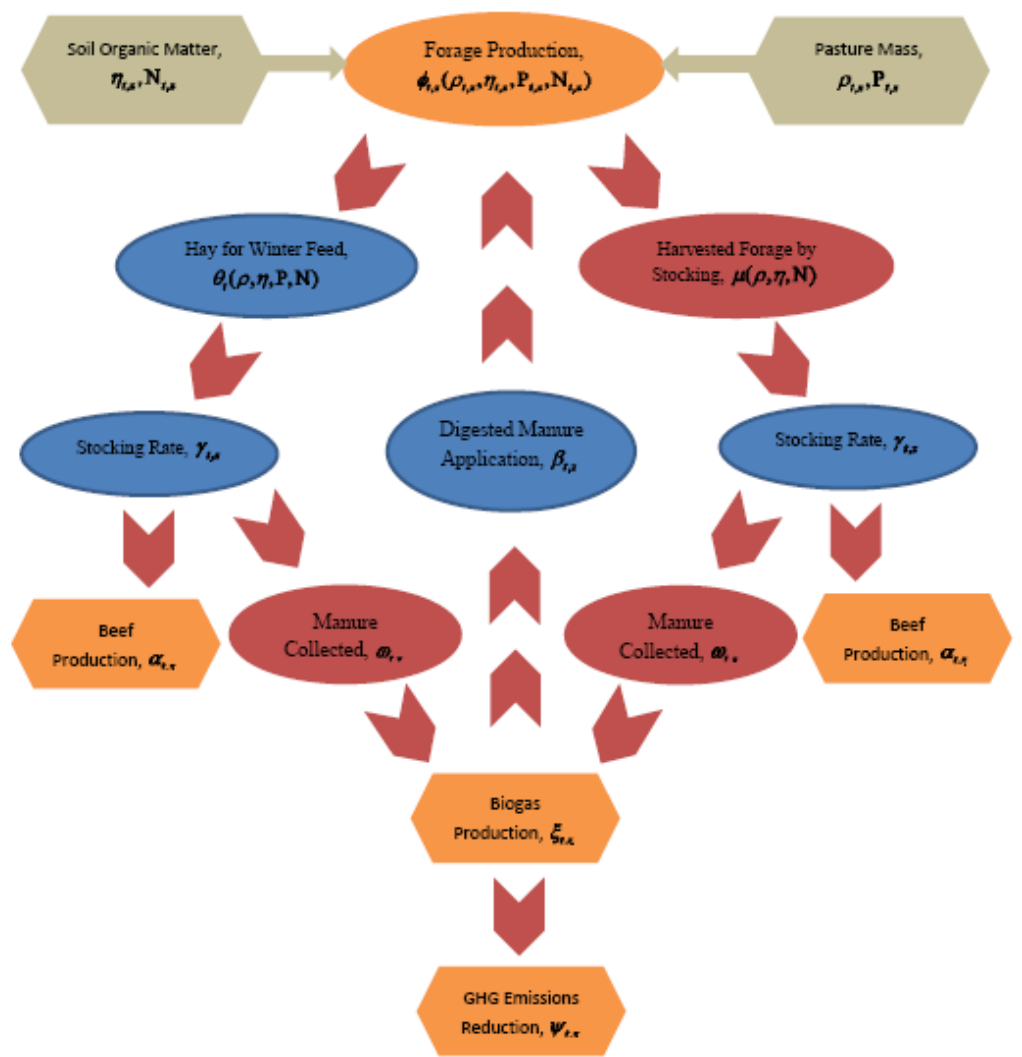

Figure 3.1: Paths of Soil Organic Matter and Pasture Mass in Locations z.

The objective function is subject to changes in pasture mass available and soil organic matter accumulation per acre and their corresponding initial amounts at the beginning of the feeding season in locations $\mathrm{z}$ in which spatial effects are taken into consideration:

$$
\Delta \rho_{t, z}=\rho_{t+1, z}-\rho_{t, z}=f\left(\gamma_{t, z}, \eta_{t, z}, \rho_{t, z}, \beta_{t, z}, v_{t, z}, \mathrm{P}_{t, z} \mathrm{~N}_{t, z}\right)
$$

Equation (5), is the change in pasture mass produced per acre in locations z which depends on the pasture mass available at the beginning of the feeding season, $\rho_{t, z}$, and the and the amount of pasture mass available at the end of the feeding season, $\rho_{t+1, z}$. The change in pasture mass available is basically represented by the growth of forage function, $\phi_{t, z}$. 
$\phi_{t, z}=f\left(\gamma_{t, z}, \eta_{t, z}, \rho_{t, z}, \beta_{t, z}, v_{t, z}, \mathrm{P}_{t, z} \mathrm{~N}_{t, z}\right)$

All these influences imply: a) forage growth would impact beef production as well as energy production. Thus, the contribution of hay for winter season and harvested forage by stocking would positively impact beef production, $\frac{\partial \alpha}{\partial \phi}>0$, shown in equation (11) and alternative energy production, $\frac{\partial \xi}{\partial \phi}>0$, or equation (12) since forage is the primary diet in this beef industry which eventually would be transformed into manure, the primary input in the biogas production process. Therefore, the GHG emission reduction function, $\frac{\partial \psi}{\partial \phi}>0$, presented in equation (13) would be positively impacted by forage growth since it contributes in carbon offsets; and b) the forage growth would also impact the GHG emission function in a positive manner, $\frac{\partial \psi}{\partial \phi}>0$, through carbon sequestration since the pasturelands would be able to sequestrate $\mathrm{CO}_{2}$ from the air.

Equation (6) defines the forage growth function which is basically a function of stocking rate, $\gamma_{t, z}$, the soil organic matter, $\eta_{t, z}$, pasture mass at the beginning of the feeding season, $\rho_{t, z}$, digested manure or natural nutrients application, $\beta_{t, z}$, the average precipitation, a weather condition, $v_{t, z}$ and the accumulated pasture mass, $\mathrm{P}_{t, z}$, as well as concentration of soil organic matter, $\mathrm{N}_{t, z}$, from locations z'. Most of these are implicitly affected by the amount of carbon available in the soil. The impacts of each variable on this function are the following (notice that subscripts $t$ and $z$ have been dropped for simplification): 
The stocking rate negatively influences forage growth, i.e. $\frac{\partial \phi}{\partial \gamma}<0$. However, digested manure or nutrient application as well as soil organic matter can be used to counteract this negative effect, i.e. $\frac{\partial \phi}{\partial \beta}>0$ and $\frac{\partial \phi}{\partial \eta}>0$, since they both increase nutrient availability which enhances forage growth per acre. In addition, this function is positively affected by the pasture mass available at the beginning of the feeding season, $\frac{\partial \phi}{\partial \rho_{t}}>0$ and precipitation influences forage growth positively, $\frac{\partial \phi}{\partial v}>0$. Moreover, forage growth is influenced by the spatial effects from locations $\mathrm{z}^{\prime}$ through the accumulated pasture mass, $\frac{\partial \phi}{\partial \mathrm{P}}>0$, in the form of hay and accumulated soil organic matter, $\frac{\partial \phi}{\partial \mathrm{N}}>0$, in the form of undigested manure from locations $\mathrm{z}^{\prime}$ to be used in locations $\mathrm{z}$.

Steady State Condition 1: As previously mentioned, the change of pasture mass available per acre is influenced by the stocking rate, the soil organic matter accumulation rate, the pasture mass at the beginning of the feeding season, the nutrient application rate, the accumulated pasture mass as well as soil organic matter concentrations from locations z' and precipitation. In other words, pasture mass is in a steady state condition or reaches equilibrium due to the influences of each variable on the forage growth, $\phi_{t, z}=f(\eta, \rho, \beta, v, \mathrm{P}, \mathrm{N}, \gamma)$, in which sustainable management decisions and clustering among locations are considered. This means that the change in pasture mass is optimized when these strategies are wisely employed since sustainable practices are taken into account in the entire space domain. This happens when stocking rate is optimized. Therefore, this contributes to the levels of beef and energy production as well as 
GHG emission reduction through a carbon offset in locations z since the resources available are efficiently utilized when the pasture mass system is at a stable stage during a given period of time. The relationship between the pasture mass, soil organic matter and beef yield is presented in Figure 3.2.

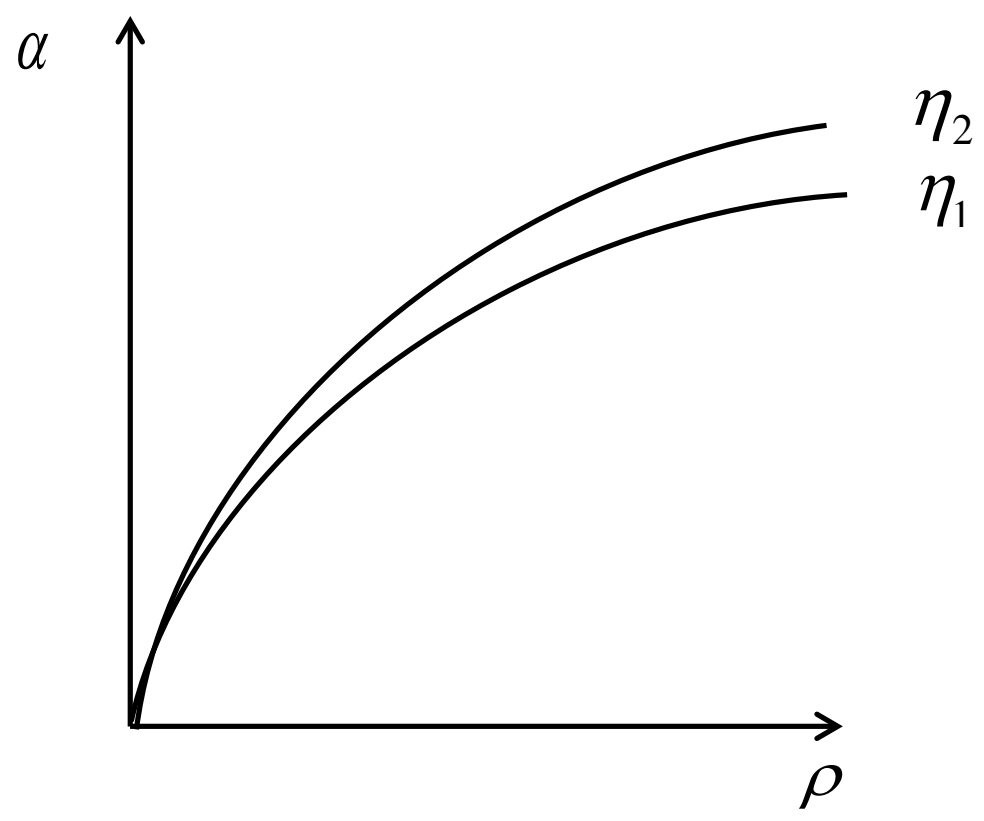

Figure 3.2: Effects of Soil Organic Matter on Pasture Mass and Beef Production. Soil organic matter influences pasture mass positively which improves beef production. The availability of nutrients $\left(\eta_{1}\right)$ in the soil would increase pasture growth which allows for animals weight gain that eventually rise beef production. On the other hand, the application of addition nutrients $\left(\eta_{2}\right)$ into pasturelands accelerates the availability of pasture mass permitting higher beef production over time at a decreasing rate.

$\rho(t=0, z)=\rho_{0, z}$

Equation (7) represents the initial pasture mass available per acre at the beginning of the feeding season in locations z. The effects of stocking rate on forage growth and their relationship with soil organic matter are illustrated in Figure 3.3. 


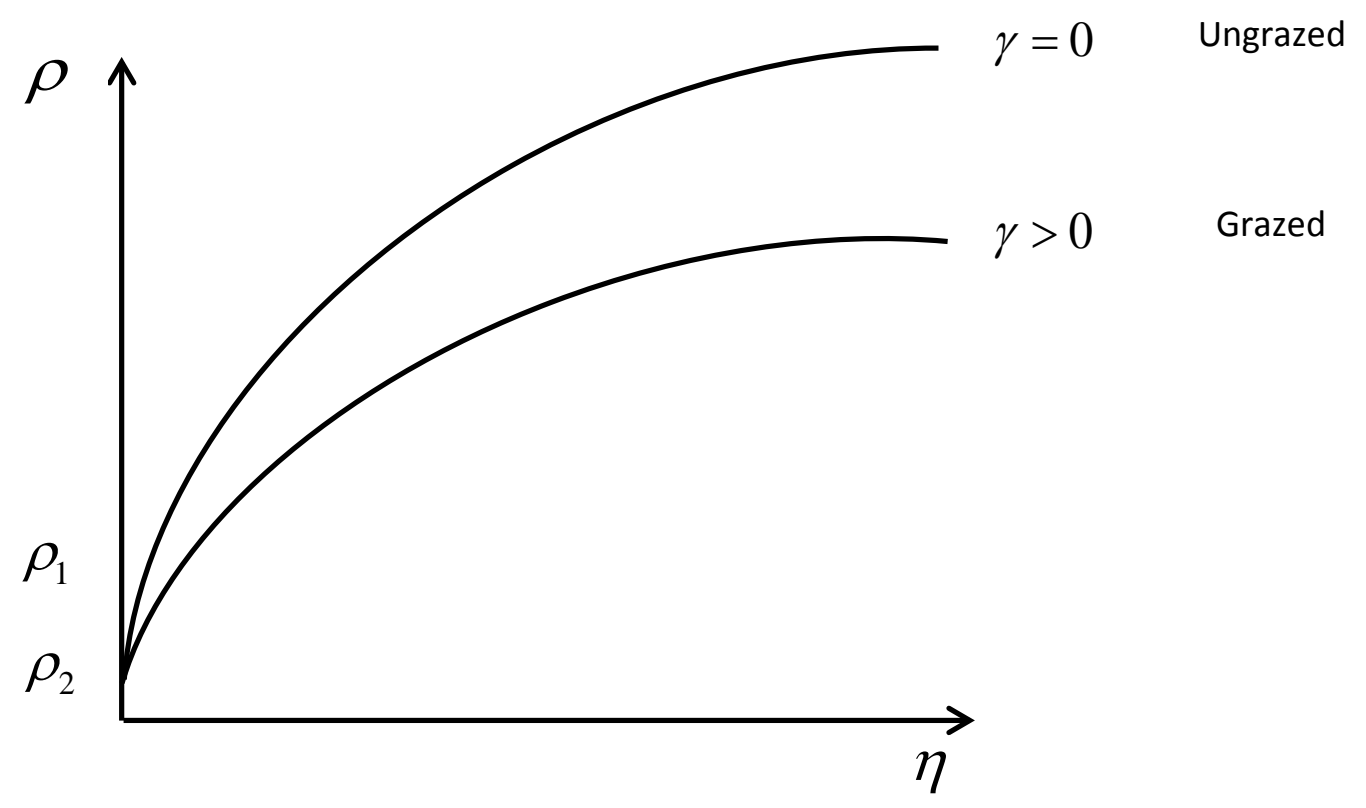

Figure 3.3: Effects of Stocking Rate on Forage Growth and their Relationship with Soil Organic Matter. Stocking rate negatively influences both pasture mass as well as soil organic matter availability while soil organic matter improves pasture mass. The absence of stocking rate $(\gamma=0)$ allows pasture mass to grow since more nutrients are available. However, the introduction of stocking rate $(\gamma>0)$ decreases the pasture mass through consumption as well as nutrients available since it extracts the nutrients accumulated from the soil.

$\Delta \eta_{t, z}=\eta_{t+1, z}-\eta_{t, z}=f\left(\gamma_{t, z}, \beta_{t, z}, \kappa \rho_{t+1, z}, \eta_{t, z}, \mathrm{~N}_{t, z}, \mathrm{P}_{t, z}\right)$

Equation (8) is the change in soil organic matter accumulated per acre in locations z which depends on the soil organic matter at the start of the feeding season, $\eta_{t, z}$, and the amount of soil organic matter available at the end of the feeding season, $\eta_{t+1, z}$, in locations $z$. The change on soil organic matter is essentially the nutrient accumulation function, $\varsigma_{t, z}$.

$\varsigma_{t, z}=f\left(\gamma_{t, z}, \beta_{t, z}, \kappa \rho_{t+1, z}, \eta_{t, z}, \mathrm{~N}_{t, z}, \mathrm{P}_{t, z}\right)$ 
Equation (9) defines the nutrient accumulation function which is a function of the stocking rate, $\gamma(t, z)$, the digested manure application, $\beta(t, z)$, the percentage of the remaining pasture mass at the end of the feeding season, $\kappa \rho_{t+1, z}$, in which $\kappa$ is a constant term with values $0<\kappa<1$, the soil organic matter available at the beginning of the feeding season, $\eta(t, z)$, the concentration of soil organic matter, $\mathrm{N}(t, z)$, as well as accumulated pasture mass from locations z'. The influences of each variable on this function are shown as follows (after dropping subscripts $t$ and $z$ for simplicity):

The stocking rate negatively affects the nutrient accumulation function, $\frac{\partial \varsigma}{\partial \gamma}<0$, since it is extracted from the soil through harvested forage by the livestock and hay production for winter feed. On the other hand, the percentage of the remaining pasture mass at the end of the feeding season, $\frac{\partial \varsigma}{\partial \kappa \rho_{t+1}}>0$, and the digested manure application, $\frac{\partial \varsigma}{\partial \beta}>0$, contribute in counteracting this negative impact. In addition, the soil organic matter at the beginning of the feeding season would influence this function positively, i.e., $\frac{\partial \varsigma}{\partial \eta_{t}}>0$. Furthermore, nutrient accumulation is positively influenced by the concentration of soil organic matter, $\frac{\partial \varsigma}{\partial \mathrm{N}}>0$, and accumulated pasture mass, $\frac{\partial \varsigma}{\partial \mathrm{P}}>0$, from locations $\mathrm{z}$ ' in a form of undigested manure and hay respectively to be used in locations $\mathrm{z}$.

Under this scenario, these influences suggest that: a) the fact that the availability of nutrients enhances forage growth for stocking implies that nutrient accumulation would positively influence beef production, $\frac{\partial \alpha}{\partial \varsigma}>0$, through the increase of pasture available for 
grazing and the winter season which eventually would increase the animal's weight. Likewise, nutrients would impact energy production in a positive manner, $\frac{\partial \xi}{\partial \varsigma}>0$, through the contribution of pasture growth and spatial influences $(\mathrm{N})$. This occurs due to the fact that the forage harvested by the stocking rate and hay for winter feeding is positively influenced by nutrient accumulation in locations z which would eventually be transformed into manure and utilized as an input for electricity production. Since alternative energy production enhances carbon offsets, GHG emission reduction function, $\frac{\partial \psi}{\partial \varsigma}>0$, is positively influenced which progressively increases GHG emission reduction in locations z.

Steady State Condition 2: The change of soil organic matter per acre is explained by the influences of the stocking rate, pastureland for carbon sequestration, digested manure or nutrient application, the percentage of the remaining pasture mass, the soil organic matter at the beginning of the feeding season, the concentration of soil organic matter and pasture mass from location z' on the nutrient accumulation function. In other words, the soil organic matter is in a steady state condition or reaches equilibrium due to the impact of each variable on nutrient accumulation, $\varsigma=f\left(\beta, k \rho_{t+1}, \eta, \mathrm{N}, \mathrm{P}, \gamma\right)$, in which sustainable management decisions are considered. This would contribute to the levels of beef and energy production and eventually GHG emission reductions through a carbon offset. This occurs because the resources available are efficiently utilized when the soil organic matter system is at a stable stage during a given period of time. The relationship between the stocking rate and soil organic matter and renewable energy production is illustrated in Figure 3.4. 


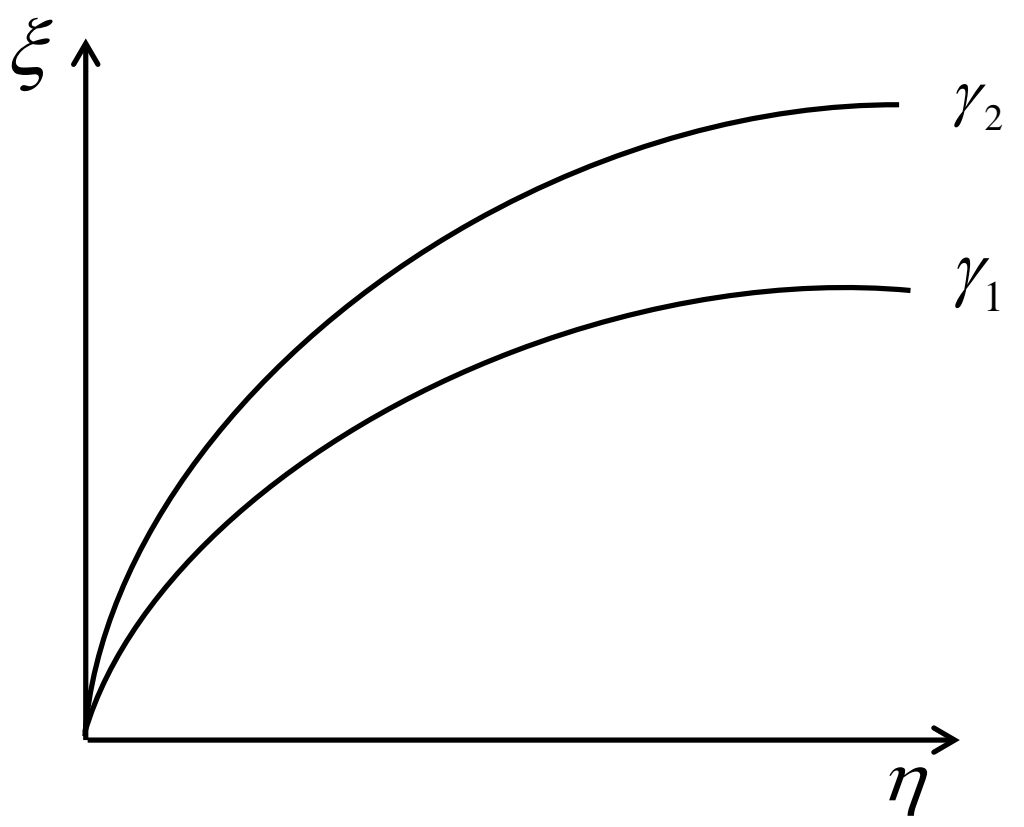

Figure 3.4: Effects of Stocking Rate on Soil Organic Matter and Energy Production. Stocking rate enhances soil organic matter in the form of manure which influences energy production positively.

$\eta(t=0, z)=\eta_{0, z}$

Equation (10) represents the initial soil organic matter available per acre in location $\mathrm{z}$ at the beginning of the feeding season.

$\alpha_{t, z}=f\left(\gamma_{t, z}, \mathrm{P}_{t, z}, \mathrm{~N}_{t, z}\right)$

Equation (11) represents beef production explicitly presented in the objective function which depends on stocking rate, $\gamma_{t, z}$, and concentrations of pasture mass, $\mathrm{P}_{t, z}$, and soil organic matter, $\mathrm{N}_{t, z}$ as depicted in Equation (4).

$\xi_{t, z}=f\left(\omega_{t, z}\left(\gamma_{t, z}\right), \mathrm{P}_{t, z}, \mathrm{~N}_{t, \mathrm{z}}\right)$

Equation (12) represents the electricity production explicitly incorporated in the objective function that depends on the amount of manure collected, $\omega_{t, z}$, which is a function of the 
stocking rate, $\gamma(t, z)$, and spatial effects of the state variables from locations $z$ '.

$\psi_{t, z}=f\left(\xi_{t, z}\right)$

Equation (13) represents the GHG emission reduction function explicitly incorporated in the objective function that depends on the amount of energy produced, $\xi_{t, z}$. The relationship between the GHG emission reduction and energy production is illustrated in Figure 3.5.

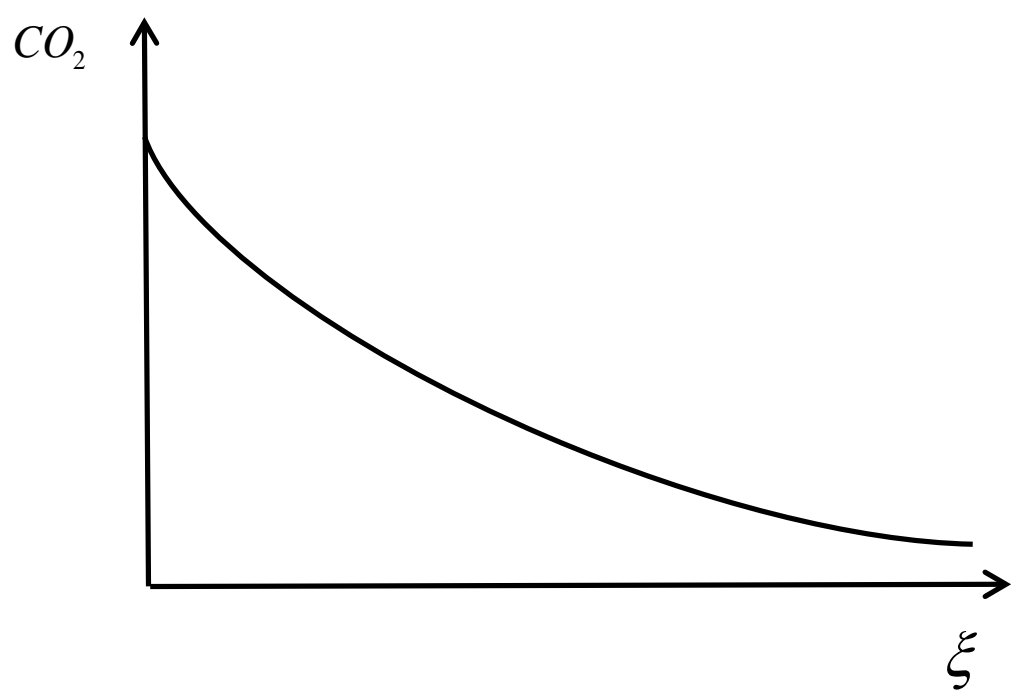

Figure 3.5: Effects of Energy Production on $\mathrm{CO}_{2}$ Emissions. Energy production enhances GHG emission reduction or decreases $\mathrm{CO}_{2}$ emissions through methane captured known as "carbon offset" technique.

Due to the fact that P and N are inputs (Brock and Xepapadeas, 2009) in the production functions (as manure and hay) presented in equations (11) and (12), this provides the basis for regional economic development through clustering systems within a diversified industry spatially distributed in an area.

As we can observe, the objective function is composed of total revenue gained from beef, $p_{\alpha} \alpha_{t, z}$, electricity, $p_{\xi} \xi_{t, z}$, and carbon offset, $p_{\psi} \psi_{t, z}$, revenues minus the variables costs associated with beef production, $c_{\alpha} \gamma_{t, z}$, which depends on stocking rate, energy production, $c_{\xi} \omega_{t, z}$, which depends on the amount of manure collected. The carbon offset is captured through 
the reduction of methane emissions as part of the alternative energy production process in which variable costs are already incorporated in the costs associated with energy production. The total costs are also impacted by fixed costs associated with grass-based beef as well as energy production and carbon offset expressed as $C S$.

As Cacho (1998) and Brock and Xepapadeas (2009) suggest, subscripts $t$ and $z$ have been dropped for simplification and to avoid confusion. For this optimal control problem, there are four types of necessary conditions that will be explained below (Saliba, 1985). As we can see, the Hamiltonian is composed of the integrand function plus the product of the co-state variables and their corresponding equation of motion (Chiang, 2000).

Equation (14) presents the Hamiltonian for this problem:

$$
\begin{aligned}
& \operatorname{MaxH}\left(\gamma, \rho, \eta, \lambda_{\rho}, \lambda_{\eta}, \mathrm{P}, \mathrm{N}\right)=p_{\alpha} f_{\alpha}(\gamma, \mathrm{P}, \mathrm{N})+p_{\xi} f_{\xi}(\omega(\gamma), \mathrm{P}, \mathrm{N})+p_{\psi} f_{\psi}(\xi) \\
& -c_{\alpha} \gamma-c_{\xi} \omega-c S+\lambda_{\rho} \Delta \rho+\lambda_{\eta} \Delta \eta
\end{aligned}
$$

(A). The derivative of the Hamiltonian with respect to the control variable must be equal to zero according to the maximum principle (Saliba, 1985). The optimal path of $\gamma$ in a spatiotemporal scenario is:

i) For $\gamma$ :

$$
\begin{aligned}
& \frac{\partial H(.)}{\partial \gamma}=0 \rightarrow p_{\alpha} \frac{\partial \alpha}{\partial \gamma}-c_{\alpha}+p_{\xi} \frac{\partial \xi}{\partial \gamma}+p_{\psi} \frac{\partial \psi}{\partial \gamma}-c_{\xi}^{\prime} \omega+\lambda_{\rho} \frac{\partial f_{\phi}(\gamma, \eta, \rho, \beta, v, \mathrm{P})}{\partial \gamma}+\lambda_{\eta} \frac{\partial f_{\varsigma}\left(\gamma, \beta, \kappa \rho_{t+1}, \eta, \mathrm{N}\right)}{\partial \gamma}=0 \\
& \rightarrow-\lambda_{\rho} \frac{\partial f_{\phi}(.)}{\partial \gamma}-\lambda_{\eta} \frac{\partial f_{\zeta}(.)}{\partial \gamma}=p_{\alpha} \frac{\partial f_{\alpha}}{\partial \gamma}+p_{\xi} \frac{\partial f_{\xi}}{\partial \gamma}+p_{\psi} \frac{\partial f_{\psi}}{\partial \gamma}-c_{\alpha}-c_{\xi}^{\prime} \omega
\end{aligned}
$$

The right hand side (RHS) of equation (15) shows the product of beef price and the influence of stocking rate on beef production plus the product of electricity price and the influence of stocking rate on the production of this renewable fuel plus the carbon price and the effects of this control variable on the GHG emission reduction function. The RHS also captures 
the variable costs associated with the amount of animal units on the farm and the variables costs associated with manure collection. On the other hand, the left hand side (LHS) of this equation expresses the product of the pasture mass co-state variable and the influence of stocking rate on forage growth and the product of the soil organic matter co-state variable and the effects of stocking rate on the nutrient accumulation function. In other words, equation (15) represents the benefits of higher stocking rate per acre in terms of profits from beef and energy production as well as carbon offsets shown on its RHS while the LHS implies the costs associated with heads per acre in terms of the marginal value of increasing one additional animal per acre to enhance beef and renewable energy production as well as to reduce GHG emissions through energy production.

(B). Another important variable is the auxiliary variable also known as the co-state variable which is basically a valuation variable (its value changes at different time periods), named the shadow price of the related state variable. This variable is integrated into the optimal control model through the Hamiltonian function. This function is used to optimize the control variable before employing the maximum principle (Chiang, 2000). In this model, the shadow price represents the amount of money farmers would be willing to pay (WTP) for an additional pound of pasture mass produced per acre and an additional lb. of soil organic matter per acre. In fact, if the cost associated with any of these two state variables were less than the shadow price, the present value of the profit stream or the value of the objective function would increase. In contrast, if the associated costs were higher than the shadow price, then the value of the objective function would decrease while an equal cost would keep it unchanged. Every co-state equation presents the change rate of each co-state variable (Saliba, 1985). Thus, the optimal path of each 
co-state variable is represented through the marginal value (Cacho, 1998, Saliba, 1985) of $\lambda_{\rho}$ and $\lambda_{\eta}:$

$\frac{\partial H(.)}{\partial \rho}=r \lambda_{\rho}-\dot{\lambda}_{\rho}$

$\dot{\lambda}_{\rho}=r \lambda_{\rho}-\frac{\partial H(.)}{\partial \rho} \rightarrow \dot{\lambda}_{\rho}=r \lambda_{\rho}-p_{\alpha} \frac{\partial \alpha}{\partial \rho}-p_{\xi} \frac{\partial \xi}{\partial \rho}-p_{\psi} \frac{\partial \psi}{\partial \rho}$

Equation (16) denotes that changes in the marginal value of pasture mass available per acre at each point in time, $\dot{\lambda}_{\rho}$, depends on the product of the discount rate, $r$, and the current value of the co-state variable, $\lambda_{\rho}$; minus the product of beef price, $p_{\alpha}$ and the influences of pasture mass on the beef production function, $\frac{\partial \alpha}{\partial \rho}$; minus the product of the electricity price, $p_{\xi}$ and the effects of the pasture mass on the energy production function, $\frac{\partial f_{\xi}}{\partial \rho}$; minus the product of the carbon offset price, $p_{\psi}$, and the influences of pasture mass on the reduction of GHG emissions, $\frac{\partial \psi}{\partial \rho}$, at each time period. Thus, the implicit cost of pasture mass produced per acre must grow at the rate of discount minus the contribution of the pasture mass available either for stocking through the harvested forage and hay per acre to the current returns from beef and energy production as well as GHG emission reductions though “carbon offsets”.

$\rho(t=0, z)=\rho_{0, z}$

$\Delta \rho_{t, z}=\rho_{t+1, z}-\rho_{t, z}=f(\gamma, \eta, \rho, \beta, v, \mathrm{P}, \mathrm{N})$

Equations (17) and (18) present the initial pasture mass available per acre at the beginning of the grazing season and its change at locations $\mathrm{z}$, respectively. 


$$
\begin{aligned}
& \frac{\partial H(.)}{\partial \eta}=r \lambda_{\eta}-\dot{\lambda}_{\eta} \\
& \dot{\lambda}_{\eta}=r \lambda_{\mu}-\frac{\partial H(.)}{\partial \eta} \rightarrow \dot{\lambda}_{\eta}=r \lambda_{\eta}-p_{\alpha} \frac{\partial \alpha}{\partial \eta}-p_{\xi} \frac{\partial \xi}{\partial \eta}-p_{\psi} \frac{\partial \psi}{\partial \eta}
\end{aligned}
$$

Equation (19) implies that the changes in the marginal value of soil organic matter per acre at each point in time, $\dot{\lambda}_{\eta}$, depends on the product of the discount rate, $r$, and the current value of the co-state variable, $\lambda_{\eta}$; a) minus the product of the beef price, $p_{\alpha}$, and the effects of soil organic matter on the beef production function, $\frac{\partial \alpha}{\partial \eta}$; minus the product of the electricity price, $p_{\xi}$, and the influences of soil organic matter on the energy production function, $\frac{\partial \xi}{\partial \eta}$; minus the carbon offset price, $p_{\psi}$, and the impacts of soil organic matter, $\frac{\partial \psi}{\partial \eta}$, on the reduction of GHG emissions at each point of time. The implicit cost of soil organic matter per acre must grow at the rate of discount minus its positive impact on forage production per acre that enhances current returns from beef and electricity production as well as methane emission or $\mathrm{CO}_{2} \mathrm{e}$ emission reductions.

$$
\eta(t=0, z)=\eta_{0, z}
$$

$$
\Delta \eta_{t, z}=\eta_{t+1, z}-\eta_{t, z}=f\left(\gamma, \beta, \kappa \rho_{t+1}, \eta, \mathrm{N}, \mathrm{P}\right)
$$

Equation (20) and (21) represent the initial soil organic matter at the start of the feeding season per acre and its change in locations z, respectively.

(C). The state equations:

$$
\frac{\partial H}{\partial \lambda_{\rho}} \Delta \rho_{t, z}=\rho_{t+1, z}-\rho_{t, z}=f(\gamma, \eta, \rho, \beta, v, \mathrm{P}, \mathrm{N})
$$




$$
\frac{\partial H}{\partial \lambda_{\eta}} \Delta \eta_{t, z}=\eta_{t+1, z}-\eta_{t, z}=f\left(\gamma, \beta, \kappa \rho_{t+1}, \eta, \mathrm{N}, \mathrm{P}\right)
$$

Equations (22) and (23) are the state equations for every state variable. Equation (22) represents the state equation for pasture mass while equation (23) denotes the state equation for the soil organic matter. These two equations are subject to the initial conditions of each state variable in order to solve them through the passage of time. These functional relationships are able to capture the effects of management decisions (control variables) on the state variables (Saliba, 1985).

(D). The endpoint conditions consider the initial conditions of every state variable as well as the transversality condition.

$$
\begin{aligned}
& \rho(t=0, z)=\rho_{0, z} \\
& \eta(t=0, z)=\eta_{0, z}
\end{aligned}
$$

The initial conditions for each state variable are shown in equations (24) and (25).

$$
\begin{aligned}
& \lambda_{\rho}(T)=\frac{\partial J_{\rho}(T)}{\partial \rho(T)} \\
& \lambda_{\eta}(T)=\frac{\partial J_{\eta}(T)}{\partial \eta(T)}
\end{aligned}
$$

Equations (26) and (27) display the transversality conditions in the final period $T$. This is the last condition considered in an optimal control model. This condition essentially represents what would occur in the final period of time (Chiang, 2000). Following Saliba's approach, these equations establish that the marginal values of each state variable considered will influence the market value of price of its related product. As we can notice, this spatial optimal control model also provides for tradeoffs between beef and energy production while abating GHG emissions by selecting stocking rate as the main decision variable in this model. 


\section{Beef, Electricity and Carbon Offset}

At the planning horizon $T$, the marginal value of pasture mass produced and soil organic matter per acre would have an impact on the market value of beef, energy and carbon prices. This occurs due to the fact that beef and energy production as well as GHG emission reductions are mutually dependent on state variables in locations $\mathrm{z}$ as well as the spatial influences of state variables from locations z' through the interaction between the stocking rate, the feeding seasons based on the harvested forage by stocking, the hay for winter feed and undigested manure.

$$
\begin{aligned}
& \underset{\gamma}{\operatorname{Max}}: V= \\
& \int_{z \in Z} \int_{0}^{T} e^{-\delta t}\left[p_{\alpha} f_{\alpha}\left(\gamma_{t, z}, \mathrm{P}_{t, z}, \mathrm{~N}_{t, z}\right)+p_{\xi} f_{\xi}\left(\omega_{t, z}(\gamma), \mathrm{P}_{t, z}, \mathrm{~N}_{t, z}\right)+p_{\psi} f_{\psi}\left(\xi_{t, z}\right)-c_{\alpha} \gamma_{t, z}-c_{\xi} \omega_{t, z}-c S_{t, z}\right] d t d z
\end{aligned}
$$

Equation (28) represents the value of the farms in locations $\mathrm{z}$ to society when spatial influences are considered.

As McConnell (1983) suggests, the socially efficient strategy would be equal to the private goal when the private discount rate, $r$, is equal to the value of the welfare of future generations, $\delta$. This value represents the implementation of sustainable practices in the present period of time and is reflected at the end of the planning horizon (T). When this interaction, $\delta=r$, takes place and the market works efficiently, society and the farmer would be efficiently interconnected and the path of the stocking rate would be wisely chosen. This would eventually influence the paths of the pasture mass and the soil organic matter per acre. This also occurs due to the fact that clustering systems enhance competition within related industries in which the firms actively involved in the clustering benefits from a productive environment. Therefore, the implementation of sustainable practices in the PBB industry would benefit the farmer as well as surrounding communities. In addition, since the farmer is taking into consideration 
environmental improvement which allows reducing potential negative externalities from he/her operation, it contributes to achieve social efficiency. 


\section{CHAPTER IV: METHODOLOGY}

\subsection{Objective 2:}

The main goal of objective two is to develop an agent-based model that replicates the complexities associated with the introduction of the diversified PBB to analyze the interaction among agents and their surrounding intertemporal environment through resource optimization.

Before providing details regarding the methodology developed for our simulation model, it is essential to point out dissimilarities in terms of the approaches conducted between the OC model (i.e., the conceptual model) and the ABM (empirical) model based on availability of data. Although the Befergyonet (its acronym, BET) model and the conceptual framework developed in objective one might share some similarities, our ABM experimental approach tends to differ in certain ways. We might have realized that both models consider the stocking rate, pasture mass and soil organic matter over space as a way of developing agglomeration economies in a region that would bring benefits to society and businesses. However, BET is more focused on optimizing these resources available in the spatial domain in order to intensify the benefits that a diversified industry would bring to the region and compare it with a specialized industry. On the other hand, our OC model focuses in obtaining the optimal stocking rate subject to these state variables with the objective of maximizing the profit streams of the farmer in which the contributions and costs associated with the state variables are analyzed when making decisions. In other words, BET refers to the optimal stocking rate derived when the pasture pass available in the spatial domain is optimized for beef production and the eventual manure production for energy and carbon offsets.

Furthermore, BET differs in some of the variables and assumptions employed in our conceptual framework. Even though the two models differ on certain assumptions, some are 
captured in both, like for example, variation in slopes across space; when pasture and manure are mobile; land is predetermined; and manure is collected during the winter season. Moreover, the influences affecting the pasture mass growth in our OC model differ from the ABM and only precipitation is used in both. Indeed, notice that in our simulation model forage growth depends on daily solar radiation, precipitation events, coordinates as well as minimum, average and high temperatures. Another variable that both models differ is the stocking rate. For example, our conceptual framework centers in obtaining the optimal stocking rate subject to these state variables with the objective of maximizing the profit streams of the farmer in which the contributions and costs associated with the state variables are analyzed when making decisions. On the other hand, BET derives the optimal stocking rate based on pasture availability versus consumption or what is also known as "carrying capacity" where the pasture available is optimized since no pasture is available for one additional head. In order to measure profitability, we employ NPV equations which are utilized by OC approaches, like for example, Torell, Lyon and Godfrey (1991), Standiford and Howitt (1992), Brock and Xepapadeas (2009), Cacho (1998), Dorfman (1969), Burt (1981) among others in the reviewed literature. Given the previously mentioned transition between our models, let's examine the development of our experimental ABM approach.

For the ABM, the NetLogo platform is employed to simulate the effects of a diversified PBB industry on the environment and society as well as farmers' profitability when resources are optimized in which we employ 11 assumptions throughout this experimental approach as describe in Table 4.1. Our model makes comparisons between specialized and diversified enterprises to evaluate profitability and its eventual environmental implications within a region for clustering systems. Indeed, economies resulting from clustering and agglomeration are 
considered in this study as an important element of a sustainable production system. In our model, we define the diversified farm as the farm of interest within the PBB industry interested in generating income from beef, energy and carbon offset sales while the specialized one is focused solely on beef production and without explicit recognition of any clustering effect.

Table 4.1: Assumptions

\begin{tabular}{|l|l|}
\hline \multicolumn{1}{|c|}{ Assumptions } & \multicolumn{1}{c|}{ Description } \\
\hline Assumption 1 & Initial pasture mass is 1,400 lbs. per acre while soil organic matter is 6,800 Kg/acre. \\
\hline Assumption 2 & $\begin{array}{l}\text { Dry matter intake per day is 3 percent while daily weight gain during grazing and } \\
\text { winter season are 1.5 and 0.87, respectively. }\end{array}$ \\
\hline Assumption 3 & $\begin{array}{l}\text { 2/3 of the paddocks are for grazing while 1/3 is used for winter feed. Pasture is } \\
\text { represented as tall fescue-clover mix that, once it is consumed at the stated stocking } \\
\text { rate, takes approximately 30 days to grow back. }\end{array}$ \\
\hline Assumption 4 & Pastureland in the PBB industry is predetermined. \\
\hline Assumption 5 & Forage is a tall fescue-clover mixture. \\
\hline Assumption 6 & Death loss is 2 percent under certainty while under uncertainty differs annually. \\
\hline Assumption 7 & Hay is completely mobile across space. \\
\hline Assumption 8 & $\begin{array}{l}\text { The farm of interest is a beef supplier under an agreement in which the average } \\
\text { stocking rate over the planning horizon is the minimum stocking rate to be sold at the } \\
\text { end of each operational year. }\end{array}$ \\
\hline Assumption 9 & The slope in the contracting farm is flat while in the nearby farms might differ. \\
\hline Assumption 10 & 90 percent of the manure in the spatial domain is recoverable. \\
\hline Assumption 11 & Manure is completely mobile across space and collected during winter season. \\
\hline
\end{tabular}

\subsection{Befergyonet Model: An Overview}

BET is a simulation model based on agent-based modeling that permits the evaluation of PBB and renewable energy production as well as carbon offsets as a function of environmental variables from a deterministic and stochastic perspective. This allows an approach to compare potential beneficial environmental effects as well as profitability under certainty and uncertainty. The model is composed of two key elements: the supply and the environmental and economic impacts interconnected through high quality beef, renewable energy and carbon dioxide emissions reduction within a specific region simulating the interaction among agents spatially distributed bringing some economic and environmental implications to the whole system. 
BET simulates pasture growth as a function of daily precipitation, solar radiation, and temperature; electricity production based on manure generated and its associated carbon offset based on methane captured in an anaerobic digester during the winter season (November to April). The association among methane emissions and $\mathrm{CO}_{2}$ arises from the fact that methane has 25 times the global warming capacity of $\mathrm{CO}_{2}$; however, when one ton of methane is utilized for energy production, it releases one ton of carbon dioxide. This implies that burning one ton of methane is equal to reducing twenty four tons of $\mathrm{CO}_{2}$ (Key and Sneeringer, 2011). Thus, the equivalence to $\mathrm{CO}_{2}$ emissions in terms of methane is called carbon dioxide equivalent $\left(\mathrm{CO}_{2} \mathrm{e}\right)$ emissions. Furthermore, our model interconnects the benefits and costs associated with PBB and renewable energy production and subsequently carbon reductions by maximizing the pasture available in a specific region among farms within a radius of distance in a planning horizon of 15 years under certain and uncertain conditions. BET is an experimental approach that also evaluates potential clustering development in which resources available such as cattle, forage allowance and manure generated within the sector are optimized within a spatially interconnected industry on a yearly basis.

This ABM is composed of pre-interaction and interaction stages. During the preinteraction stage, the model simulates pasture growth as a function of daily irradiance, rainfall and temperature as well as latitude based on historical data for 15 years for the deterministic and stochastic approaches in order to obtain the control variable or the optimal stocking rate per year over the entire spatial domain. During the interaction phase, the interactive world becomes active and the interaction among agents takes place generating emerging patterns and data based on their rational behavior. In fact, the model is designed to be run for a total of over 10,900 iterations repeated from 5 to 10 times for each scenario exercised in order to obtain a fair 
variability from the stochastic simulation. We employed a total of seven scenarios in which every scenario (under the existence/absence of carbon prices and cost-share programs) was tested under six hypothetical clustering systems, specifically from zero to five clustering members as depicted in Table 4.2.

Table 4.2: Scenarios

\begin{tabular}{|c|c|c|c|c|c|c|c|}
\hline \multicolumn{8}{|c|}{ Scenarios Conducted in ABM Simulation* } \\
\hline & \multicolumn{7}{|c|}{ Carbon Prices } \\
\hline Clustering System & $\$ 0.00$ & $\$ 13.00$ & $\$ 26.00$ & $\$ 13.00$ & $\$ 26.00$ & $\$ 13.00$ & $\$ 26.00$ \\
\hline $\mathbf{0}$ & $(0,0,0)$ & $(0,13,0)$ & $(0,26,0)$ & $(0,13,20)$ & $(0,26,20)$ & $(0,13,50)$ & $(0,26,50)$ \\
\hline 1 & $(1,0,0)$ & $(1,13,0)$ & $(1,26,0)$ & $(1,13,20)$ & $(1,26,20)$ & $(1,13,50)$ & $(1,26,50)$ \\
\hline 2 & $(2,0,0)$ & $(2,13,0)$ & $(2,26,0)$ & $(2,13,20)$ & $(2,26,20)$ & $(2,13,50)$ & $(2,26,50)$ \\
\hline 3 & $(3,0,0)$ & $(3,13,0)$ & $(3,26,0)$ & $(3,13,20)$ & $(3,26,20)$ & $(3,13,50)$ & $(3,26,50)$ \\
\hline 4 & $(4,0,0)$ & $(4,13,0)$ & $(4,26,0)$ & $(4,13,20)$ & $(4,26,20)$ & $(4,13,50)$ & $(4,26,50)$ \\
\hline \multirow[t]{3}{*}{5} & $(5,0,0)$ & $(5,13,0)$ & $(5,26,0)$ & $(5,13,20)$ & $(5,26,20)$ & $(5,13,50)$ & $(5,26,50)$ \\
\hline & \multicolumn{3}{|c|}{$0 \%$} & \multicolumn{2}{|c|}{$20 \%$} & \multicolumn{2}{|c|}{$50 \%$} \\
\hline & \multicolumn{7}{|c|}{ Cost-Share Percentage } \\
\hline
\end{tabular}

This simulation experiment was designed to evaluate potential influences from a diversified pasture fed industry in most counties in WV based on data available as a representation of the Appalachian region. We used Monongalia County for the different scenarios exercised on this simulation; however, the model can be run for any other county to simulate the potential impacts for the proposed industry on each county.

NetLogo allows choosing important elements such as stocks, variables, flows and links to perform the simulation in a dynamic format (Bakshy, 2007). For instance, each of these elements is identified and linked to each other so it simulates the variables that influence the flows that eventually reduce or increase the stocks values over time. In this model, the daily pasture growth and forage available for grazing and hay, beef production, electricity generation from anaerobic digester, manure production, carbon offset and $\mathrm{CO}_{2}$ baseline have been 
categorized as stocks. On the other hand, some variables are represented as values or expressions that would have an effect on inflows and outflows (represented as pipelines) and available through arrows in the system dynamics modeler. In this model, environmental as well as economic variables are integrated in the system dynamics as a form of extraction rates such as forage intake and carbon offset rate as well as costs and net present values associated with the daily interactions.

The advantages of this agent-based software consist of: (i) the capability to integrate routines written in Java language into the model and synchronize language programming with the systems dynamic modeler; (ii) the capability to provide instructions to users before, during, and at the end of the simulation; (iii) the availability to illustrate the interaction among agents and space through graphs as well as visual representation; (iv) the flexibility to export simulation results in different file extensions such as txt and csv for further analysis in other programs as well as during the simulation in its interface view; (v) the ability to develop a control panel to manipulate the initial conditions and parameters of the model; (vi) the advantage of importing data to be used in the simulation; (vii) flexibility of using extensions (BET employs RExtension) to perform statistical instruments during the simulation.

In our approach, a system dynamic modeler was developed in order to capture the dynamics over time and space expressed through mathematical equations using NetLogo. Figures 4.1 and 4.2 present the system dynamic modeler of the concept proposed. In the system dynamic diagram, links allow a value from a variable or stock into a stock or flow making them available from one source to another in order to perform the simulation (Bakshy, 2007). As we can appreciate in Figure 4.1, the largest rectangular boxes represent the stocks that are influenced by the pipeline-shapes that store equations composed of values located either in the code tab, the 
interface view or in the variables presented as green rectangular boxes (smaller boxes) in the diagram while the arrows or links connect values among the previously explained components. Note that some variables are connected to more than one arrow when variables are used in other functions allowing for multi-use and eliminating unnecessary replications of the same variable in the system such as the "Pgr-Temp-Adj" variable that is used by "RGR-ENV" and "RGR-ENVSTOC” depicted in Figure 4.1.

The stocks are able to change over time due to the influences caused by changes on their flows. The flows are affected by changes in the values of their variables and time making the stocks either to increase or decrease over time. These variables might be identified as a parameter or value stored in the variable or identified in the interface view under the simulation control panel. Thus, the interactions taking place in the whole system would basically have an impact on stocks that eventually will be reflected on production, profitability among other components of the system. Figure 4.2 shows a closer view of one of the segments represented in the complete flowchart.

Additionally, the main simulated equations utilized for the system dynamics are discussed in details on Section 4.6. In order to run these simulated equations, the system dynamics needs to be well-synchronized with language programming considering time and space. Figure 4.3 illustrates part of the code developed for the simulation. This code shows a segment of the first steps to create the agents in BET in which NetLogo identifies as "breeds". The coding section is crucial for ABM developed with NetLogo and requires trials and errors, especially if the model has never been built before. Additional segments of the code developed in BET are illustrated on Figures A-1 to A-4 as samples of the Java language utilized by the NetLogo platform. 


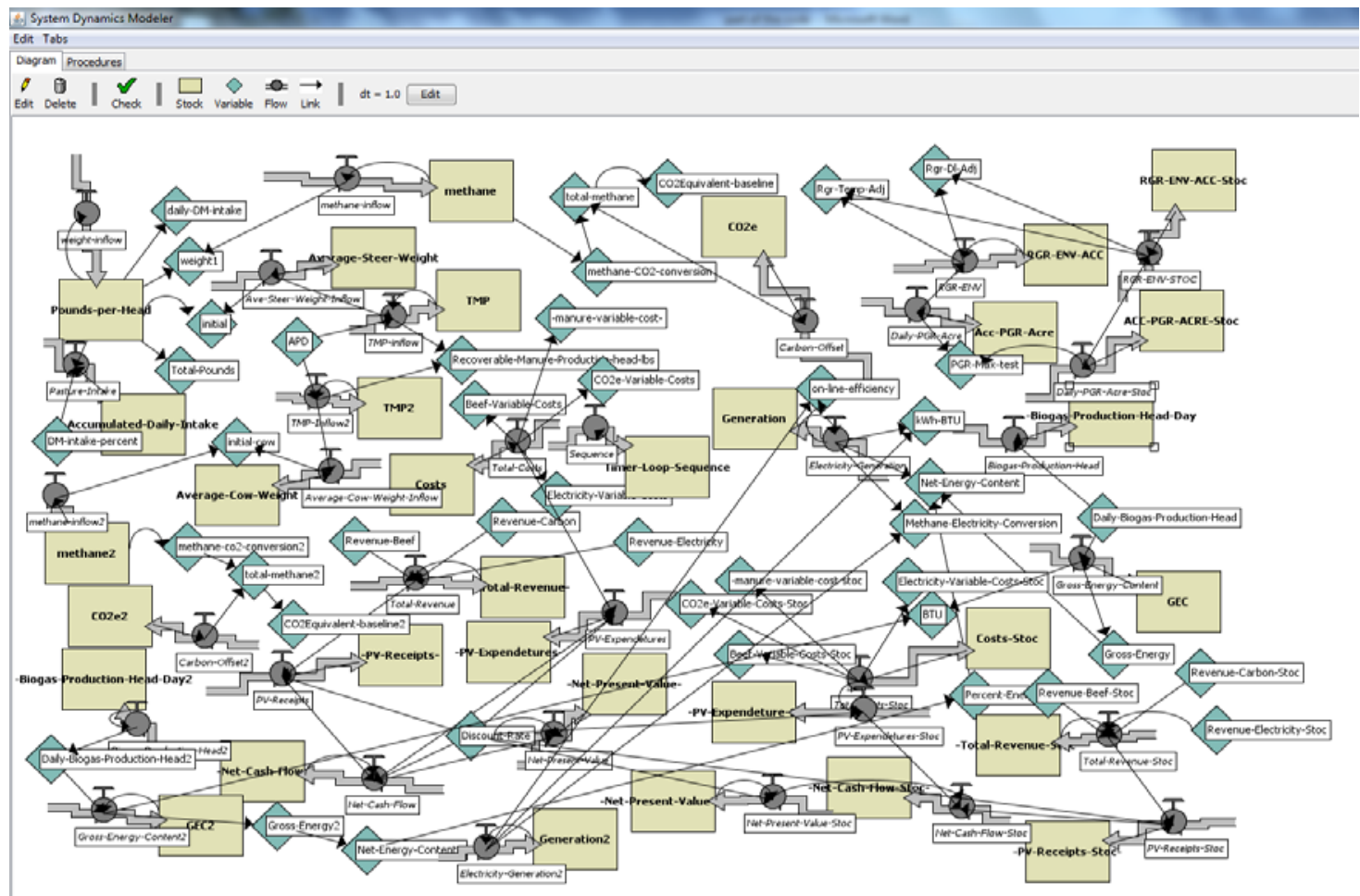

Figure 4.1: NetLogo-System Dynamics Modeler used for Simulation: Complete Flowchart. The figure above shows the system dynamic modeler used in BET model. The largest rectangular boxes represent the stocks that are influenced by the pipeline-shapes that store equations composed of values located either in the code tab, the interface view or in the variables presented as green rectangular boxes in the diagram while the arrows or links connect values among the previously explained components. Note that some of variables are connected to more than one arrow since that variable might be used in other functions. Figure 4.2 shows a segment of the complete flowchart for a more specific explanation. 


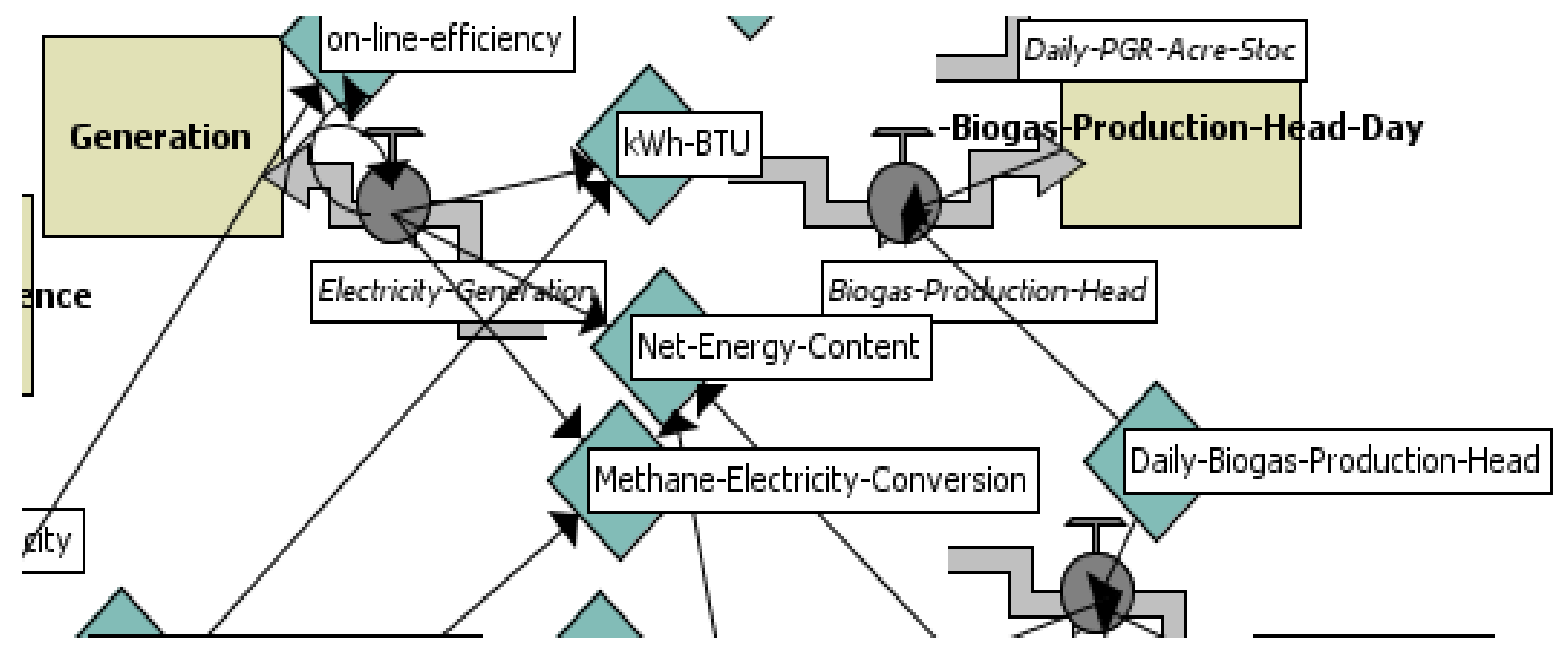

Figure 4.2: NetLogo-System Dynamics Modeler: A Segment.

Note: The flow (pipeline) named "Electricity-Generation" stores an equation composed of the variables (e.g. on-line-efficiency, Net-Energy-Content, etc.) that might be identified as a parameter or value stored in the variable or identified in the interface view under the simulation control panel. The flow changes depending on changes in variables during each iteration proving different values over time while the links (arrows) help make values available from one section to another. Then, the energy produced is accumulated in the stock called "Generation". Notice that "Generation" also depends on changes in the flow identified as "-Biogas-Production-Head" making this a dynamic system along the planning horizon.

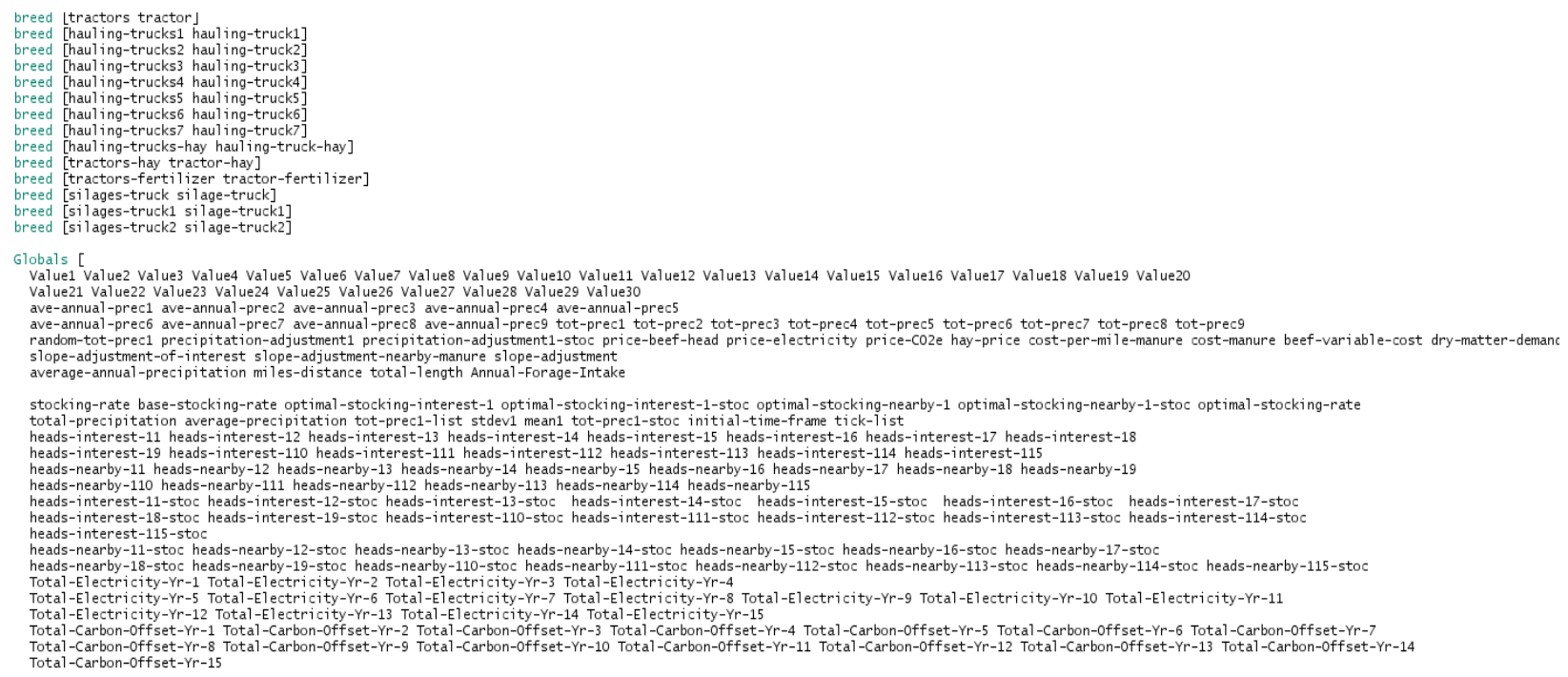

Figure 4.3: NetLogo-Programming Language in Java.

Note: In the coding section, the interacting elements of the "world" such as agents and global variables among other components are created and synchronized with the system dynamics modeler. 


\subsection{Experimental Model: Agents, System and Interactions}

4.3.1 World. The simulated world consists of a 49 by 49 grid of coordinates with a patch size of 3 (world landscape) in which agents (turtles and patches) interact based on the resources available throughout space. Figure 4.4 illustrates the measurements of the world build up in our model through grids. In our ABM, dynamic and static agents are identified as farmers, farms, stocking rates, vegetation, tractors, manure storage, anaerobic digesters, manure transporters, silage hauling trucks, pasturelands (green) and roads (gray). The interaction among these agents on the system is eventually reflected in the production of final products as well as returns to the farm of interest. In fact, it is intended to simulate a realistic model of plan-animal interaction based on entrepreneur decisions within an emerging PBB industry.

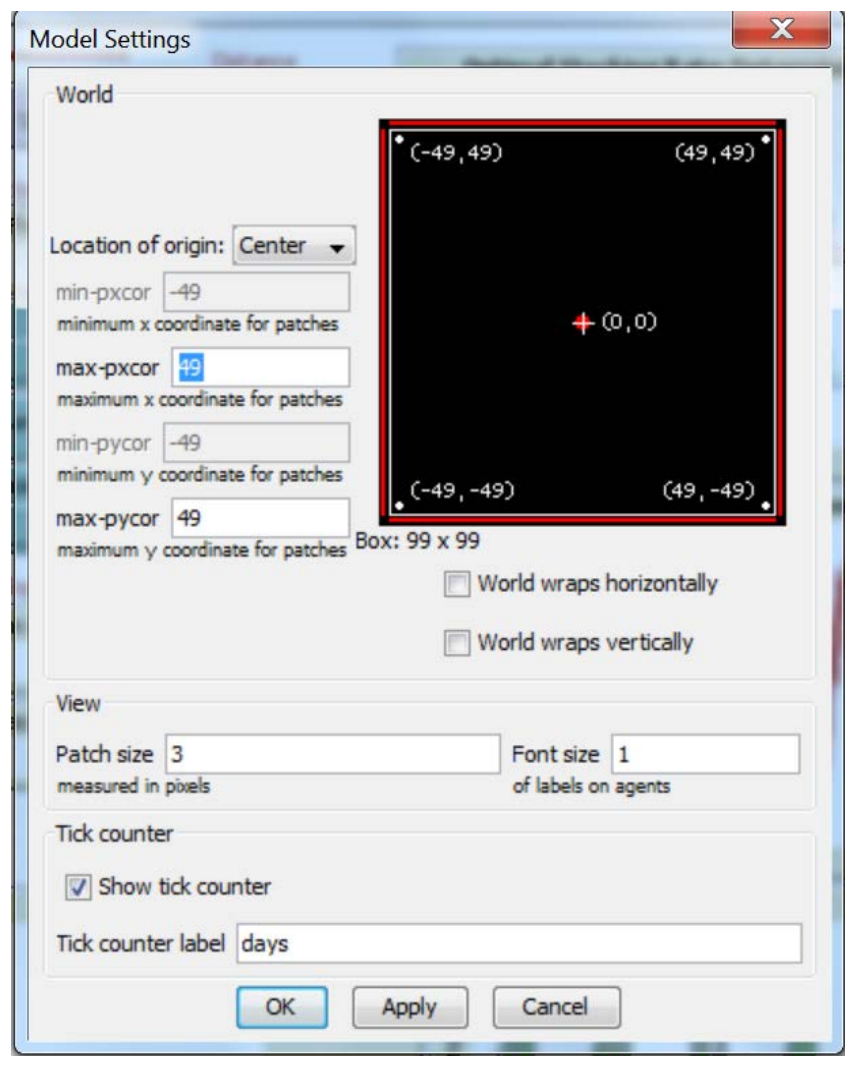

Figure 4.4: NetLogo-World Setting. 
4.3.2 Farm Locations and Farmers. There are a total of nine farms spatially distributed. Every farm in the spatial domain relies on 93 acres of pastureland which is divided into 6 paddocks (Schuster et. al, 2001) of approximately 15 acres each where10 patches represent 1 acre in NetLogo terms. Figure 4.5 shows the interactive system developed as a representation of the system to be simulated. The farm of interest is a stocker farm identified with the color red surrounded by adjacent cow/calf farms (gray), stocker farms (brown) and one silage farm (blue) within a radius of approximately 20 miles derived from the interaction among participating farms in the clustering system and invoked by the farm of interest. Farms are distributed throughout a grid of patches identified by their coordinates allowing the simulation to measure their distances when the clustering system is activated. On the other hand, the model also simulates farmers' interaction with the livestock during the grazing season by rotating it from one paddock to the next within an intertemporal context. This interaction provides a close to reality representation of a PBB industry where the land resources are optimized. This occurs when the forage system fits with the total amount of livestock as an approach to undertake appropriate pasture management techniques (William and Hall, 1994). 


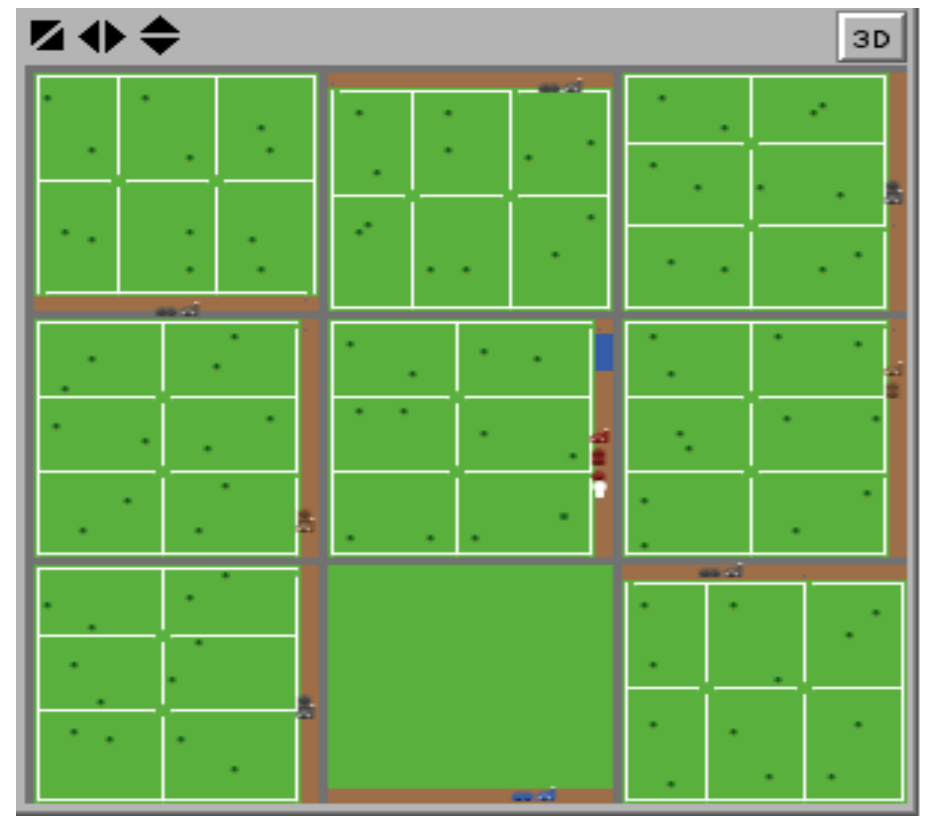

Figure 4.5: Interactive World in NetLogo.

4.3.3 Stocking Rate. It is assumed that the daily pasture intake per head is 3 percent of its body weight (Zobell, Burrell and Bagley, 1999, Rayburn, 2005, Schuster et. al, 2001) with a daily weight gain of 1.5 and 0.87 pounds on a daily basis during grazing (May to October) and winter (November to April) seasons, respectively (Rayburn, 2008, Blaser et., al 1986, VAFS, 1969). It is also fundamental to point out that we employ a daily pasture intake of 3 percent of body weight as an approach to get high individual animal performance. In fact, the increase of grazing intensity would cause a competition effect between forage nutrititive value and quantity (Sollenberger and Vanzant, 2011). Thus, the relationship between forage nutritive value and quantity of pasture available is taken into acccount when the stocking rate is optimized. Furthermore, the livestock grazes $2 / 3$ of the paddocks while $1 / 3$ is used for hay or silage for winter feed each year based on expert opinion. The livestock is composed of an Angus breed with an initial weight of 500 pounds (Rayburn, 2002, Schuster et. al, 2001) purchased at the end of April from adjacent cow/calf farms and grazing is assumed to start in early May and moved to a building during the winter season where animals are fed and manure is collected. In fact, BET 
identifies the closest cow/calf farms and the amount of livestock (calves) available to fit the maximum sustainable stocking rate needed in the contracting business creating a clustering between the farm of interest and cattle suppliers each year.

The stocking rate is derived during the first stage of the simulation and randomly distributed on paddocks by the farmer during the second phase of the modeling. During the grazing season, animals are rotated between paddocks for optimal forage consumption. After reaching approximately 900 lbs. (April), the animals are sold for slaughtering and a new stocking rate is brought to begin the annual operational cycle over again. It is important to mention that beef prices are seasonal which tends to reach the highest during April compared to October with a difference of approximately 5 percent (Hahn, 2012) making appealing to beef producers to sell during this particular season. However, our approach employs annual average prices.

4.3.4 Manure Hauling Trucks. These trucks simulate the manure haulers transporting the manure from adjacent cow/calf farms to the farm of interest during the winter season. The manure collected during this period of time is used to generate electricity and carbon offsets in the contracting business.

4.3.5 Silage Transporters. These trucks simulate silage transportation from the closest silage supplier to the farm of interest and nearby stocker farms. This occurs when the forage production on these farms are limited to satisfy the amount of animals purchased on an annual basis.

4.3.6 Carbon Offset Counter. It is a static agent with the purpose of explicitly illustrating the amount of the current $\mathrm{CO}_{2}$ equivalent reductions that have been reduced during the winter season. Although this static agent does not move, it indeed depends on the carbon offset stock developed in the system dynamics modeler for execution. 
4.3.7 Lagoon. This static agent simulates a manure lagoon or pond to explicitly show the $\mathrm{CO}_{2} \mathrm{e}$ baseline that would be generated from manure during the winter season if it were deposited into a pond instead of using it for electricity generation. This agent depends on $\mathrm{CO}_{2} \mathrm{e}$ emissions generated in the system dynamics.

4.3.8 Manure Collection Counter. This agent is the manure storage in the farm of interest. This is another static agent with the main function of illustrating the amount of manure collected during the winter season in the interacting world.

4.3.9 Anaerobic Digester. This agent represents the daily electricity generated from the manure collected during the winter season. This agent is located at the contracting farm in the simulated world.

4.3.10 Paddocks. Paddocks play an essential role in the PBB industry since it contributes in optimizing the amount of pasture available. In other words, they represent the grazing area in which animals are exposed to a natural environment for approximately180 days.

4.3.11 Pasture. The forage is represented through green patches that interact with the stocking rate when consumed. In our model, pasture is represented as tall fescue-clover mix that, once it is consumed at the stated stocking rate, takes approximately 30 days to grow back.

4.3.12 Roads. This is the area in which manure, silage and cattle trucks transport their inputs from nearby farms to the farm(s) making the request for beef and electricity production. These are basically patches designed to represent the pathways for the mobilization of the resources needed within the region.

4.3.13 Winter Building. The structure in which the stocking rate is placed for the winter season and is fed with forage. Also, it is the location for manure collection which is transferred to the adjacent anaerobic digestion system. 
4.3.14 Trees. This simulates the typical surrounding vegetation in a PBB farm representing seasonal changes during an operational year. As a result of intertemporal changes, trees change color as a representation of the four seasons in WV based on current temperature.

4.3.15 Links. Links are useful agents with the main purpose of connecting the clustering system during simulation. They also measure the average distance in miles among the members of the cluster during the interaction phase.

4.3.16 Silage Tractors. These tractors simulate hay collection for winter season. They collect forage only on $1 / 3$ of the total acreage or 2 paddocks out of the 6 paddocks in which the area is fertilized approximately a month before pasture collection. Also, these agents are invoked by the farm of interest at the end of Spring and Summer seasons every year throughout the planning horizon.

4.3.17 Fertilizer Applicators. It is assumed that the fertilization season starts in April at a rate of two paddocks per month. This agent is also invoked by the farm of interest and takes place during the interaction stage.

4.3.18 Cattle Hauling Trucks. These trucks simulate the supply of cattle from the cow/calf farms to the farm of interest. This event occurs at the beginning of each operational year before grazing season starts.

\subsection{Selections: Buttons, Choosers, Switches and Monitors}

4.4.1 Buttons. The first buttons under the "Simulation Control Panel” (SCP) are categorized as "System Setup”, “Simulation” and "Simulation by Step”. They have been designed to setup and refresh the initial conditions, run the simulation continuously until reaching the planning horizon and run the model step by step or one iteration at the time. 
4.4.2 Clustering System. The model allows selecting the composition of the clustering system for manure supply by changing the number of farms in the system from the chooser "Clusters" under the SCP. This allows users to perform the simulation under different clustering systems for sensitivity analysis generating some economic and environmental impacts within the region. It allows users to select from 0 to 5 clusters to simulate their interaction and their influences within the system or world.

4.4.3 Distance Factor. The “Distance-Factor” permits users to select an estimated radius distance from the farm of interest with respect to adjacent farms. For the purpose of our experimental model, the system measures a radius distance of approximately 20 miles (Weinheimer, 2008) by using a distance factor of 0.5 . The distance factor has been created to provide some flexibility to potential users that might desire to choose different mile distances within the clustering system. In fact, users have the option to select $0.4,0.5,0.8,1$ or 1.2 to represent an approximation of 15, 20, 30, 40 or 50 radius mile distance between farms, respectively.

4.4.4 County Selection. The "Country-WV" permits county selection to execute the simulation based on specific county data in order to identify the potential environmental and economic impacts in a specific region. Due to lack of data, most of the counties in WV can be simulated in BET.

4.4.5 Initial Weight. The "Initial-Weight" option allows selecting the initial weight per head at time zero. In this experimental study, we define 500 lbs. as the initial weight based on a survey conducted of farmers in the pasture-fed beef industry at the national level (Rayburn and Lozier, 2002) and reach a final weight of approximately $900 \mathrm{lbs}$. at harvest. However, this chooser permits users to select an initial weight between 400, 450, 500 or 550 . 
4.4.6 Carbon Price. The "Carbon-Prices-List” provides a list of the commonly used carbon prices (Key and Sneeringer, 2011, Baylis and Paulson 2011 and EPA, 1999) in order to perform a sensitivity analysis based on changes in carbon prices assuming the existence of a carbon market. In fact, it is expected that pressure to decrease greenhouse gas emissions could begin increasing in the future; therefore, carbon prices would eventually rise significantly. However, uncertainty still exists with regard to the carbon offset market in a cap-and-trade framework (Key and Sneeringer, 2011). This is one of our parameters for policy recommendations.

4.4.7 DM-Intake-List. Although our default dry matter intake is 3 percent, BET provides the option of changing this percentage. This was done for the benefit of prospective users of the model providing some flexibility in simulation performance.

4.4.8 Switches. Switches displayed in the SCP, like for example, "Show-Weight?”, “Show-Manure?”, "Show-CO2-Baseline?”, “Show-CO2-Offset?”, "Show-Electricity?” and "Show-Profitability?" are used to either activate or deactivate stocking rate weight, manure production, $\mathrm{CO} 2$ baseline generation, carbon offset, electricity production on a daily basis while the business economic performance is shown at the end of the simulation, respectively. The values are explicitly presented as tags or labels in some of the dynamic (animals) or static (manure storage, anaerobic digester, pond or manure lagoon and the carbon offset counter) agents while the interaction is simulated.

4.4.9 Monitors. Monitors were incorporated in our model since they keep us updated about the state of the simulation. For instance, “Transportation Frequency” shows the number of trips manure hauling trucks need to execute during the winter season (from adjacent farms to the farm of interest) and being requested by the farm of interest. The "Average Radius Miles” shows 
the average miles between nearby farms and the farm of interest when the clustering system is active. Also, the "Pre Interaction: Days” and “Interaction: Days” are monitors able to keep track of the days or iterations before the world and during the world interaction. The "Slope Range: Farm of Interest” and “Slope Range: Nearby Farms” represent the slope range on these areas based on the data collected from the Web Soil Survey (USDA, 2009). In this model, we use the average slope which is prompted through the SLOPE-ADJUSTMENT variable in BET based on coordinates identified on the Web Soil Survey and monitored under the “Terrain Slope” section in the interface view. The sloping factor is based on slope ranges for specific locations in which slopes within ranges between zero to ten percent, eleven to thirty and thirty one to sixty are adjusted as 1.0, 0.7 and 0.3, respectively. Figure 4.6 shows all the features expressed in section 4.4. Furthermore, the death loss percentage is monitored under both certainty and uncertainty simulations. The county location is also displayed through the "Latitude” monitor under the “County Selection.”

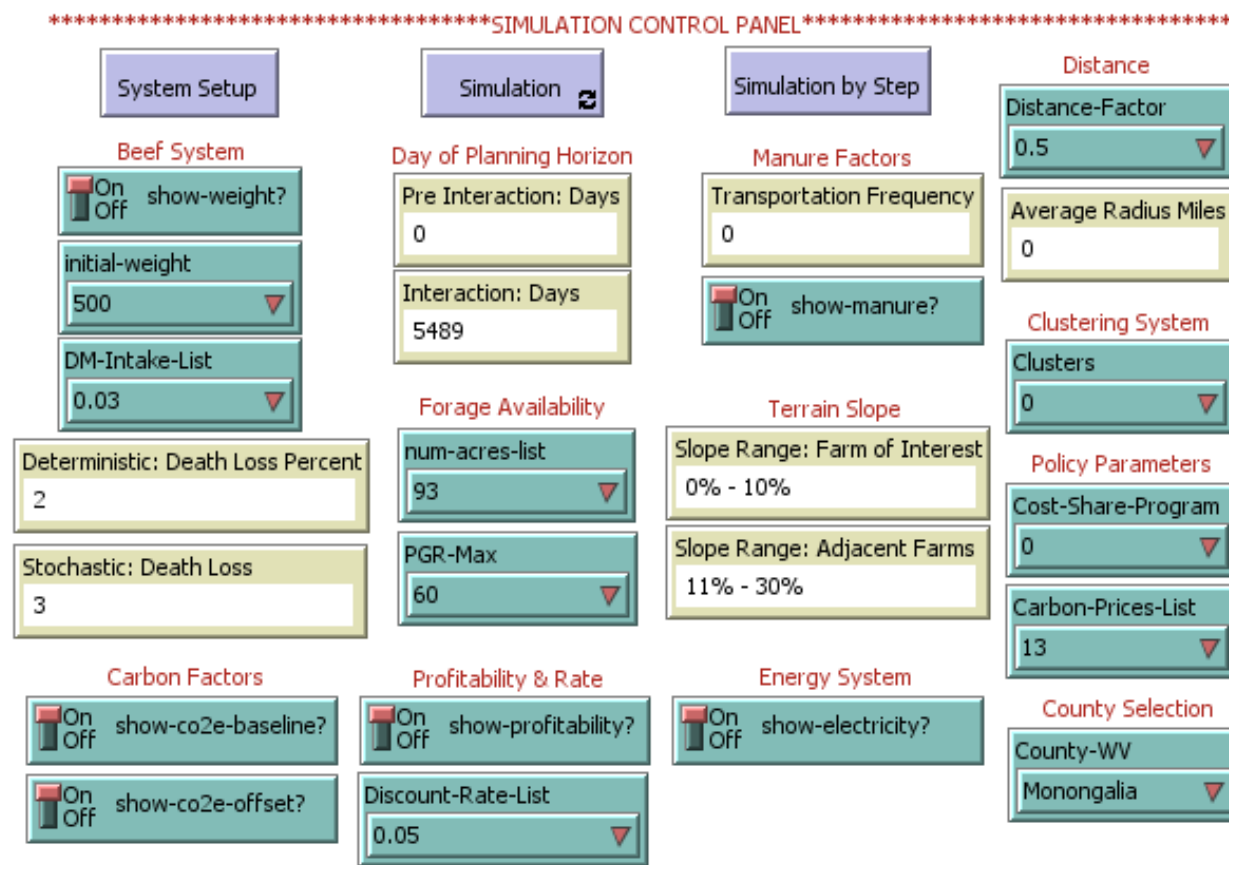

Figure 4.6: NetLogo-Simulation Control Panel (discussed in section 5.4). 
4.4.10 Cost-Share Program. The "Cost-Share-Program" selection provides a list of percentages that can be hypothetically considered as a policy development tool in order to share the costs associated with the initial capital investment needed to afford the anaerobic digester in the PBB industry. This allows users to choose from different cost-share options, especially when conducting sensitivity analysis toward profitability.

\subsection{Outcome from Emerging Patters: Results Generation}

Besides the interaction within the system illustrated in the interactive world, BET has been conveniently programmed to provide simulation results in several forms.

4.5.1 Plots. Plots are graphical representations of the system interaction in which stocking rate, pasture growth rate and average temperature and precipitation rate and depicted over time during the first simulation stage. Others plots are illustrated such as daily beef production, renewable energy generation and carbon offset as well as $\mathrm{CO}_{2}$ emissions during the second phase of the simulation performance.

4.5.2 Output. The model also provides results of the stocking rate based on the system interaction in the interface window below the "Simulation Results" box during the two phases of the simulation. Although complete outcomes are stored in a spreadsheet, this allows users to have a quick view of some of the results.

4.5.3 Total Outcomes. Outcomes from the ABM can also be exported to a spreadsheet for further evaluation once the simulation is completed. This way, a more comprehensive database is generated that can be accessed through a program such as MS-Excel for comparison purposes and further analysis. In order to perform this task, a window providing instructions appears before the simulation takes place right after the "System Setup" button is clicked. After this task has been executed, it is just a matter of choosing the conditions explained under section 4.4- 
Selections and by clicking either "Simulation" or "Simulation by Step" button explained in section 4.4.1 - Buttons to perform the simulation.

\subsection{Simulated Equations and Assumptions}

4.6.1 Simulated Equations and Assumptions. Since the BET model is a dynamic model that interacts based on interconnected equations as well as coding, we present the main equations (equations 1 to 37) used for the simulation illustrated below. However, the Java code or language program developed in NetLogo provides complete information of the entire combination of equation and the code required to perform the simulation. Appendix Figures A-1 to A-4 illustrate coding samples of BET developed in NetLogo since language programming plays a fundamental part for appropriate model performance. The model has also been made available at the NetLogo User Community Models website at http://ccl.northwestern.edu/netlogo/models/community/BEFERGYONET\%20MODEL as a contribution for researchers and other parties interested in either using, extending or learning more about the model.

As an initial condition at time zero, we are assuming that an initial pasture mass is 1,400 pounds per acre (Cacho 1998, Rayburn, 2005) while the soil organic matter value has been identified as 6,800 Kg/acre. As a way of simplifying the complexities described in our theoretical approach, our soil organic matter assumption is based on a 2 inches soil layer with a 3 percent organic matter in which 58 percent is composed of carbon or 7,900 Kg (Ward, 2004). In fact, under acceptable management practices, state variables would reach equilibrium when the control variable is under optimal conditions and the time horizon is sufficient. In other words, the system is intended to reach a productive pattern that can be sustained by keeping it under a stable operation (Costanza and Neuman, 1997). Nonetheless, the use of manure as fertilizer may differ 
among the literature reviewed. For instance, the implications of using tall fescue grass and clover mix as the primary diet for animals might require approximately 200 lbs. per acre on an annual basis (Rayburn et. al, 1998, Parsch, Popp and Loewer, 1997) to assure the nutrients needed in the soil for plant growth. In fact, the percentage composition of manure produced by beef cattle is typically $0.54,0.18$ and 0.39 with an approximation of 3:1:2 in terms of nitrogen $(\mathrm{N})$, phosphorus (P) and potassium (K) (Rayburn et. al, 2006). On the other hand, Evanylo and Peterson (2000) express that approximately 1,025 pounds per acre of biosolids from anaerobic digestion systems can be applied in tall fescue fields. Thus, in order to assure that the pasturelands acquire the necessary nutrients, 620 pounds of digested manure are applied per acre annually which might not a limitation since in the contracting farm over 1,500 lbs. is produced per head annually.

Assumption 1: Initial pasture mass is 1,400 lbs. per acre while soil organic matter is 6,800 Kg/acre.

In our approach is also assumed that the daily pasture intake per head is 3 percent of its body weight (Zobell, Burrell and Bagley, 1999, Rayburn, 2005, Schuster et. al, 2001) with a daily weight gain of 1.5 and 0.87 pounds on a daily basis during grazing and winter seasons, respectively (Rayburn, 2008, Blaser et., al 1986, VAFS, 1969). Furthermore, the livestock grazes $2 / 3$ of the paddocks while $1 / 3$ is used for hay or silage for winter feed each year based on expert opinion.

Assumption 2: Dry matter intake per day is 3 percent while daily weight gain during grazing and winter season are 1.5 and 0.87 , respectively.

Assumption 3: 2/3 of the paddocks are for grazing while 1/3 is used for winter feed. 
In our model, pasture is represented as tall fescue-clover mix that, once it is consumed at the stated stocking rate, takes approximately 30 days to grow back.

Pasture Growth. The pasture growth equation is a dynamic equation intended to estimate relative plant growth rate of forage crops based on daily solar radiation, precipitation events, coordinates as well as minimum, average and high temperatures simulated in NetLogo based on expert opinion (Ed Rayburn, Forage Extension Specialist, West Virginia University) and Lee, Boyer and Dickerson (1979), Wilensky (1999) and Wilensky (2005). This equation is crucial in our simulation model since the optimal consumption of the pasture available mainly determines the optimal stocking rate for each year and eventually, beef and electricity production as well as a carbon offset. In addition, our simulation considers a rest interval of approximately 30 days for tall fescue-clover mix to regrow after grazing as well as silage collection (Rayburn et. al, 1998, Rayburn, 2005) since “erect-growing forage species” have been identified as best to be used also for silage or hay due to their high yield potential (Abaye, Green and Rayburn, 2006) which are frost seeded every three years in order to supply a considerable component of the cattle's diet (McCann, 2010). In fact, a survey conducted of PBB producers at the national level identified cool season grass-clover as an extremely important component of the forage system (Rayburn and Lozier, 2002). Furthermore, studies in which the grass-legume mixture as tall grass-clover has been compared to other grass-legume mix (tall-grass alfalfa and bluegrass-clover), have demonstrated that tall grass-clover presents faster growth rate on average than other mixtures (Yohn and Rayburn, 2000). In BET, every farm in the spatial domain relies on 93 acres of pastureland which is divided into 6 paddocks (Schuster et. al, 2001).

Assumption 4: Pastureland in the PBB industry is predetermined.

Assumption 5: Forage is a tall fescue-clover mixture. 


$$
\text { Daily PGR Acre }=\text { RGR ENV * PGR MAX }
$$

The daily pasture growth rate per acre (Daily PGR ACRE) is defined as relative growth rate associated with the total environmental interaction (PGR ENV) times the expected maximum pasture growth rate (PGR MAX) in which PGR-MAX is assumed to be constant with a value of 60 (lbs./acre).

$$
\text { RGR ENV }=\text { RGR TEMP * RGR DL * RGR H2O }
$$

The RGR ENV depends on the relative growth rate due to mean air temperature (RGR TEMP) times relative growth rate based on day length multiplied by expected maximum pasture growth rate (PGR MAX) and the relative growth due to available soil water (RGR-H2O) in which RGR TEMP is defined as follows:

If TAVE < UPPER CRITICAL TEMP; then RGR TEMP = UPPER CRITICAL TEMP - TAVE * (1 / (UPPER CRITICAL TEMP - UPPER OPTIMUM TEMP).

Otherwise; RGR TEMP = 0; where the UPPER CRITICAL TEMP = 90 and UPPER OPTIMUM TEMP $=70$.

Now, if TAVE < UPPER OPTIMUM TEMP; then RGR TEMP = 1 .

On the other hand, if TAVE < LOWER OPTIMUM TEMP; then RGR TEMP $=($ TAVE - LOWER OPTIMUM TEMP $) *(1 /$ LOWER OPTIMUM TEMP LOWER CRITICAL TEMP); where LOWER OPTIMUM TEMP = 50 and LOWER CRITICAL TEMP $=40$.

However, if TAVE $<$ LOWER CRITICAL TEMP; then RGR TEMP $=0$.

In order to estimate daily evapotranspiration or the movement of water to the air from sources such as soil, the following equations are employed to measure solar radiation on a given day of the year (DOY). 
LAT RADIANS $=$ PI * LATITUDE $/ 180$

Latitude radians (LAT RADIANS) are influenced by PI or 3.1415 times the latitude (LATITIDE) divided by 180 .

$$
\begin{aligned}
& \mathrm{DL}=24 * \operatorname{ACOS}(0-\text { TAN }(\text { LAT RADIANS }) * \text { TAN }(\text { DEC }) / \text { PI } \\
& \text { DEC }=0.41015 * \operatorname{SIN}(0.01721 *(\text { DOY })-1.389)
\end{aligned}
$$

where; DL reflects length of a particular day of the year (DOY) and DEC measures the declination of the earth's axis to the sun. DEC basically determines the angle at noon of the sun light hitting a horizontal surface on the earth at a given latitude.

In addition, the relative growth rate based on day length (RGR DL) is represented as follows:

$$
\text { RGR DL = }
$$

If DL is less than MIN DAY LENGTH; then RGR DL is 0; otherwise, RGR-DL equals DL MIN DAY LENGTH) / (MAX DAY LENGTH - MIN DAY LENGTH); where MIN DAY LENGTH and MAX DAY LENGTH are 9.15 and 14.85, respectively.

$$
\text { LAMBDA }=
$$

LAMBDA represents the solar longitude which depends on $\mathrm{D}$, the number of days following the vernal equinox (March 21), as follows:

If $\mathrm{D}$ is greater than 186; then LAMBDA equals $\mathrm{D}$ - 186; otherwise, LAMBDA is equal to 180 times D divided by 186.

$$
\begin{aligned}
& R=(1-0.001672 \wedge 2) /(1+0.01672 * \operatorname{COS}(P I *(77.5+L A M B D A) / 180)) \\
& D=D O Y-80
\end{aligned}
$$

Furthermore, $\mathrm{R}$ is the radius vector which is basically defined as the ratio of the earth-sun distance and its mean that also depends on LAMBDA. 


$$
\begin{gathered}
\mathrm{SP}=889.23 / \mathrm{R} \wedge 2 *(\mathrm{COS}(\mathrm{LAT} \mathrm{RADIANS}) * \mathrm{COS}(\mathrm{DEC}) * \mathrm{SIN}(\mathrm{H}) \\
\left.\left.-H^{*} \operatorname{COS}(H) * 180\right) / P I\right) \\
H=(P I *(D L / 2)) / 12
\end{gathered}
$$

On the other hand, SP characterizes the daily total of potential solar radiation on a horizontal surface at a given location while $\mathrm{H}$ represents the hour angle. It is important to mention that SP is identified as an extremely valuable parameter due to the fact that its flux density is highly correlated with the standard (long-term mean) cycles of global radiation.

PAN EVAP $=(-0.2345-0.0326 *$ PRECIPITATION $+0.002188 *$ TAVE +0.0002088

$$
* \mathrm{SP}+0.004202 *(\mathrm{TMAX}-\mathrm{TMIN}))
$$

Moreover, PAN EVAP is the pan evaporation for a particular weather station in a specific county. The equation PAN EVAP is limited by setting PAN EVAPD $=0$ when PAN EVAP is negative in order to have positive values; specifically: If PAN EVAP < 0; then PAN EVAPD = 0; otherwise, PAN EVAPD carries the value of PAN EVAP.

$$
\mathrm{ASW}=
$$

In addition, the available soil water at the current day (ASW) takes the following form: If PREVIOUS ASW + PRECIPITATION - PREVIOUS EFF ET > ASW MAX; then ASW = ASW MAX; otherwise ASW is defined as PREVIOUS ASW + PRECIPITATION - PREVIOUS EFF ET.

Likewise, the amount of rainfall available on a daily basis plays a crucial role in our model. Despite the fact that other variables such as temperature and coordinates are fundamental in our pasture growth model, rainfall is the key player in our equation and it is introduced through the PRECIPITATION variable. Actually, changes in climatological conditions between 
years cause forage fluctuations significantly in which inadequate rainfall induces a reduction on pasture growth (Yohn and Rayburn, 2000, Holechek, 1988, Parsch, Popp and Loewer, 1997).

Also, the PREVIOUS ASW is the lag of the variable ASW or the available soil water from the previous day while PREVIOUS EFF ET is the previous day's evapotranspiration based on ASW-PCT (the available soil water today expressed as a percentage of ASW MAX or ASW divided by ASW MAX) in which ASW MAX is the maximum available soil water that the soil can hold that has been defined as:

$$
\text { ASW MAX }=(2 * \text { RYE }-4)
$$

In this equation, RYE represents the soil realistic yield expected which is defined as a constant equals to 4 .

\section{EFF ET $=$}

On the other hand, EFF ET, the effective evapotranspiration due to ASW PCT $=0$ when ASW PCT $\leq 0$. In addition, when the variable ASW PCT equals 0; then EFF ET takes the following form:

$$
\text { EFF ET }=\text { PAN EVAPD } * \text { EVOTRANS vs PANEVAP } * \text { PGR }-\mathrm{H} 2 \mathrm{O}
$$

Here, the EVOTRANS vs PANEVAP variable represents the ratio ET to weather station pan evaporation for cool-season forages (such as tall fescue) with a value of 0.79.

$$
\text { RGR H2O = }
$$

Moreover, RGR H2O, the relative growth rate due to available soil water, equals to 1 if ASW PCT > ASW ABOVE (available soil water percentage at which plant growth starts decreasing due to water shortage). For cool-season grasses, ASW ABOVE is about 50 percent or 0.5. In contrary, if ASW PCT < ASW ABOVE, RGR H2O takes the following form:

$$
\text { RGR H2O = (12* ASW } \left.-\mathrm{PCT}^{\wedge} 2-16 * \text { ASW }-\mathrm{PCT}^{\wedge} 3\right)
$$




\section{REL CUM GROWTH =}

In addition, when DOY (day of the year) = 1, REL CUM GROWTH, the variable representing relative cumulative pasture growth is set to zero. On the other hand, when DOY $>1$ this variable takes the following form:

\section{REL CUM GROWTH = PREVIOUS REL CUM GROWTH + RGR ENV;} in which the PREVIOUS REL CUM GROWTH represents the lag of REL CUM GROWTH or the REL CUM GROWTH of the previous DOY. The other variable employed is the CUM GROWTH which is basically the growth accumulated over time defined as:

\section{CUM GROWTH = REL CUM GROWTH * PGR MAX}

For the stochastic pasture growth, some of the previous equations were modified as an approach to integrate stochastic precipitation in order to provide a better representation of the climatological events in real life. In our approach, we use precipitation due to the fact that pasture yield relies heavily on rainfall (Rayburn, 2003). In fact, we employ the same fifteen years of daily historical weather data (Parsch, Popp and Loewer, 1997) utilized for the deterministic simulation. Our approach for the stochastic daily rainfall is based on the mean weekly precipitation and its standard deviation from normal distribution (Pang et. al, 1999).

Another variable incorporated in our simulation is the death loss based on percentages employed in previous studies (Ferreira, 2001, Eberly and Groover, 2011 and Schuster et al., 2001). In our ABM, this variable has been set up as two percent every year under certainty while the stochastic variable is a random number up to three percent that changes on an annual basis throughout the planning horizon.

Assumption 6: Death loss is 2 percent under certainty while under uncertainty differs annually. 
Stocking Rate. The amount of steers for the annual operation depends on the forage capacity grown on the farm on a yearly basis and the slope of the terrain. In order to identify the maximum sustainable amount of animals on each farm in the entire region in our ABM, our approach is based on Redfearn and Bidwell (2009), Holechek (1988), Wilensky (1999) and Wilensky (2005). In fact, the management decision of using rotational grazing induces stocking rate to utilize more of the pasture available resulting in increased animal grazing days per acre (Rayburn, 2005). The optimal stocking rate is bounded by the pasture availability and the average slope (USDA, 2009) identified for specific locations and implemented in the model based on sloping factors (Holechek, 1988). In effect, the slope in the farm of interest is assumed to be flat as suggested in our theoretical model while in adjacent locations may vary depending on the specific data for that particular location at the county level. Furthermore, since the model maximizes the pasture available within the entire simulated system, the farm of interest would not need to interact with adjacent silage farms because the maximum sustainable stocking rate depends only on the forage available at the farm of interest; however, it might not reflect reality.

In order to incorporate the interaction among the adjacent silage suppliers in our interactive model, the average stocking rate throughout the entire planning horizon is assumed to be the minimum amount of cattle required by the buyer at the end of each operational year in both stochastic and deterministic simulations. Thus, when the optimal stocking rate in the contracting farm (farm of interest) is expected to be lower than the amount agreed with the final product purchaser due to pasture limitations, the farm of interest requests the adjacent silage farm to supply the silage needed in order to satisfy the forage demanded by the minimum amount of livestock agreed. This emerging pattern allows our simulation to have a closer approach to real agent interaction. In fact, BET has been programmed to measure the average stocking rate 
throughout the entire planning horizon which represents the minimum number of livestock to be sold at the end of each operational year. This permits the interaction between stocker farms and the silage provider solely when the maximum sustainable stocking rate is below the average stocking rate.

Assumption 7: Hay is completely mobile across space.

Assumption 8: The farm of interest is a beef supplier under an agreement in which the average stocking rate over the planning horizon is the minimum stocking rate to be sold at the end of each operational year.

Under the assumption that the precipitation does not vary between the farm of interest and adjacent farms and the slope in the farm of interest is flat while in nearby farms might differ, we identify the maximum sustainable stocking rate as follow:

STOCKING RATE $=($ TOTAL USABLE FORAGE / FORAGE DEMAND $)$

* SLOPE ADJUSTMENT

Where total usable TOTAL USABLE FORAGE is defined as the total forage production per acre times the total amount of acres available (ACRES) in units of pounds while FORAGE DEMAND is based on the daily animal weight (WEIGHT HEADS) times the daily dry matter intake (DM DAILY INTAKE) multiplied by the days of grazing and winter feed (DAYS INTAKE) as follows: TOTAL USABLE FORAGE $=$ FORAGE PRODUCTION $*$ ACRES FORAGE DEMAND = WEIGHT HEADS * DM DAILY INTAKE

* DAYS INTAKE

WV is characterized by hilly terrain that might cause grazing limitations to animals. This limitation is captured by integrating the SLOPE ADJUSTMENT variable. In fact, the spatial distribution of forage influences intake rate that eventually affect productivity and sustainability (Laca, 2000). Furthermore, stocking rate tends to gather and graze more in flat or less steep 
slopes since the steeper the slope the less pasture in the site is consumed decreasing the grazable land area for the stocking rate (Laca, 2000, Holechek, 1988). In order to identify the optimal stocking rate in locations were the terrain is not flat as a representation of the region, the slope cannot be ignored.

Assumption 9: The slope in the contracting farm is flat while in the nearby farms might differ.

Electricity Generation. The source of energy generated is identified as renewable, due to the fact that it comes from a constantly available flow of input (Bhattacharyya, 2011). The energy generation equation has been built up based on EPA (2004), Barker (2001), Beddoes (2007), Wilensky (1999) and Wilensky (2005) approaches for our simulation.

$$
\begin{aligned}
& \text { GENERATION }=\text { NET ENERGY CONTENT * METHANE ELECTRICITY } \\
& \text { CONVERSION * KWH BTU * ON-LINE EFFICIENCY }
\end{aligned}
$$

where variables ON LINE EFFICIENCY, KWH BTU and METHANE ELECTRICITY

CONVERSION are constants defined as 0.90, 0.000292997 and 0.25 , respectively.

$$
\text { NET ENERGY CONTENT }=
$$

On the other hand, NET ENERGY CONTENT is influenced by the GROSS ENERGY multiplied by the PERCENT ENERGY in which the latter is a constant with a value of 0.3554 .

GROSS ENERGY CONTENT =

Furthermore, the GROSS ENERGY CONTENT is represented as the DAILY BIOGAS PRODUCTION HEAD times BTU. The BTU variable is a constant commonly used with the value of 600 that reflects the biogas energy content (EPA, 2004, Balsam and Ryan, 2006, Beddoes, 2007 and Baker, 2001).

DAILY BIOGAS PRODUCTION HEAD = 
The DAILY BIOGAS PRODUCTION HEAD is composed of the DAILY POUNDS PER HEAD times a biogas production factor with the value of 0.03440 .

Carbon Offset. The use of anaerobic digesters also provides potential GHG emissions reduction to livestock producers (in this particular case, the PBB industry) when capturing methane from the manure generated as a sustainable management practice (Baylis and Paulson, 2011). In fact, these reductions on methane emissions can be sold to greenhouse emitters who might either willingly desire to reduce their own emissions or encounter emissions caps (Key and Sneeringer, 2011).

CARBON OFFSET = DAILY METHANE PRODUCTION * 24

The CARBON OFFSET equation is influenced by the DAILY METHANE

PRODUCTION * 24. This is because methane has around 25 times the heat trapping capacity of $\mathrm{CO}_{2}$ or global warming of $\mathrm{CO}_{2}$; however, once it is captured through the anaerobic digester, 1 ton of methane used for energy is equivalent to removing 24 tons of $\mathrm{CO}_{2}$.

CO2 BASELINE = DAILY METHANE PRODUCTION * 25

Based on the same reasoning, CO2 BASELINE is equal to DAILY METHANE PRODUCTION times 25 (Baylis and Paulson, 2011, EPA, 2004, Forster et. al, 2007, EPA, 1999, Wilensky, 1999 and Wilensky, 2005). This model is able to estimate the amount of $\mathrm{CO}_{2}$ equivalent emissions (or methane emissions) baseline based on total methane generated. The methane production is based either on the amount of heads spatially distributed in the entire interactive world on a yearly basis when a clustering system is taken into account or by the amount produced only by the farm of interest under the absence of an anaerobic digester in which manure is deposited into a manure lagoon allowing emissions to be released into the atmosphere. 
In fact, the CO2 BASELINE represents the carbon dioxide emissions generated by the cows in the cow/calf farm and the steers on the farm of interest (stocker farm) under certainty and uncertainty, respectively. On the other hand, the CARBON OFFSET shows their respective $\mathrm{CO}_{2}$ equivalent emissions reduction from deterministic and stochastic points of view.

DAILY METHANE PRODUCTION =

DAILY POUNDS PER HEAD * METHANE CONVERSION FACTOR * VS * MMPCA * MD * TPD

The variable METHANE CONVERSION FACTOR is a percent with a value of 0.698 specifically for the state of West Virginia while VS (total volatile solids) for high pasture-diet cattle is 10.1 (NRCS, 2011). Furthermore, the maximum methane producing capacity, MMPC, is valued 0.00384 and MD (methane density) is defined as 0.041 while TPD (daily ton factor) is a constant as 0.0005 or 1/2000 (EPA, 2004 and EPA, 1999).

Manure Production. As mentioned earlier, under the assumption that each animal is purchased (in the farm of interest) at 500 lbs. and reaches approximately 900 lbs. before it is taken to the slaughterhouse and 1,000 lbs. cow in cow/calf farms across space; DMP or daily manure production in NetLogo is defined as follows (NRCS, 2011, Wilensky, 1999 and Wilensky, 2005) under the assumption that only 90 percent of the production is recoverable (NRCS, 1995):

\section{DAILY MANURE PRODUCTION $=$ AAW * BHFDM * STK}

AAW (daily average animal weight) is influenced by the IW (incoming weight plus (OW) outgoing weight divided by 2 or AAW $=(\mathrm{IW}+\mathrm{OW}) / 2$ which fluctuates on a daily basis throughout the simulation. On the other hand, the variable BHFDM represents the high forage 
diet manure production by a beef cattle which is a constant with an average value of 10.1 pounds per 1,000-lbs. of animal. This is multiplied by the stoking rate (STK) during that particular year.

Assumption 10: 90 percent of the manure in the spatial domain is recoverable based on NRCS (1995).

Assumption 11: Manure is completely mobile across space and collected only during winter season as an approach to enhance clustering systems in the region.

Cost of Investment (Anaerobic Digester). As the number of head increases (as clustering members), the costs associated with the anaerobic digester increases at a decreasing rate. Based on the Key and Sneeringer (2011) approach and using data from case studies published by Beddoes et. al (2007), the cost parameters are estimated in NetLogo when the following log-log functional form is employed:

$$
\ln (K)=\alpha+\beta \ln (N)+\varepsilon
$$

in which $\mathrm{K}$ represents the observed capital cost of the technology and construction, $\mathrm{N}$ is the number of heads while the estimated parameters $\alpha$ equals $\exp (\hat{\alpha})$ and $\beta$ equals $\hat{\beta}$. In order to obtain the cost of investment, the estimated parameters are used in the following equation:

$$
K=\alpha^{*}(N)^{\beta}
$$

It is assumed that the technology employed is a plug-flow digester since it is the typical technology used in Pennsylvania (Leuer, Hyde and Richard, 2008). The cost associated with the technology comprises the design and construction of the pump as well as construction observation and assistance, hydrogen sulfide filter, utility charge, power lines, electric generator, effluent holder, solid separators, building, pit heating and so forth (Key and Sneeringer, 2011, Leuer, Hyde and Richard, 2008).

Net Present Value. A PBB farm considering investing in an anaerobic digester has the 
options of either investing in a diversified business or maintaining its current sustainable business. In order to identify the farm of interest profitability, we use the net present value or discounted cash flow approach. In fact, the net present value (NPV) is a formal approach that condenses ecological and economical evaluations of a managing process within a planning horizon predetermined in which every contribution (net revenues) throughout the time under consideration is discounted up to the present day given a certain interest rate (Costanza and Neuman, 1997). The NPV would help us in evaluating the motivation behind venturing a diversified enterprise or continue under a specialized pasture based beef business from a profitability standpoint. The following presents our profitability approach based on Perman et. al, (2003) and Key and Sneeringer (2011) and programmed in NetLogo (Wilensky, 1999 and Wilensky, 2005) under the assumption that the farm of interest is faced with diminishing returns:

(i) If the NPV of the diversified business is positive ( $\left.N P V_{B E C}>0\right)$ and the NPV of the PBB business ( $N P V_{B}>0$ ), the investment into the anaerobic digester should be considered.

(ii) If the $N P V_{B E C}<0$ and $N P V_{B}>0$; then, the investment on the anaerobic digester is an unacceptable option and solely PBB enterprise is profitable.

$$
N P V_{B E C}=P V_{R_{B E C}}-P V_{E_{B E C}}=\sum_{t=0}^{T} R_{B E C} /(1+d)^{t}-\sum_{t=0}^{T} E_{B E C} /(1+d)^{t}
$$

$N P V_{B E C}$ is composed of the present value receipts, $P V_{R_{B E C}}$, minus the present value expenditures, $P V_{E_{B E C}}$, generated from the diversified business.

$$
P V_{R_{B E C}}=R_{B E C}^{t=0}+R_{B E C}^{t=1} /(1+i) \ldots+R_{B E C}^{T=15} /(1+i)^{T}
$$

$P V_{R_{B E C}}$ captures the summation of revenues generated from PBB and electricity production as well as carbon offsets over the planning horizon in which $i$ is the discount rate or 
the value of money, $t$ represents indexes time and $T$ is the planning horizon and lifespan of the anaerobic digester. In other words, it reflects the discounted value of expected net receipts.

$$
P V_{E_{B E C}}=E_{B E C}^{t=0}+E_{B E C}^{t=1} /(1+i) \ldots+E_{B E C}^{T=15} /(1+i)^{T}
$$

Moreover, $P V_{E_{B E C}}$ represents the summation of discounted expenditures or costs associated with the PBB production, energy generation and carbon emissions reduction based on capital and variable costs with regards the entire operation.

$$
N P V_{B}=P V_{R_{B}}-P V_{E_{B}}=\sum_{t=0}^{T} R_{B} /(1+d)^{t}-\sum_{t=0}^{T} E_{B} /(1+d)^{t}
$$

On the other hand, $N P V_{B}$ is defined as the present value receipts, $P V_{R_{B}}$, minus the present value expenditures, $P V_{E_{B}}$, associated with the $\mathrm{PBB}$ production only during the planning horizon in which $P V_{R_{B}}$ is represented as:

$$
P V_{R_{B}}=R_{B}^{t=0}+R_{B}^{t=1} /(1+i) \ldots+R_{B}^{T=15} /(1+i)^{T}
$$

While $P V_{E_{B}}$ takes the following form:

$$
P V_{E_{B}}=E_{B}^{t=0}+E_{B}^{t=1} /(1+i) \ldots+E_{B}^{T=15} /(1+i)^{T}
$$

Using the same reasoning illustrated with the diversified enterprise, $P V_{R_{B}}$, and $P V_{E_{B}}$ is employed; however, the specialized business is solely a PBB farm.

4.6.2 Data Sources. The data used for the simulation are included in Tables A-1 to A-12 in the Appendix section. Climatological and WV county data, like for example, precipitation, temperature and average slopes are compiled from NOAA and Web Soil Survey (2009). On the other hand, the number of acres of pastureland per beef farm is an averaged value identified in previous studies conducted by Evans et al. (2007). Moreover, costs associated with beef production such as pasture production per acre and costs of production per head are based on 
Eberly and Groover (2011) and Schuster et. al. (2001) while cattle prices are based on Hahn (2012) and Rayburn (2006). Costs and prices were adjusted for inflation using the inflation calculator developed by DOL (2012). Also, it is assumed that the price of purchased silage is $\$ 88$ per ton (Judy, 2011). Furthermore, the daily pasture intake per animal and the sloping factor data have been compiled from Zobell, Burrell and Bagley (1999), Rayburn (2005) and Holechek (1988). Also, energy prices are commercial prices (EPA, 1999, Beddoes et. al, 2007) based on historical data published by the US Energy Information Administration (2012) and forecasted using the trend method based on Bhattacharyya's (2011) approach in order to establish cyclical trends since the value of electricity is volatile and might continuously vary (EPA, 1999). Furthermore, the selected dicount rate and the average costs associated with the maintenance and monitoring of the anaerobic digester as well as the planning horizon for the NPV estimation are based on Key and Sneeringer (2011) and Baylis and Paulson (2011). Moreover, costs related to manure collection are based on Ribaudo et. al (2003) and Weinheimer (2008) which includes manure base charges, transportation costs per mile and cost of manure per ton. On the other hand, the capital costs associated with the anaerobic digester are based on case studies identified by Beddoes et. al (2007) and parameters are derived using the Key and Sneeringer (2011) approach.

\section{CHAPTER V: RESULTS AND DISCUSSION}


The patterns emerged through this ABM simulation that allow us to understand the complexities associated with the introduction of the diversified PBB into the region and eventual benefits to entrepreneurs within the industry, society and the surrounding environment.

\subsection{Results and Discussion}

5.1.1 World Interaction. It is important to point out that the production approach assumed here is somewhat forward-looking and idealistic, but based on actual trends and current priorities. The industry configuration assumed in this study is, by definition, more horizontally and vertically integrated than that found in conventional beef production since we incorporate renewable energy production as well as $\mathrm{CO}_{2} \mathrm{e}$ emissions reduction as an approach to enhancing the stream of benefits to farmers and society (i.e., multiple products produced in a spatially and intertemporally integrated manner). The simulation model developed for this purpose is useful in answering "what if" questions and enhances our understanding of the interactions among a large number of variables as well as helping reduce the time and costs associated with experimentation. In fact, modeling work associated with ecological and agricultural systems tends to be categorized as an applied development or investigation with a practical objective (Thornley and France, 2007).

During the interaction, the system identifies the amount of cattle available over space and is able to supply the livestock required by the farm of interest from the closest adjacent cow/calf farms at yearly basis. As we can appreciate, Figure 5.1 shows the interaction between the cow/calf farms and the contracting farm as part of the emerging patterns in the clustering system represented by the yellow links among businesses. Interaction between the farm of interest (stocker farm) and the cow-calf farms in the region during the cattle supply process in which livestock is provided by farms available in the region at yearly basis. Another interaction that 
takes place is that the process of rotating the livestock during grazing season. BET simulates farmers rotating the cattle during the grazing season from one paddock to another in the entire spatial domain. Fertilizer applications (digested manure) are also simulated by BET as well as harvested forage for winter feed. Figures 5.2 and 5.3 illustrate the interactions during the grazing season.

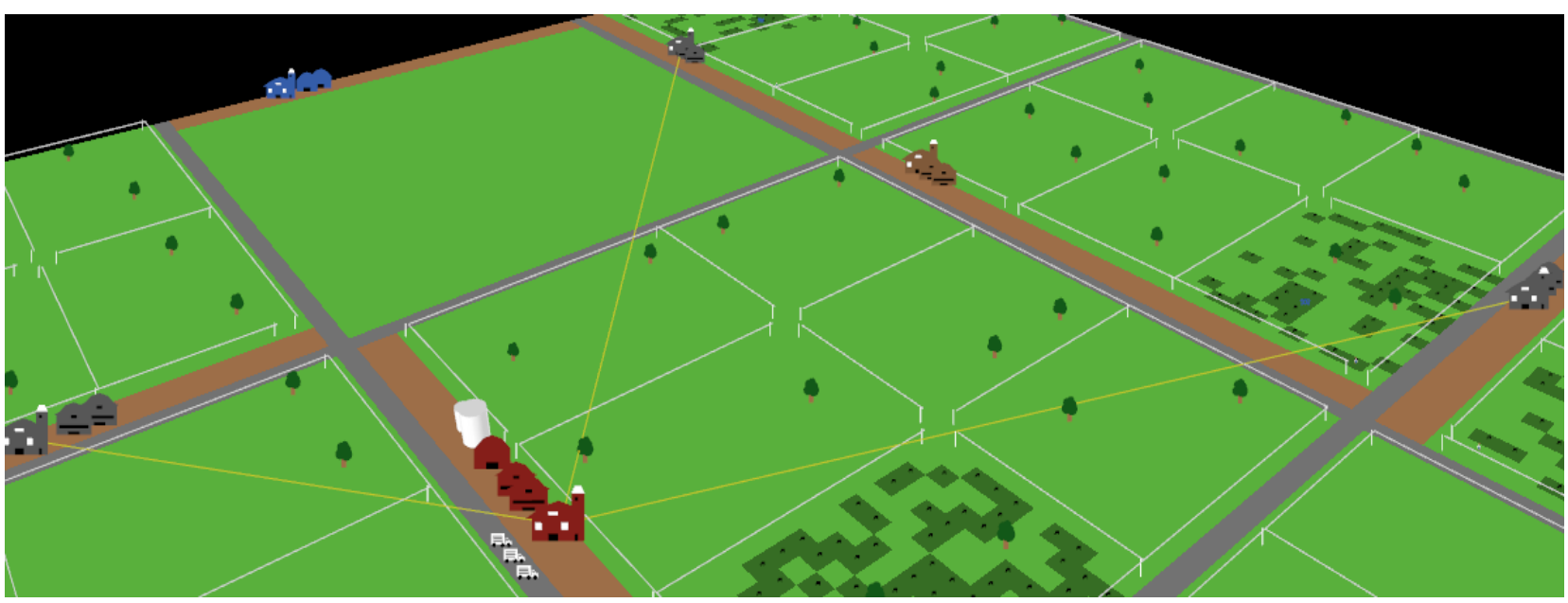

Figure 5.1: Interaction between the farm of interest (stocker farm) and the cow-calf farms in the region during the cattle supply process in which livestock is provided by farms available in the region at yearly basis hauled by cattle trucks. In this particular year, BET identifies that three adjacent cow/calf farms are able to supply the stocking rate needed in the contracting farm.

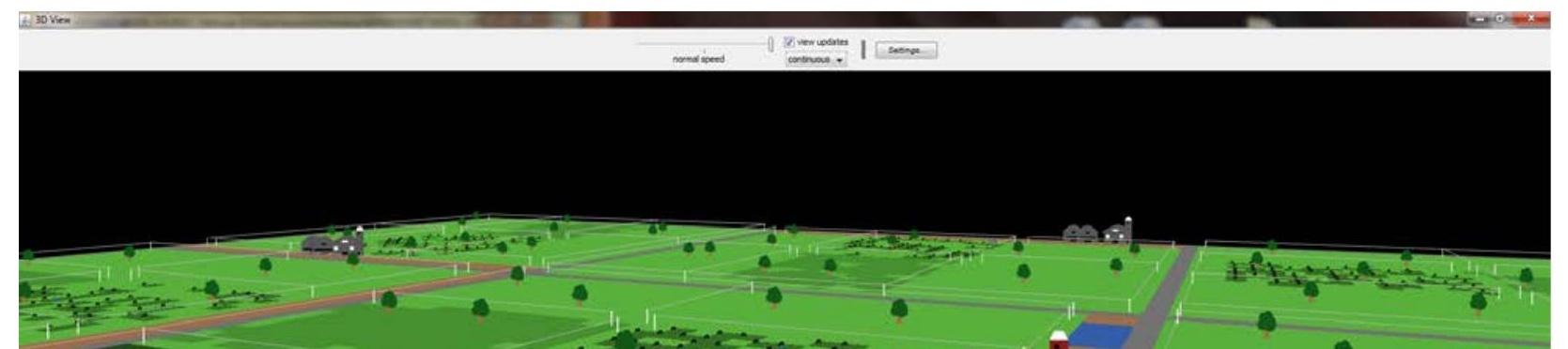


Figure 5.2: A representation of the interaction among agents within the system during the grazing season in which the farmer rotates stocking rate in 2/3 of the paddocks while 1/3 of the paddocks are used for silage for winter feed (based on expert opinion) and using $1^{\text {st }}$ and $2^{\text {nd }}$ cuts each year (Rayburn, 2008 ).

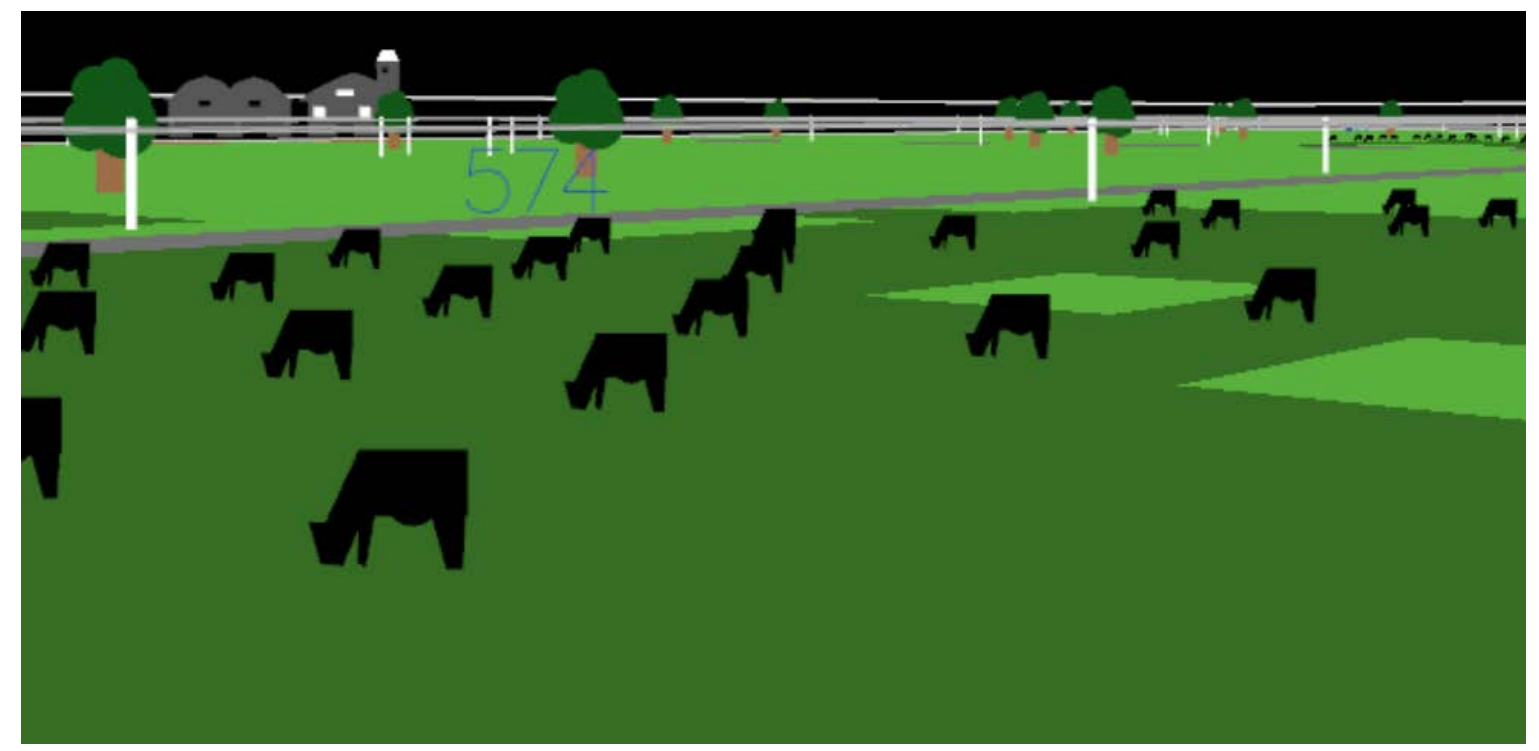

Figure 5.3: On every iteration, one head of cattle is randomly chosen to illustrate its current weight during the grazing season simulation.

Figure 5.4 presents the interaction between the stocker farms and the silage supplier in the region and each farm requests the adjacent silage farm to supply the silage needed in order to satisfy the forage demanded by the minimum amount of heads under agreement or contract. This 
emerging pattern allows our simulation to have a closer approach to real life scenarios at the regional level.

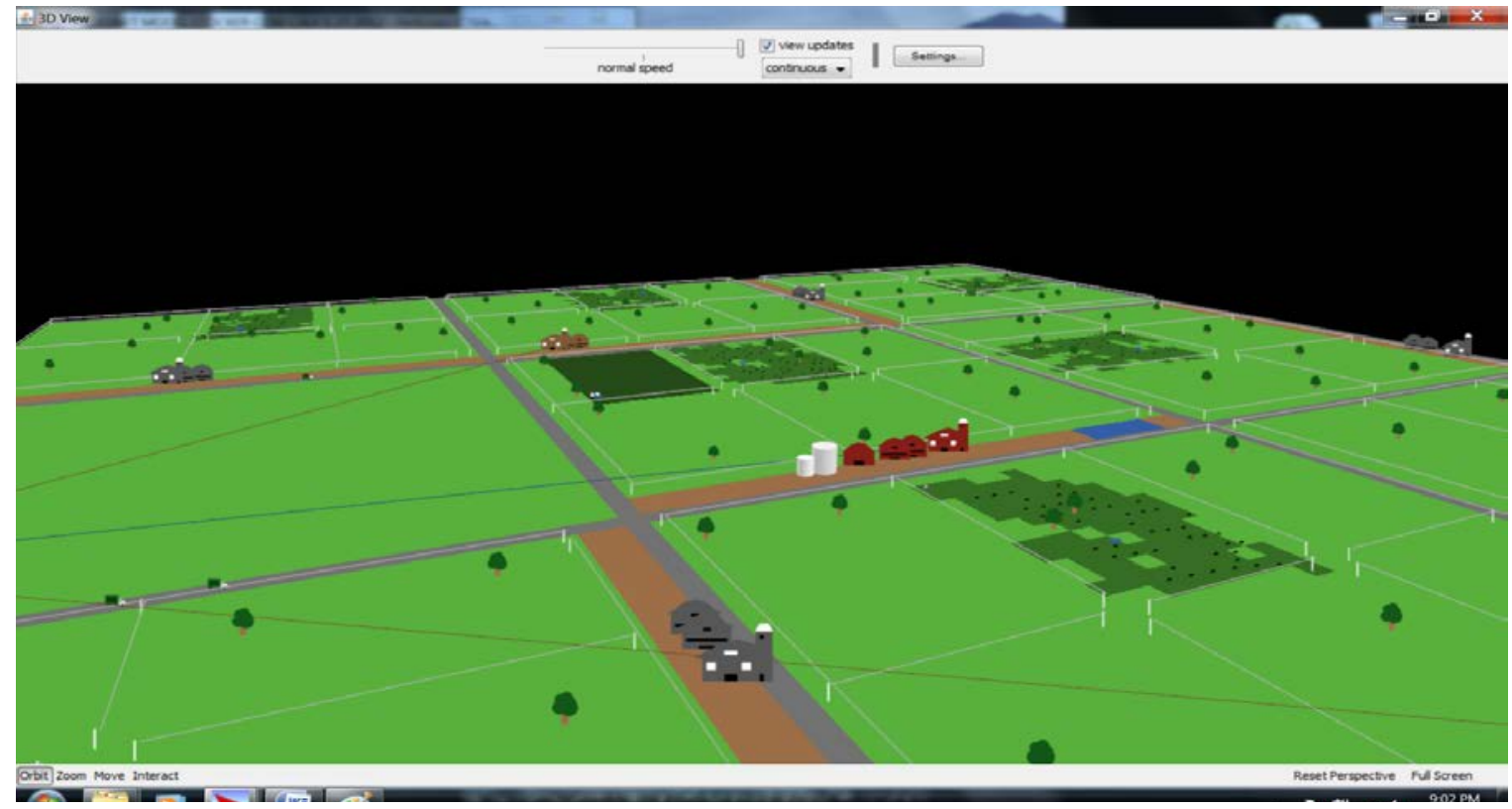

Figure 5.4: When livestock consumption is greater than the forage available in the farm of interest, the farm of interest contracts with the adjacent silage farm to supply the input in order to satisfy the forage demanded by the stocking rate. This occurs only when the optimal stocking rate based on forage available on stocker farms is below the average stocking rate (based on mean stocking rate over 15 years) to be sold at the end of the operational year. Hauling trucks are invoked by the farm of interest so the interaction taking place.

The farm of interest is the only business taking the risk of retaining ownership of the animals after the grazing season is complete. The intuition behind this farmer's decision is due to the fact that during the winter season, the cattle are confined to a handling facility or similar building for continued beef and energy production and its eventual $\mathrm{CO}_{2} \mathrm{e}$ emissions reduction expecting to obtain higher profitability than a specialized PBB enterprise at the end of the planning horizon through electricity sales, beef and carbon offset. Once the grazing season is finished, adjacent cow/calf farms sell their calves and maintain their cows during the winter season becoming part of the clustering system through manure collection. Figure 5.5 illustrates the links between farms represent the clustering system that connects the farm of interest with nearby cow/calf enterprises as well as manure transporters as a way of optimizing the resources 
available causing agglomeration economies within the region.

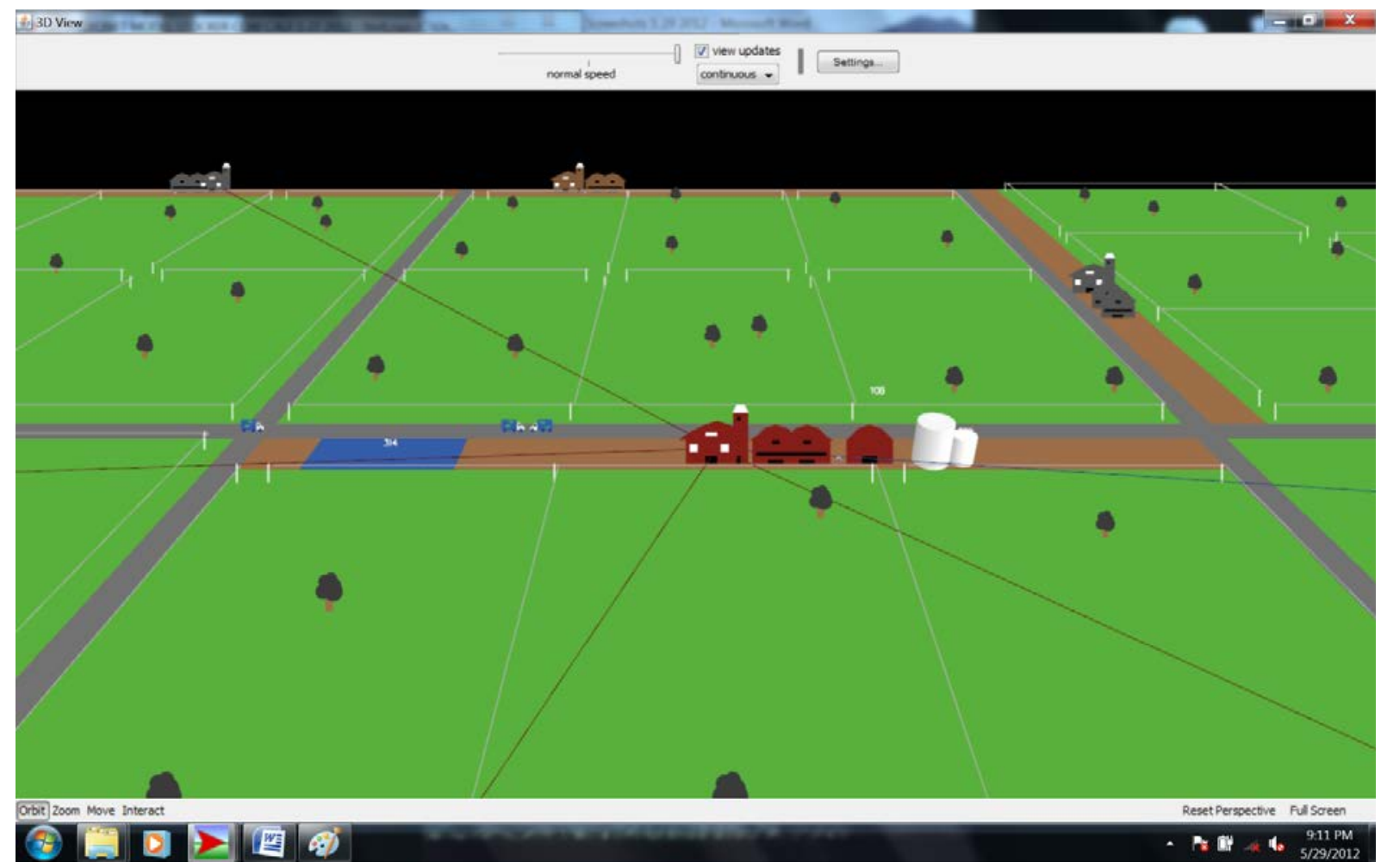

Figure 5.5: During the winter season, animals are confined to a building where manure is collected in the entire spatial domain. The manure produced in nearby farms is transported by hauling trucks to the farm of interest for energy generation while methane is captured through the anaerobic digester. The activation of the clustering is invoked by the farm of interest.

The model is able to show estimates through labels attached to agents such as the simulated pond (to the left of the farm of interest depicted below) which depicts the $\mathrm{CO}_{2} \mathrm{e}$ emissions baseline generated if the manure produced within the clustering system is deposited into the pond. BET is programed to explicitly illustrate estimations of the manure produced during the winter period of each year as well as energy generation and the amount of carbon offset as presented in Figure 5.6.

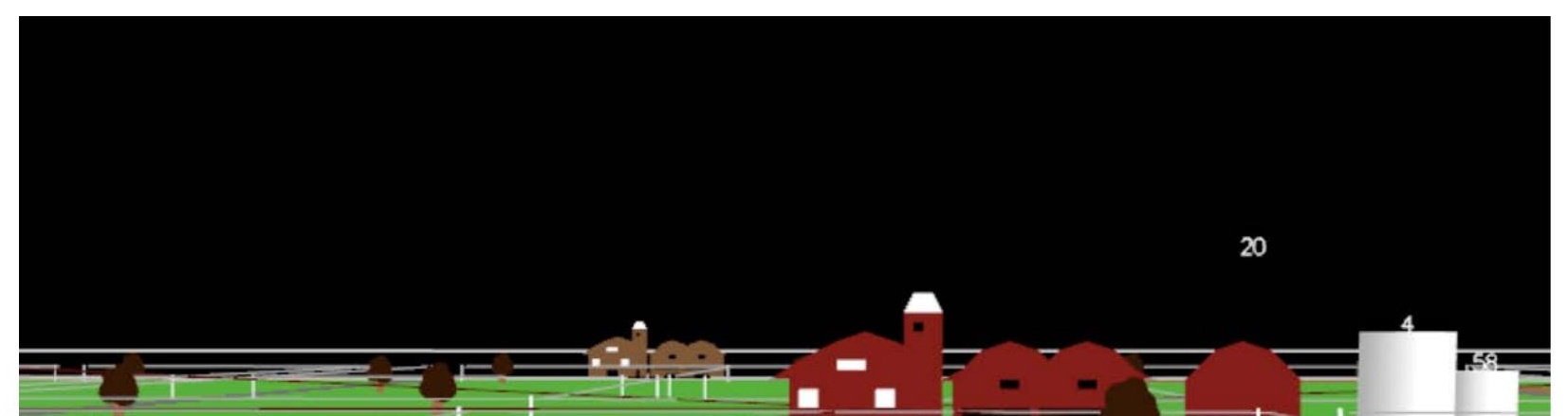


Figure 5.6: From left to right, the interacting world illustrates an estimate of: $\mathrm{CO}_{2}$ equivalent emissions baseline (60 tons), manure collected (20 tons), electricity generation (4 MWh) and carbon offset (58 tons) through the anaerobic digester at the daily basis during winter period.

\subsubsection{BET Model and Outcomes. This simulation model offers the advantages of} generating simulation results in the interface view while running the simulation. For instance, BET derives the annual stocking rate graphically as well as in the simulation results box during the first stage of the simulation as depicted in Figure 5.7 (interface view). It also provides the NPV for the specialized and diversified enterprises as well as the cost of technology under stochastic and deterministic scenarios at the end of the simulation. The interface view also gives the parameter estimates derived from ordinary least square (OLS) for the cost of technology and energy price trends. In addition, during this phase stochastic and deterministic precipitation and pasture growth as well as temperature are simulated simultaneously. On the other hand, the primary products (beef, energy and carbon offset) are graphically presented in the interface view during stage two in which agents spatially located interact. Moreover, the model provides simple instructions to the export outcomes spreadsheet as depicted in Figures 5.8 and 5.9.

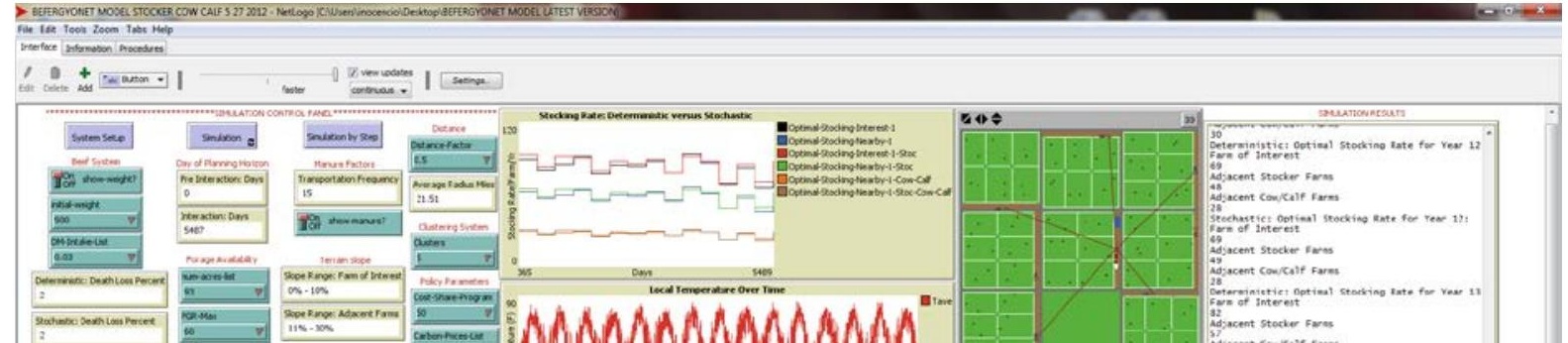


Figure 5.7: The model is programmed to display some of the simulation results of the interface view through plots (graphs) and the "Simulation Results" box shown to the right.

As shown in Figure 5.8, BET exports simulation results to a spreadsheet file with csv extension named netlogoresults.csv. This file stores results and selected parameters such as county, members in the clustering system, carbon price, cost-share percentages, stocking rates, technology costs, annual net revenues and NPVs for further analysis and comparison between simulations under different scenarios.

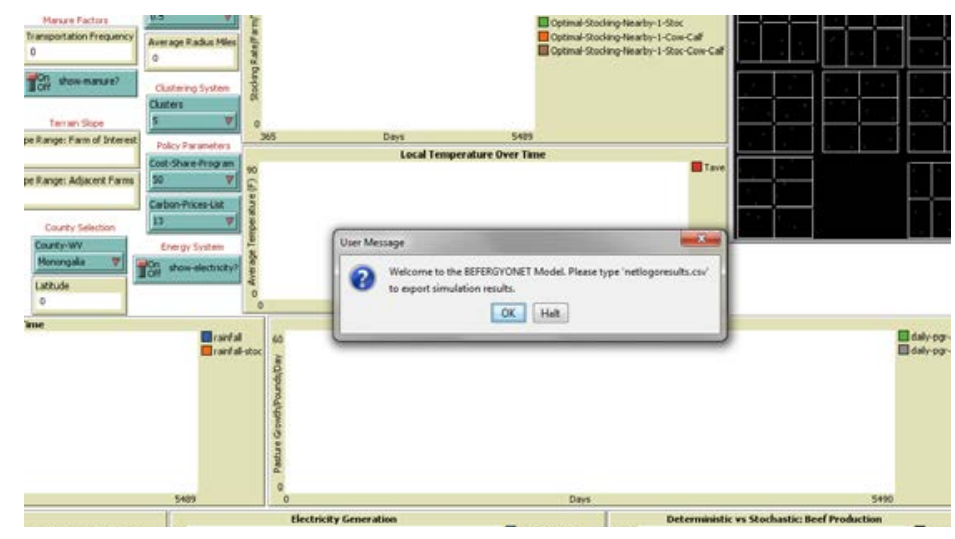

Figure 5.8: BET is conveniently programmed to provide instructions of how to export complete simulation results to a spreadsheet before simulation starts. After the completion of the simulation, users can access the "netlogoresults.csv" file for further evaluation.

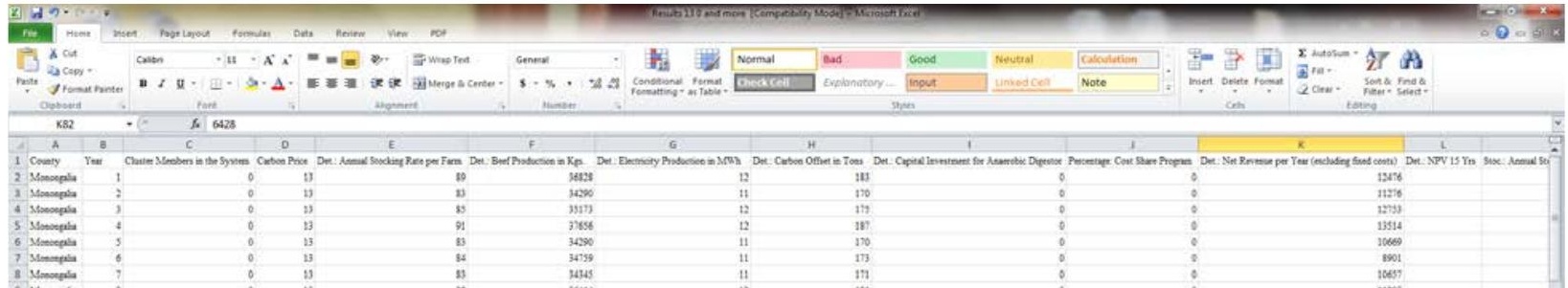


Figure 5.9: After the simulation is complete, results are exported in the form of a spreadsheet using csv extension to be accessed through MS-Excel or any other compatible program.

As previously mentioned, our model considers fescue-clover mixture as the primary forage for the business. Under appropriate fertilization and well-managed practices, tall fescue grasses are able to produce approximately 5.1 tons of dry matter per acre per year with a standard deviation of 1.4 tons (Rayburn, 2003). Our assumption also coincides with the majority of PBB businesses (65 out of 83) at the national level, who considers a cool-season grass-clover combination as highly important in their forage system (Rayburn and Lozier, 2002). In fact, pasture yield relies heavily on precipitation (Rayburn, 2003) while legumes contribute building up nutrients available such as nitrogen in the soil or its fertility allowing for more pasture availability (Raine, 2001). Thus, a tall fescue-clover mixture along with appropriate digested manure application and the initial soil organic matter condition permit nutrients to be at a steady state each year. In fact, the effect of fertilization and nutrient availability depends on the pasture growth rate which depends on temperature and precipitation (Rayburn et. al, 1998, Rayburn, 2005). Therefore, the pasture growth (pasture mass) emerging patterns on a daily basis provide 
an insightful understanding and closer real life interactions of the primary input in the PBB industry. Figures 5.10 and 5.11 illustrate the pasture yield per acre in pounds on a yearly basis derived from the simulation while Figures 5.12 to5.15 present graphical results of the precipitation and temperature for one year as well as over the entire planning horizon.

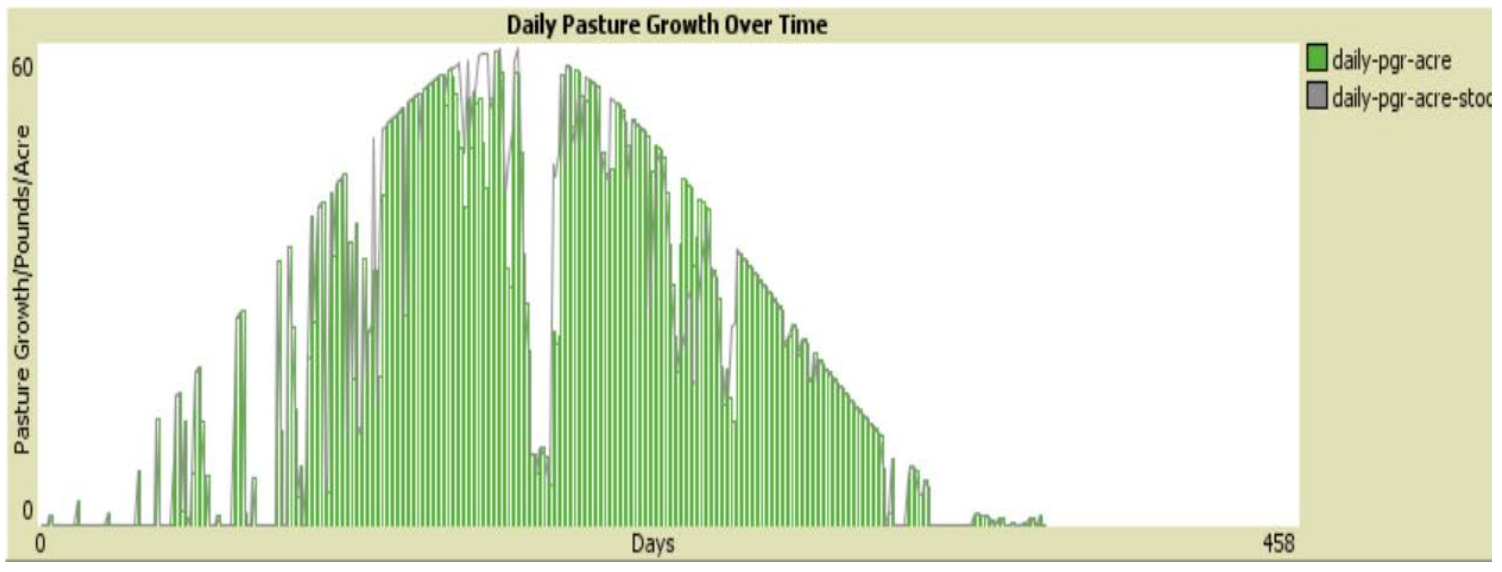

Figure 5.10: Daily pasture growth in pounds per acre over one year. The spaces between the daily pasture growth under deterministic (green) and stochastic (gray) simulations is a reflection of droughts, while the vertical bars coincide with rainy seasons or higher precipitation shown in Figure 5.11.

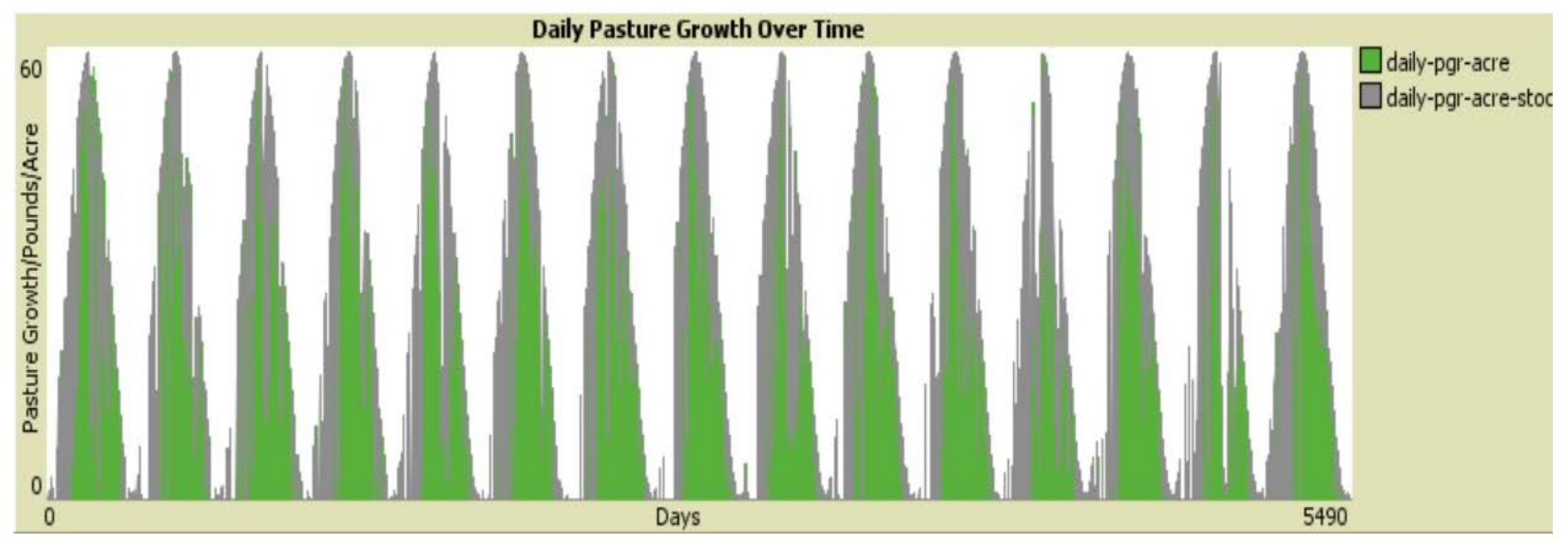

Figure 5.11: Daily pasture growth in pounds per acre over the planning horizon (15 years). The daily pasture growth is a dynamic function intended to estimate absolute plant growth rate of forage crops based on daily solar radiation, precipitation events as well as minimum, average and high temperatures.

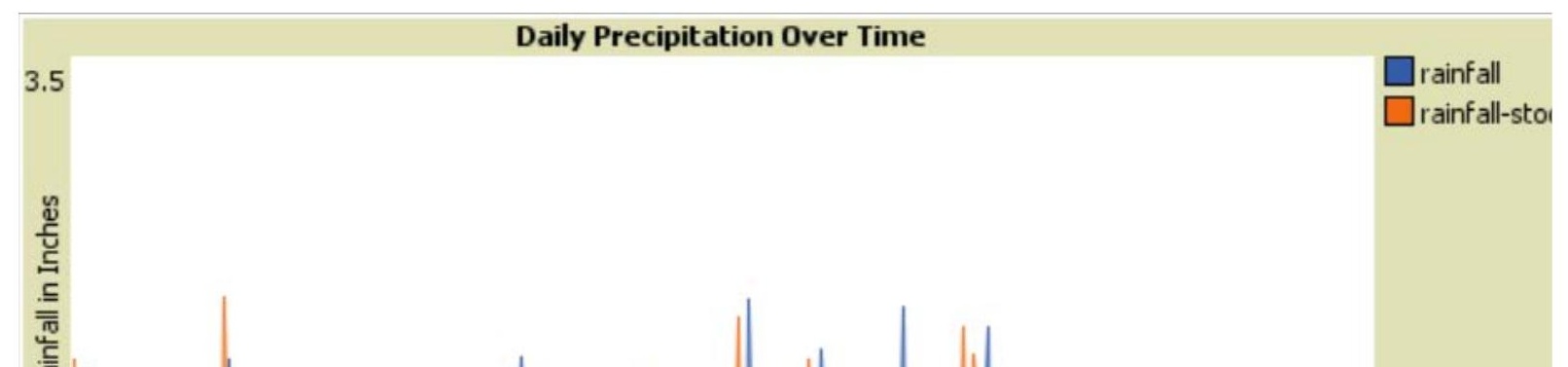


Figure 5.12: Daily stochastic and deterministic precipitations in inches for one year.

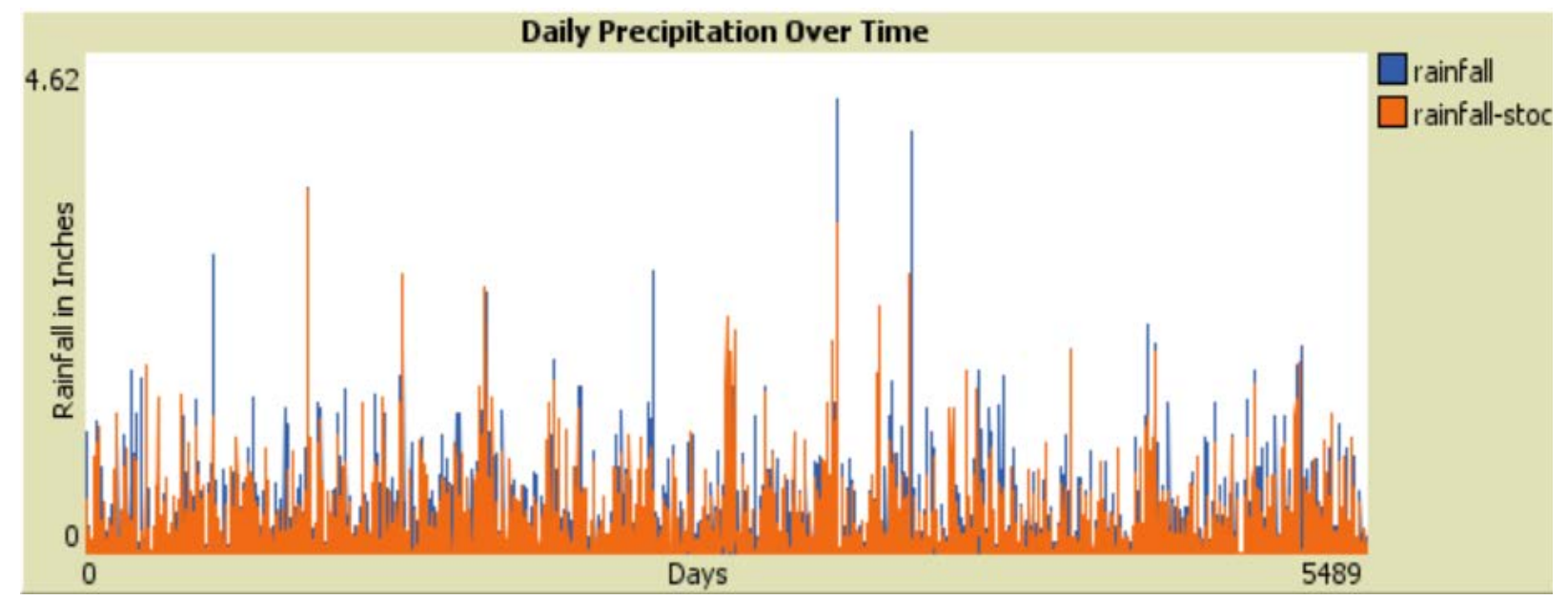

Figure 5.13: Pasture growth is influenced by the rate of precipitation. In fact, annual forage production has been determined to be strongly correlated to increased precipitation (Scaglia et. al, 2009). During drought seasons, pasture growth tends to be lower while during rainy season it grows significantly. Above, we can appreciate the stochastic (orange) and deterministic (blue) precipitation simulated by BET for the entire planning horizon. 


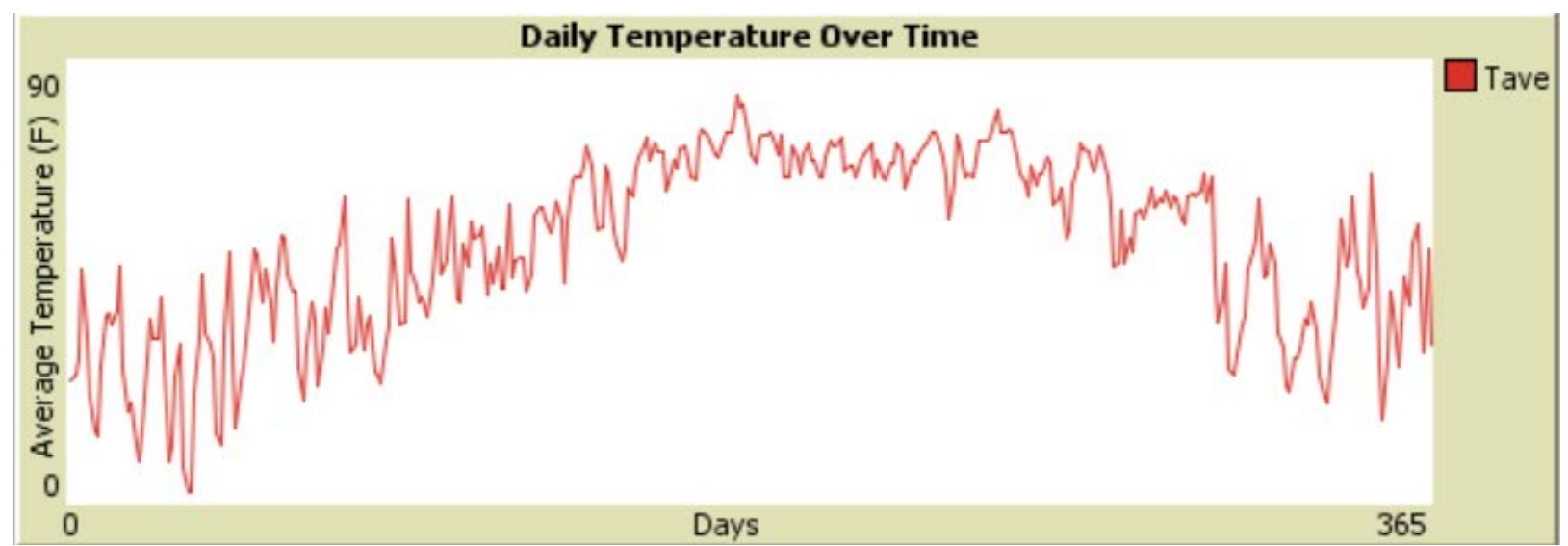

Figure 5.14: The above graph shows the fluctuations on temperature for one year while the graph below considers the entire planning horizon

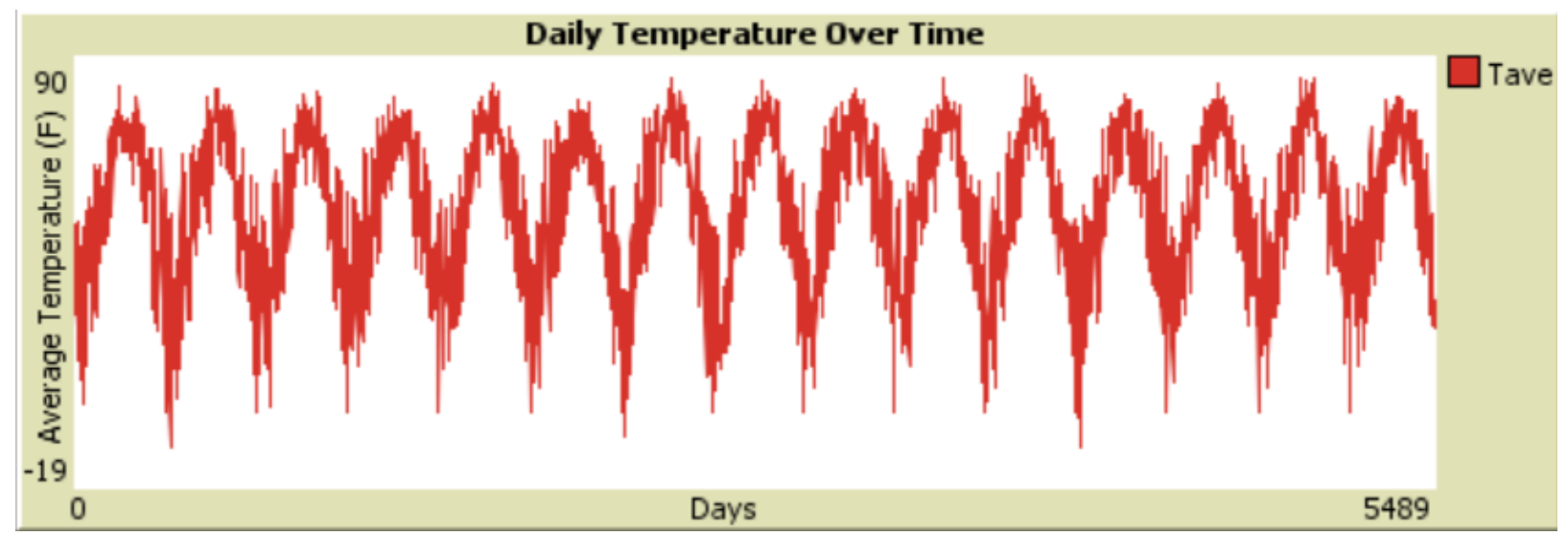

Figure 5.15: During the simulation, pasture growth increases with higher temperatures while it starts to decrease at lower temperatures. This can be appreciated when comparing Figures 5.9 and 5.13.

The pasture yield over the planning horizon varies depending on essential elements such as daily rainfall (as previously mentioned) that eventually determines the forage allowance for the stocking rate on an annual basis. The simulation shows a mean forage production of 7,236 lbs./acre/year with a 642 lbs./acre/year standard deviation with a maximum production of 8,216 and a mean forage production of 7,424 lbs./acre/year with a $611 \mathrm{lbs}$./acre/year standard deviation having a maximum production of 8,351 lbs./acre/year over the planning horizon, under certain and uncertain simulations respectively as depicted in Figure 5.16. Results also show that the 
highest daily forage growth (depending on the climatological conditions of that particular year) occurs between the months of May and June which coincides with Scaglia et. al, 2008 and Rayburn, 2005 (Figure 5.11).

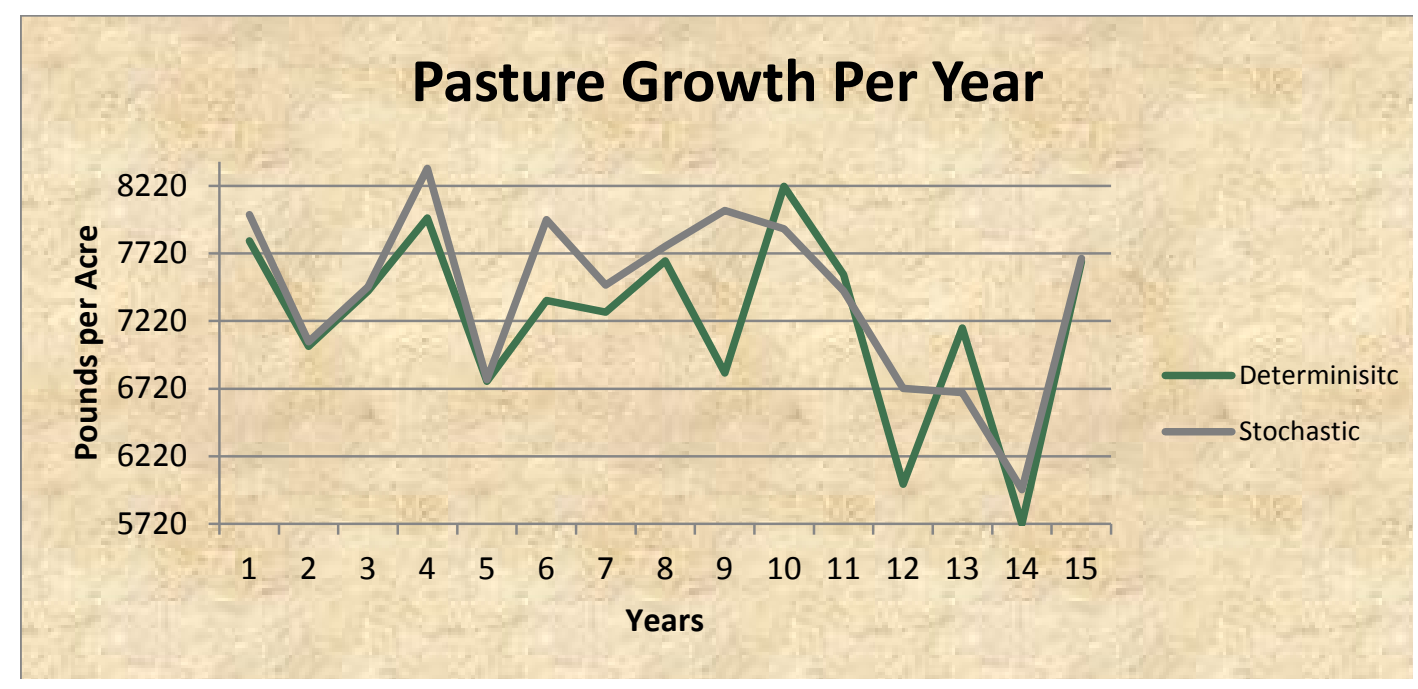

Figure 5.16: Total annual forage yield per acre over 15 years.

The stocking rate plays a significant role in our model. Due to the fact that animals tend to gather and graze more in flat or less steep slopes, the steeper the slope the less pasture in the site is consumed decreasing the grazable land area for a given stocking rate (Laca, 2000, Holechek, 1988). We can appreciate from Figure 5.17 that farms in locations with steeper slopes would consider lower stocking rate than the flatter ones. The pasture growth function is crucial in our simulation model since the pasture available mainly determines the optimal stocking rate for each year and, eventually, the beef and electricity production as well as carbon offset. The stocking rate for the annual operation depends on the annual forage capacity of the farm and the slope of the terrain. In addition, the stocking rate will determine the amount of digested manure generated for nutrient application. Our results identify that more than 1,500 pounds of digested manure could be produced per head after the manure is used for energy generation. This would allow the farm of interest to generate the appropriate amount of this by-product to be applied to 
its 93 acres since approximately 620 pounds would be applied per acre annually for pasture production. This implies that an excess of digested manure would be produced that can be used in adjacent locations as fertilizer.

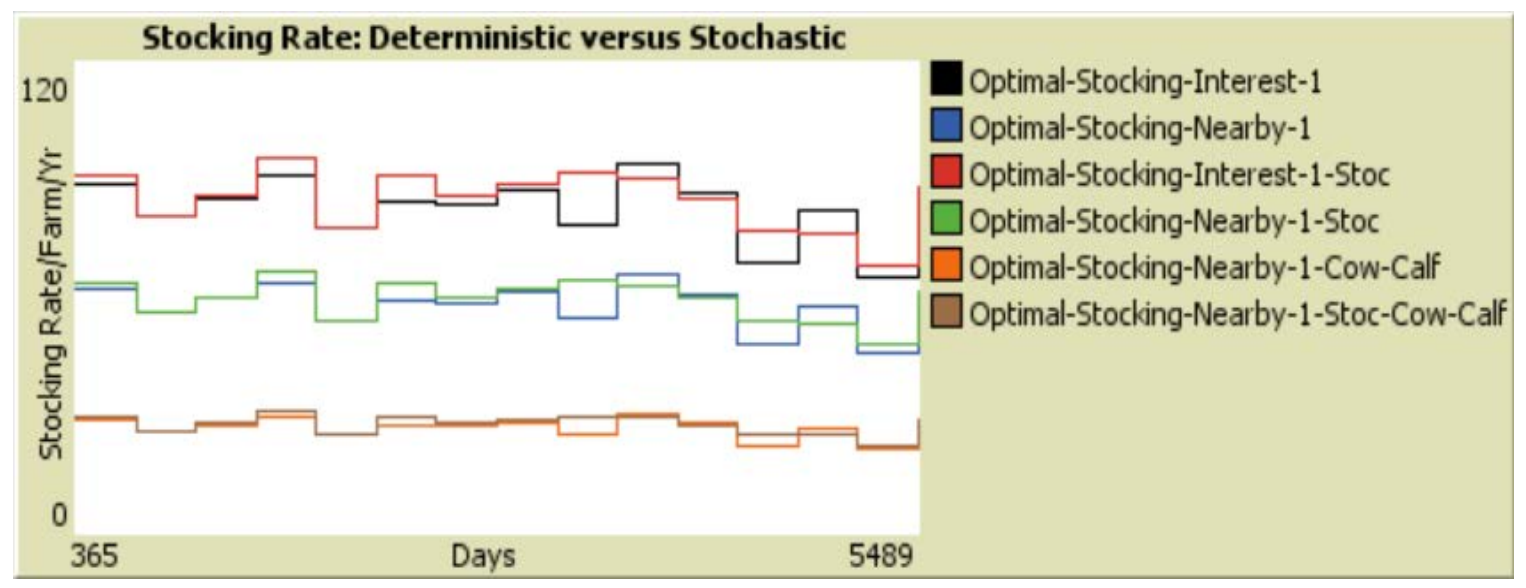

Figure 5.17: The above figure illustrates annual stocking rate (total animal units per farm) differences between the farm of interest (stocker) and adjacent stocker farms due to differences in average slopes when forage available is optimized. It also considers the stocking rate on adjacent cow/calf farms in which the animal unit (AU) represents a 1,000 lb. cow with calf (Redfearn and Bidwell, 2009, William and Hall, 1994). The "optimal-stocking-interest-1" (black) and "optimal-stocking-interest-1-stoc" (red) represent the stocking rate of the farm of interest (stocker farm) under deterministic and stochastic simulations, respectively. On the other hand, "optimal-stocking-nearby-1" (blue) and "optimal-stockingnearby-1-stoc" (green) denote the stocking rate of the nearby stocker farms under certainty and uncertainty, respectively. At last, the "optimal-stocking-nearby-1-cow/calf" and "optimal-stockingnearby-1-cow/calf-stoc" displays the adjacent cow/calf farm from a deterministic as well as stochastic perspective, respectively. As previously mentioned, on this model we refer to the optimal stocking rate as the maximum sustainable production.

The results from BET are compared with those developed by Eberly and Groover (2011) on their stocker steers budget. They employed 1.35 acres per head for their budget which concides with two of our stocking rate estimations during the lowest annual forage production (years 12 and 14). Based on our data, our estimated stocking rate tends to be higher than suggested by Eberly and Groover (2011); but, their publication does not specify the data used for their assumption. As we have seen, the pasture growth which ultimately determines the stocking rate tends to vary depending on many factors such as climatological and geographical conditions. On the other hand, Yohn and Rayburn (2000) conservatively estimated that approximately one 
acre per head during grazing season is the recommended rate based on 1997-1999 data. Overall, the more forage allowance, the higher the annual stocking rate per acre.

Table 5.1: Annual stocking rate in the farm of interest (stocker) over the planning horizon (15 years).

\begin{tabular}{ccc}
\hline \multicolumn{3}{c}{ Stocking Rate-Stocker Farm: Acres per Head } \\
\hline Year & Deterministic & Stochastic \\
1 & 1.04 & 1.02 \\
2 & 1.15 & 1.15 \\
3 & 1.09 & 1.08 \\
4 & 1.02 & .97 \\
5 & 1.19 & 1.19 \\
6 & 1.11 & 1.02 \\
7 & 1.12 & 1.08 \\
8 & 1.06 & 1.04 \\
9 & 1.19 & 1.01 \\
10 & 0.99 & 1.03 \\
11 & 1.07 & 1.09 \\
12 & 1.35 & 1.21 \\
13 & 1.13 & 1.21 \\
14 & 1.41 & 1.37 \\
15 & 1.06 & 1.06 \\
\hline
\end{tabular}

For a cow/calf farm, our simulation results are compared to the ones identified by Scaglia et. al (2008) in which they conducted three experimental replicates of cow-calf pairs during the grazing season. They obtained 0.71 hectares per head (1.75 acres per head) for two experimental studies and 0.91 hectares per head (2.25 acres per head) in the third one. The annual stocking rate derived from BET has some variability over the planning horizon due to the forage available on a yearly basis. However, the results depicted in Table 5.2 tend to present similarities to the ones identified by Scaglia et. al (2008) in their experiment. 
Table 5.2: Annual stocking rate for adjacent cow/calf farms over the planning horizon. Note: The estimation of this stocking rate plays a fundamental role during the winter season since it is used to estimate the manure needed for the anaerobic digester in the farm of interest.

\begin{tabular}{|ccc|}
\hline \multicolumn{3}{|c|}{ Stocking Rate - Cow/Calf Farm: Acres per Head } \\
\hline \hline Year & Deterministic & Stochastic \\
1 & 1.60 & 1.55 \\
2 & 1.79 & 1.79 \\
3 & 1.66 & 1.66 \\
4 & 1.55 & 1.50 \\
5 & 1.86 & 1.86 \\
6 & 1.72 & 1.55 \\
7 & 1.72 & 1.66 \\
8 & 1.66 & 1.60 \\
9 & 1.86 & 1.55 \\
10 & 1.50 & 1.60 \\
11 & 1.66 & 1.66 \\
12 & 2.11 & 1.86 \\
13 & 1.72 & 1.86 \\
14 & 2.21 & 2.11 \\
15 & 1.66 & 1.60 \\
\hline
\end{tabular}

The inclusion of carbon offsets through an anaerobic digester is not only a way to reduce part of the methane produced in the PBB industry but also a form of generating additional income when a carbon market exists. Figure 5.18 illustrates $\mathrm{CO}_{2} \mathrm{e}$ baseline values in tons and its relative carbon offset estimates derived from our model simulation in the farm of interest. We can also observe in Figure 5.19 that the greater the clustering system, the more $\mathrm{CO}_{2} \mathrm{e}$ emissions are captured through the anaerobic digester. 


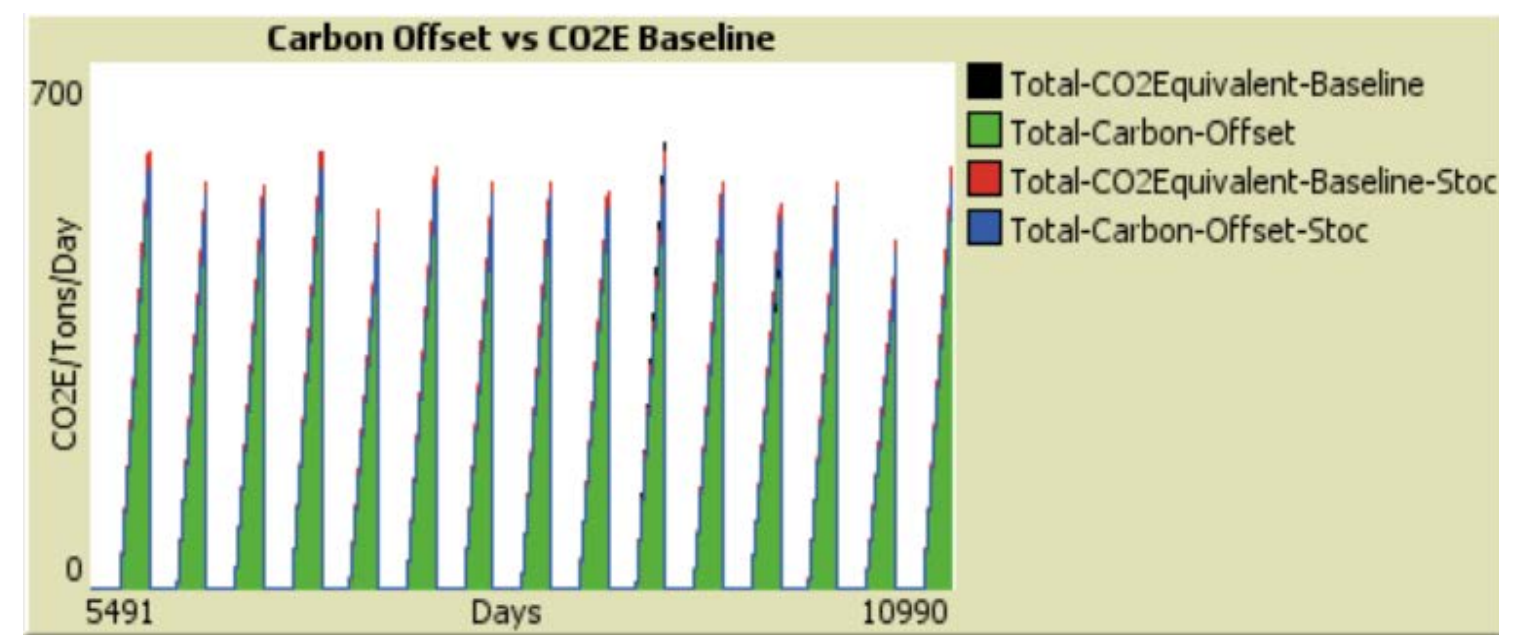

Figure 5.18: Carbon offset compared to $\mathrm{CO}_{2}$ e baseline under deterministic and stochastic scenarios during winter season under a clustering system of five members.

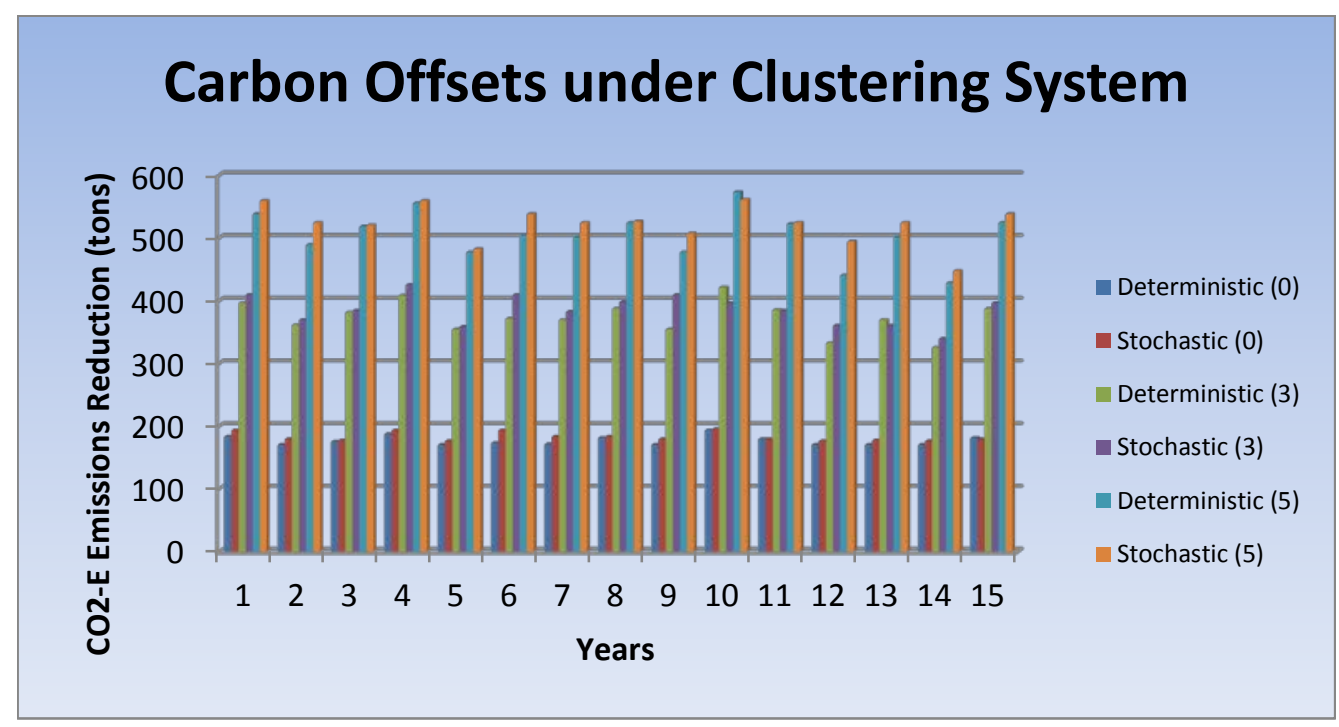

Figure 5.19: Carbon offset in tons over time under a 0, 3 and 5 clustering system.

Note: This reflects the annual amount of $\mathrm{CO}_{2}$ equivalent emissions reduction over the planning horizon (15 years) with respect to the total amount of methane generated at a given stocking rate (through manure) on a yearly basis.

BET is also programmed to estimate the amount of renewable energy produced on the farm of interest. When the clustering system is greater than zero, electricity production depends not only on the methane generated during winter at a given stocking rate on the farm of interest (stocker farm) but also adjacent farms (cow/calf farms) spatially distributed in the system. Figure 5.20 presents a plot (in NetLogo terms) or graphical representation of the energy production 
during the interaction phase under stochastic and deterministic simulations. We can appreciate, by looking at Figure 5.21, that more renewable energy can be generated when more farms join a regional cluster, implying a synergistic effect reflecting a year to year variation.

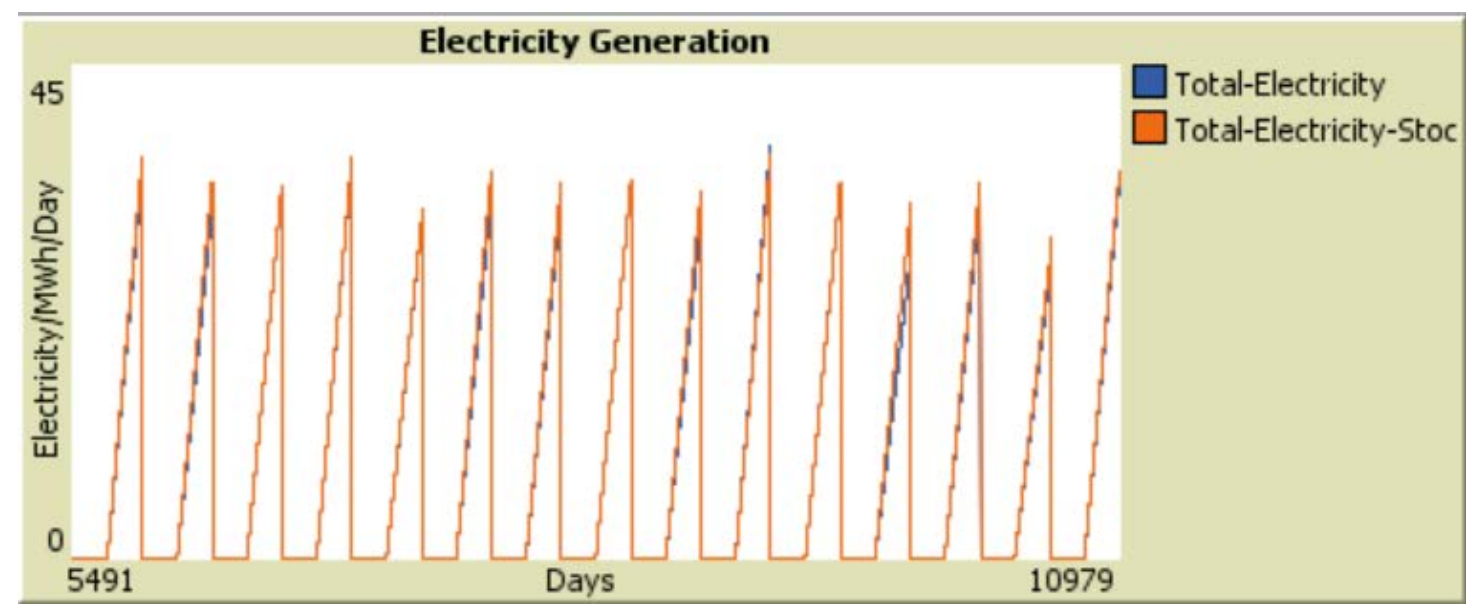

Figure 5.20: Energy generation under deterministic and stochastic scenarios produced during winter season. Note: "Total-Electricity" represents the total amount of daily electricity measured in megawatts per hour (MWh) generated in the farm of interest under certainty while the "Total-Electricity-Stoc" estimates electricity production stochastically.

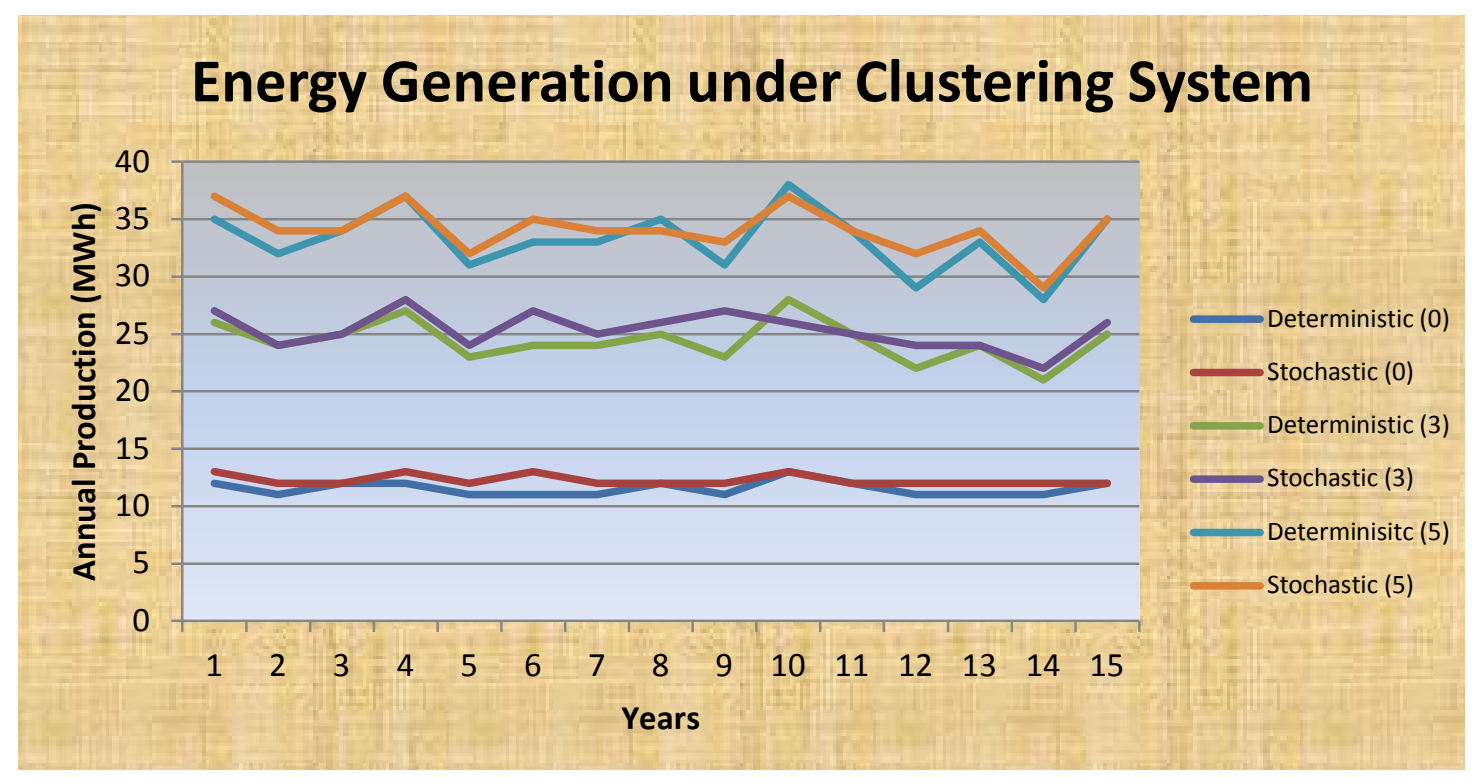

Figure 5.21: Energy generation (deterministic and stochastic) over the planning horizon when 0, 3 and 5 clusters are taken into consideration. 
Beef production in the farm of interest is also measured in our model. Beside the clustering system formed by the manure production, another cluster is developed when the adjacent silage farm supplies silage. This occurs when the expected pasture consumption by the stocking rate is higher than the amount of forage available in the stocker farms spatially distributed. Beef production fluctuations (in kilograms) illustrated in Figures 5.22 and 5.23 reflects the variability on stocking rate on a yearly basis over the planning horizon.

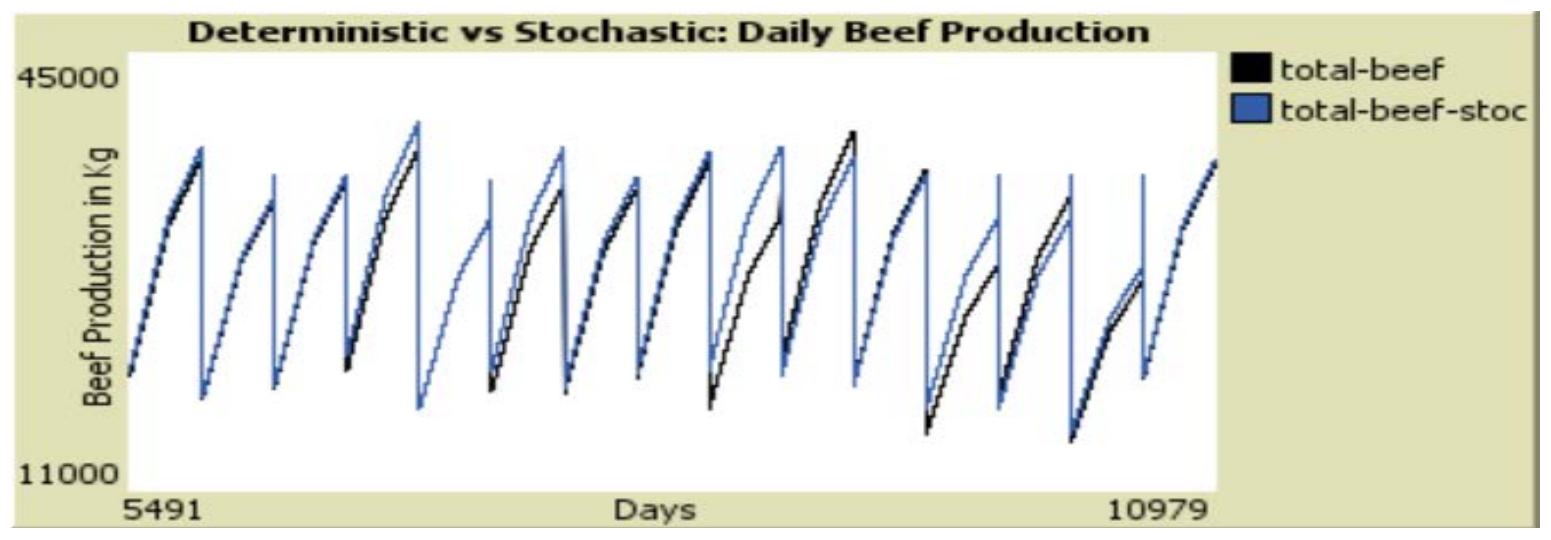

Figure 5.22: Annual beef production under deterministic and stochastic scenarios derived during system interaction over 15 years.

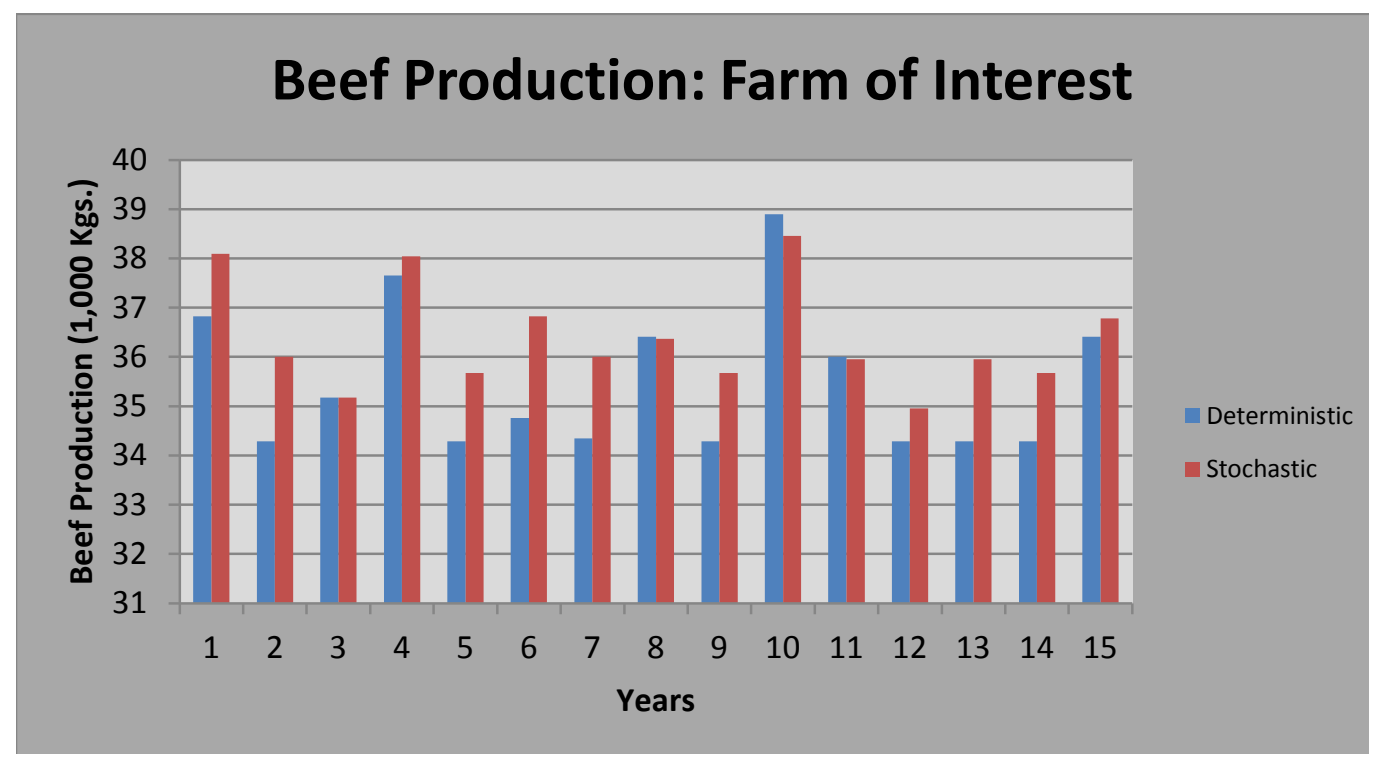

Figure 5.23: Besides the plot developed in NetLogo, the above graph presents more precisely the annual beef production over 15 years. 
Moreover, the cost of the anaerobic digestion system, considered as an environmentalfriendly technology, depends on the stocking rate under consideration. When a clustering system is absent, BET only takes into account the stocking rate available in the farm of interest. On the other hand, the amount of animals spatially distributed takes importance under a clustering system; therefore, the capital investment toward this technology considers the stocking rate distributed. Table 5.3 shows the costs associated with anaerobic digesters without or under a clustering system.

Table 5.3: Investment costs associated with anaerobic digester. Note: As the number of heads increase (together with clustering members), the costs associated with the anaerobic digester increases at a decreasing rate, implying economies of size.

\begin{tabular}{|lll}
\multicolumn{3}{c|}{ Capital Investment: Anaerobic Digester in the Farm of Interest $\mathbf{( \$ \mathbf { 0 0 0 } )}$} \\
\hline Clustering Members & Deterministic & Stochastic \\
$\mathbf{0}$ & 155.8 & 158.3 \\
$\mathbf{1}$ & 174.2 & 176.2 \\
$\mathbf{2}$ & 190.0 & 192.4 \\
$\mathbf{3}$ & 204.0 & 206.4 \\
$\mathbf{4}$ & 216.8 & 219.2 \\
$\mathbf{5}$ & 228.4 & 231.4 \\
\hline
\end{tabular}

Besides all the social and environmental benefits that a diversified enterprise might bring to the region, the farm of interest requires an economic or profit motivation in order to launch this new venture. Our profitability approach is based on the NPV within the planning horizon of 15 years. We compare the NPV between the diversified business against the specialized enterprise. Our approach differs from the ones previously mentioned under Chapter III: Review of the Literature-Renewable Energy since we suggest a centralized system located on a small farm (with less than 300 heads under a clustering system) that would purchase the manure produced by nearby farms not only taking the risk of the capital investment associated with this technology but also the costs of manure collection.

5.1.3 Sensitivity Analysis. Different sensitivity analyses with respect to profitability were conducted to observe under what carbon price and cost share percentage combination the 
diversified PBB industry would be able to diversify its profit streams while contributing to surrounding society as well as the environment. The clustering system does not have an impact on the specialized business, since the spatial effects only applies to the proposed diversified enterprise; especially when comparing NPV.

5.1.3.1 Zero carbon prices and no cost share program. As we can appreciate from Figure 5.24, the absence of an offset market and cost share program would not allow beef farmers to adopt an anaerobic digester; therefore, environmental improvements as well as additional income to businessman within the PBB industry cannot be achieved under current market conditions. Results shown in Figure 5.24 illustrate the NPV between these two alternatives in which the specialized industry generates a positive NPV while the proposed diversified farm is found to be unprofitable under both deterministic and stochastic situations. Indeed, we can observe that while the clustering system increases of the NPV of the diversified enterprise decreases. It is important to point out that besides the costs of the anaerobic digester, the farm of interest needs to consider the costs associated with manure collection within the spatial domain if the objective is to diversify its income stream. 


\section{Clustering System Excluding Carbon Prices and Cost Share Programs}

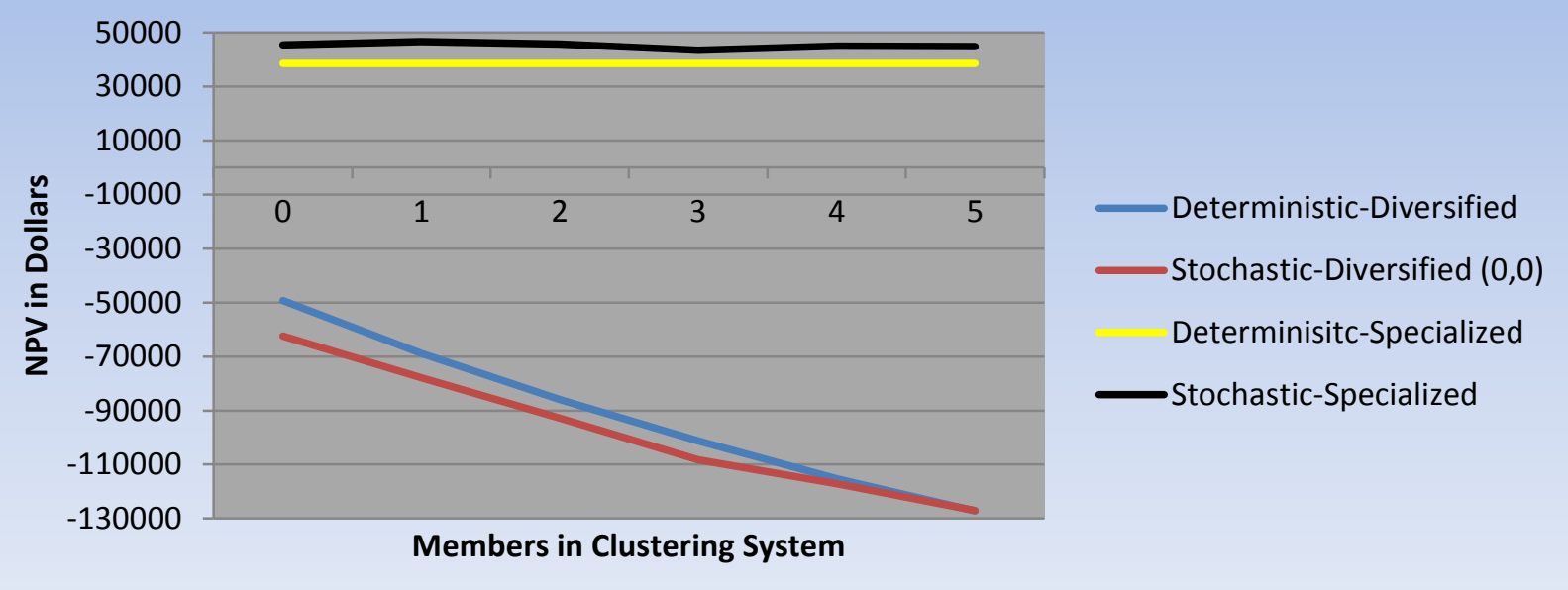

Figure 5.24: Net Present Value (NPV) over the planning horizon. Note: This graph does not consider a cost share program while carbon price is set to zero $(0,0)$. We can observe that the specialized enterprise is the only alternative showing positive NPV over 15 years. Notice that the clustering system does not have an impact on the specialized business, since the spatial effects only applies to the proposed diversified enterprise; especially when comparing NPV.

Our model identifies that it is not economically viable to venture a diversified PBB enterprise if farmers do not get an economic incentive after investing in advanced technologies that not only generate renewable energy but also reduce $\mathrm{CO}_{2}$ equivalent emissions when compared to a specialized PBB business.

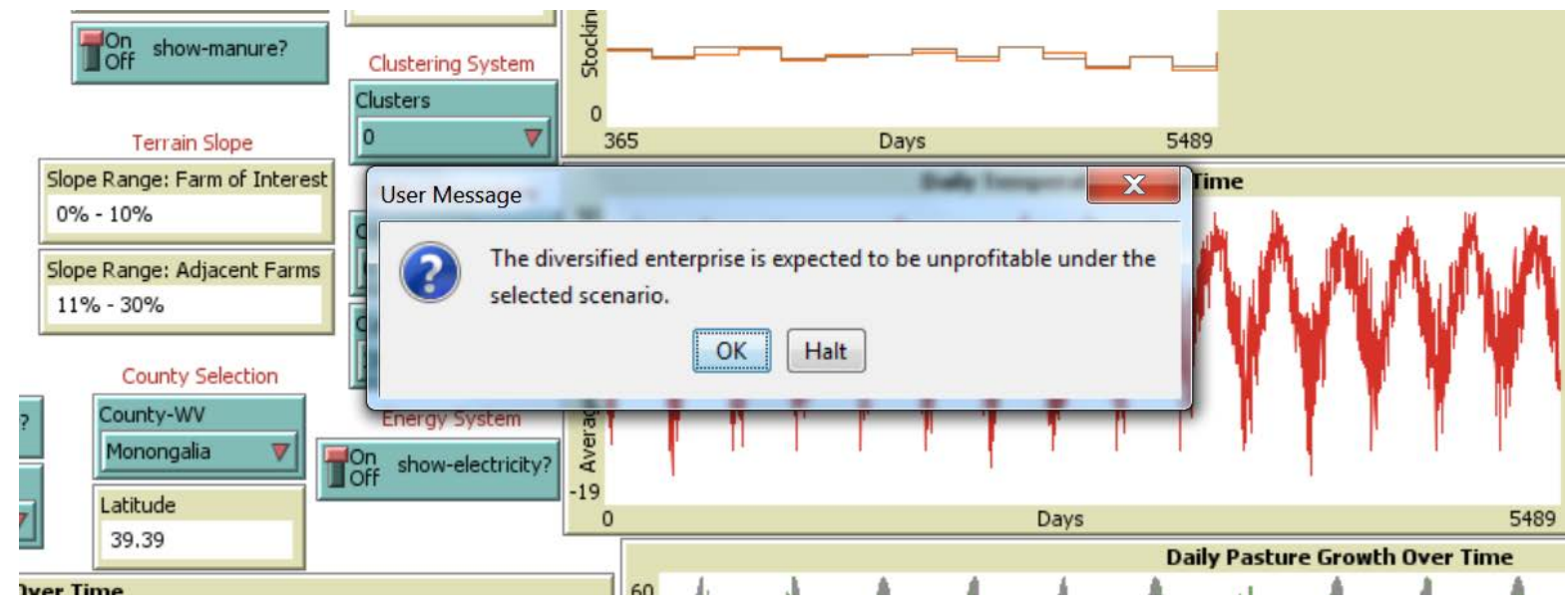

Figure 5.25: An unprofitable notice prompted to users after simulation. Note: A notice is prompted after simulation is complete exposing the profitability status based on selected parameters and system interaction. The illustration above alerts that the farm of interest would obtain a non-positive NPV under the scenario selected while the figure below expresses it in the interacting world. 


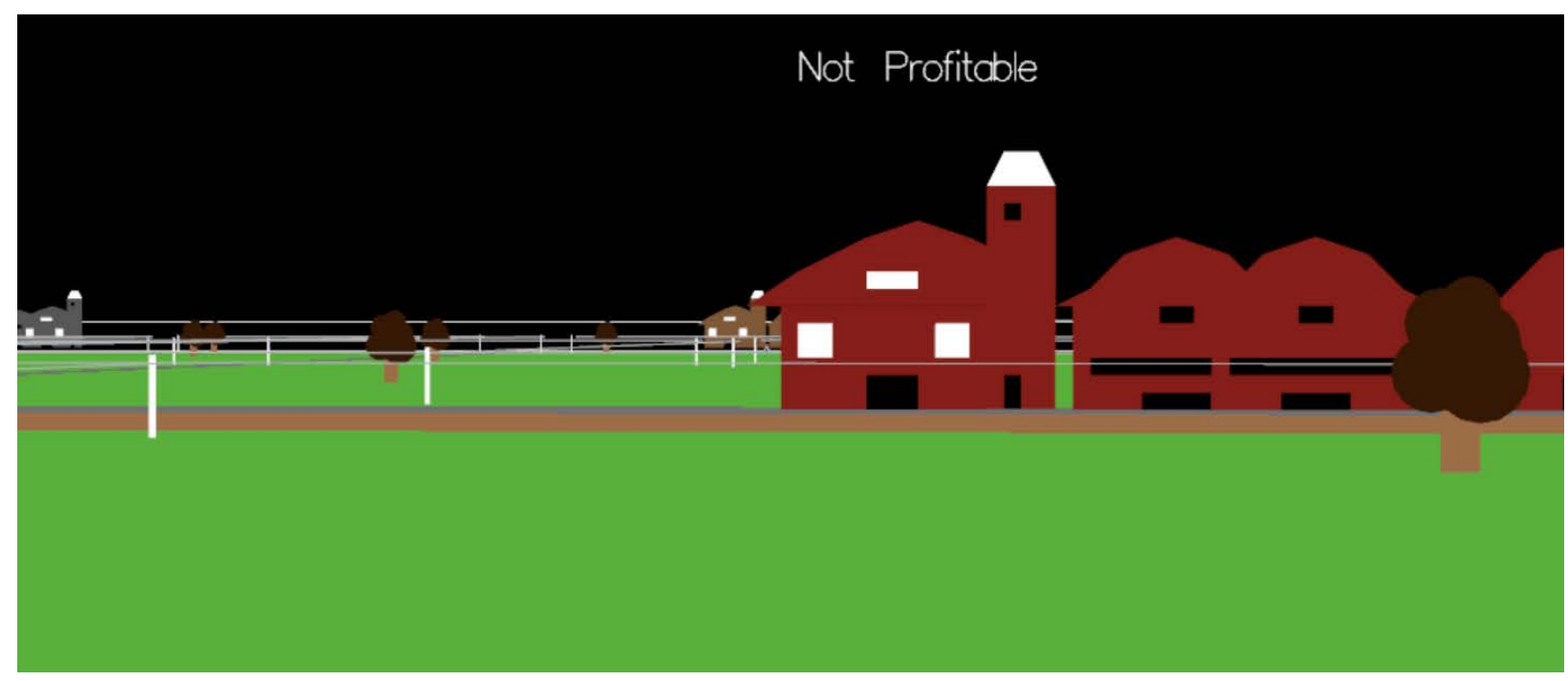

Figure 5.26: An unprofitability notification in the interacting world. Note: The profitability status is also depicted in the interacting world after the simulation is finished.

5.1.3.2 Carbon prices $(\$ 0,13$, and 26$)$ and no cost share program. We ran the model under most commonly used carbon prices (\$0, \$13 and \$26) per $\mathrm{CO}_{2}$ equivalent tons (Key and Sneeringer, 2011, Baylis and Paulson 2011 and EPA, 1999) without considering cost share programs. Results show that while carbon prices increase, NPV decreases at a decreasing rate under stochastic and deterministic scenarios; however, the diversified venture still results in nonpositive NPV even when considering carbon prices of \$13 and \$26 within all the clustering system options in the model as shown in Figure 5.27. 


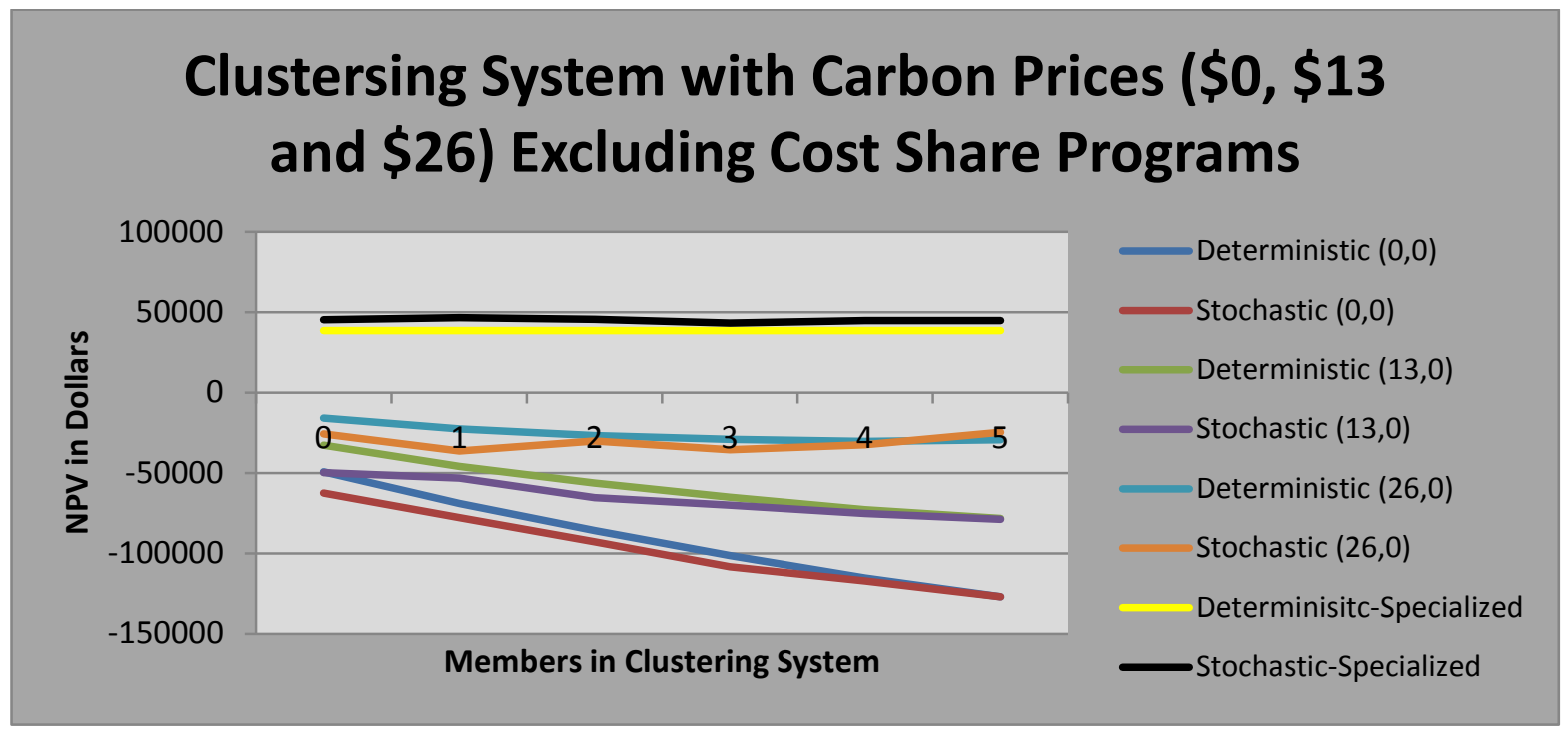

Figure 5.27: Net present value (NPV) over the planning horizon under different carbon prices. The NPV values do not reflect cost-share programs.

5.1.3.3 Carbon prices (\$13) with cost share (20\% and 50\%). As depicted in Figure 5.28, the combination of a carbon price of $\$ 13$ per each $\mathrm{CO}_{2}$ e ton reduced together with 20 percent of cost share toward the anaerobic digester still shows negative NPVs at each level of clustering. On the other hand, the combination of a carbon price of $\$ 13$ per $\mathrm{CO}_{2} \mathrm{e}$ ton reduced combined with a 50 percent cost share program results in a positive NPV under stochastic as well as deterministic simulations. Even though the NPV in the stochastic simulation is positive, the specialized farm is still more economically viable with a NPV range of $\$ 46,000$ to $\$ 42,000$ (compared to $\$ 33,000$ to $\$ 37,000$ for the diversified farm). On the contrary, if the farm of interest absorbs even 50 percent of the cost of the anaerobic digester, assuming that the carbon price is \$13, the diversified enterprise becomes more attractive from a profitability stand point within a clustering system (with less than or equal to two members) under certainty. Based on the results, the diversified venture would be more economically attractive than the specialized farm when up to two adjacent cow/calf farms become part of the regional clustering system at a carbon market 
price of $\$ 13$ per $\mathrm{CO}_{2} \mathrm{e}$ emissions reduced since the NPV tends to be higher than the specialized NPV up to two clustering members.

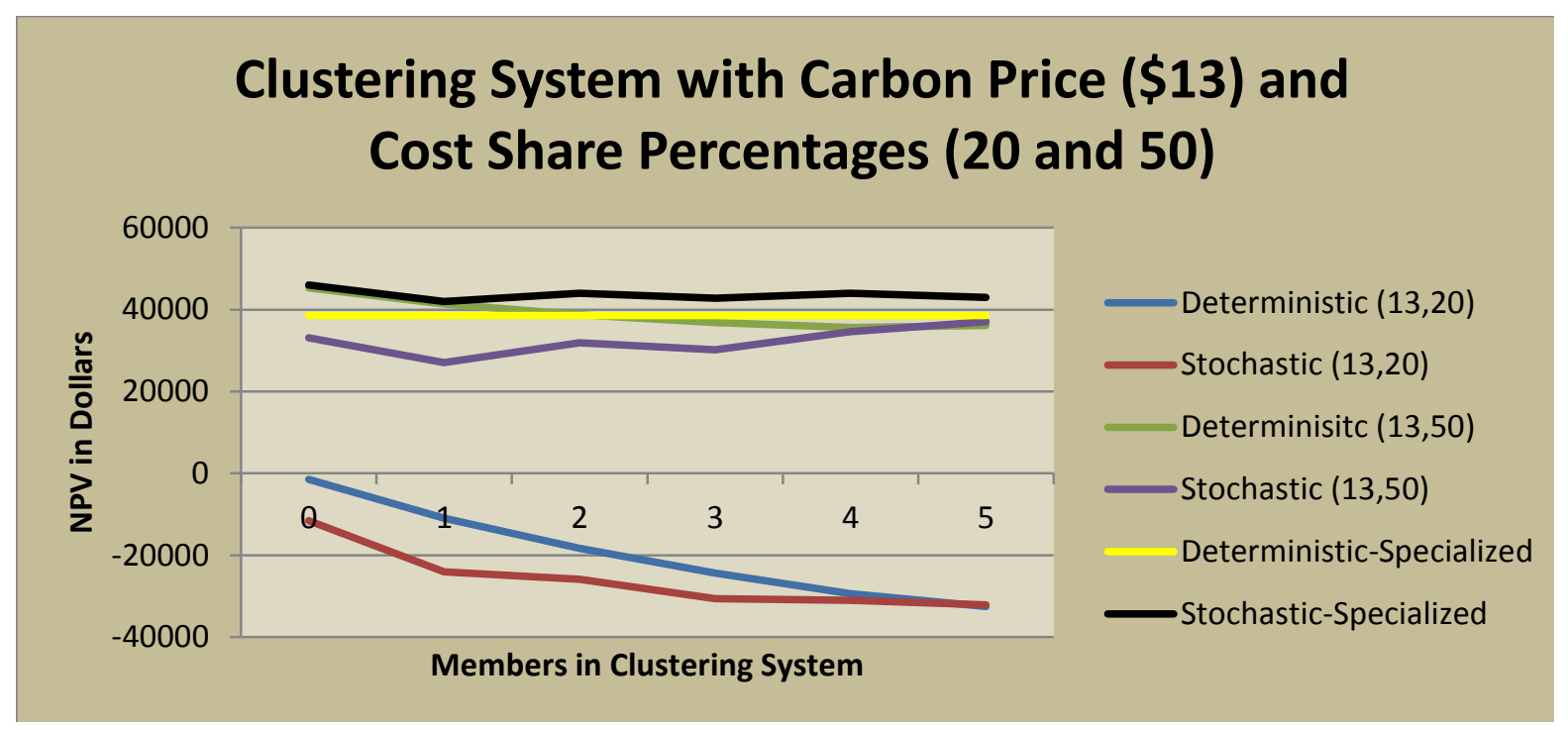

Figure 5.28: NPV over the planning horizon with a carbon price of $\$ 13$ under different cost-share percentages (20 and 50 percent).

5.1.3.4 Carbon prices (\$26) with cost share (20\% and 50\%). As we can appreciate from Figure 5.29, although a combination of 20 percent share cost program with a carbon price of \$26 improves profitability compared to a combination of \$13 carbon price when farmers invest only 80 percent of the technology, it would not be enough for a PBB farm to switch from a specialized to a diversified enterprise since its NPV is significantly lower than the specialized business. Nevertheless, if the entrepreneur would have to pay only 50 percent of the technology while carbon price is $\$ 26$, the new venture would be economically attractive when each clustering system is considered from stochastic and deterministic perspectives. In contrast to the previous profitability status as depicted in Figures 5.25 and 5.26; our model shows a positive profitability status at the end of the simulation in the interface view and interacting world as shown in Figures 5.30 and 5.31. 


\section{Clustering System with Carbon Price (\$26) and Cost Share Percentages (20 and 50)}

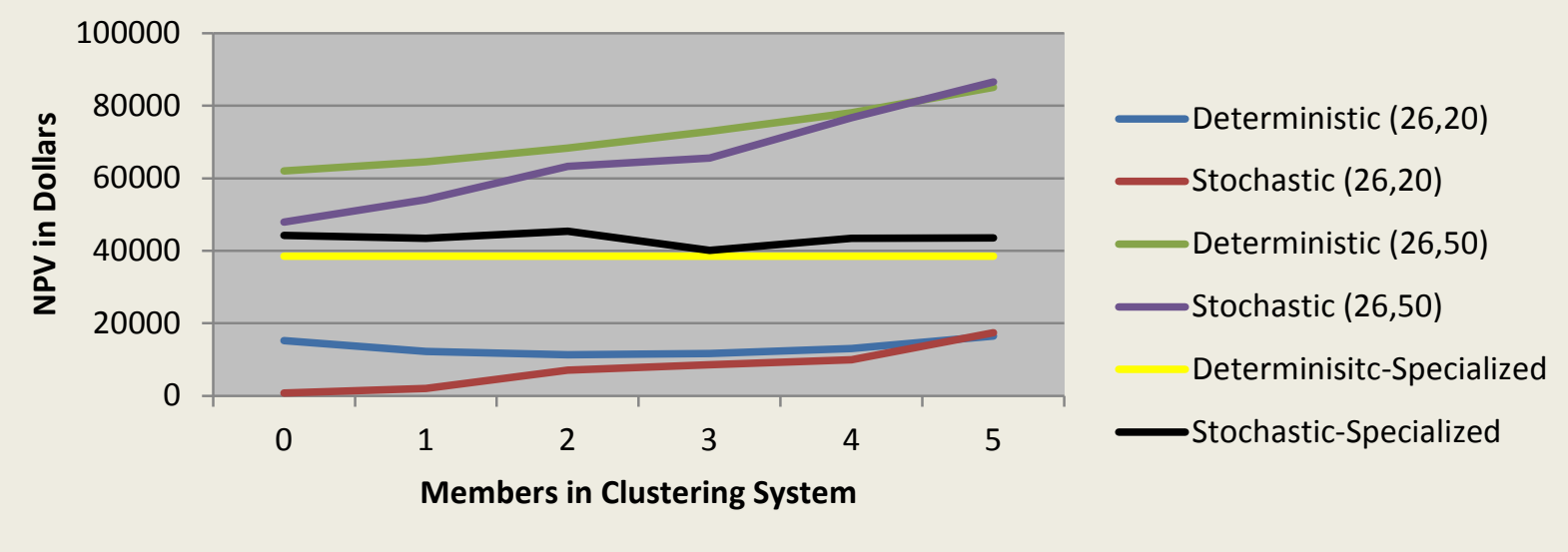

Figure 5.29: NPV over the planning horizon with a carbon price of $\$ 26$ under different cost-share percentages (20 and 50 percent).

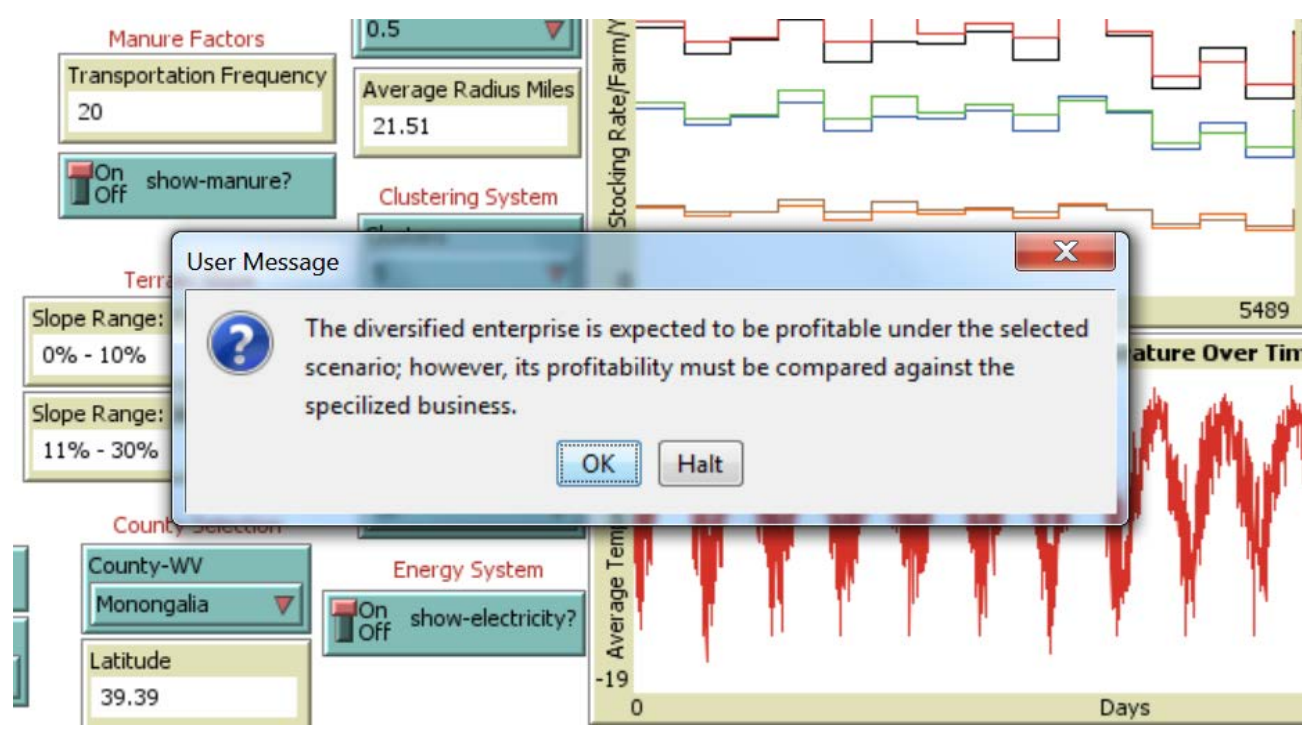

Figure 5.30: The illustration above illustrates a positive NPV under the scenario selected, while the interacting world (Figure 5.30) shows the profitability status of the farm of interest. 


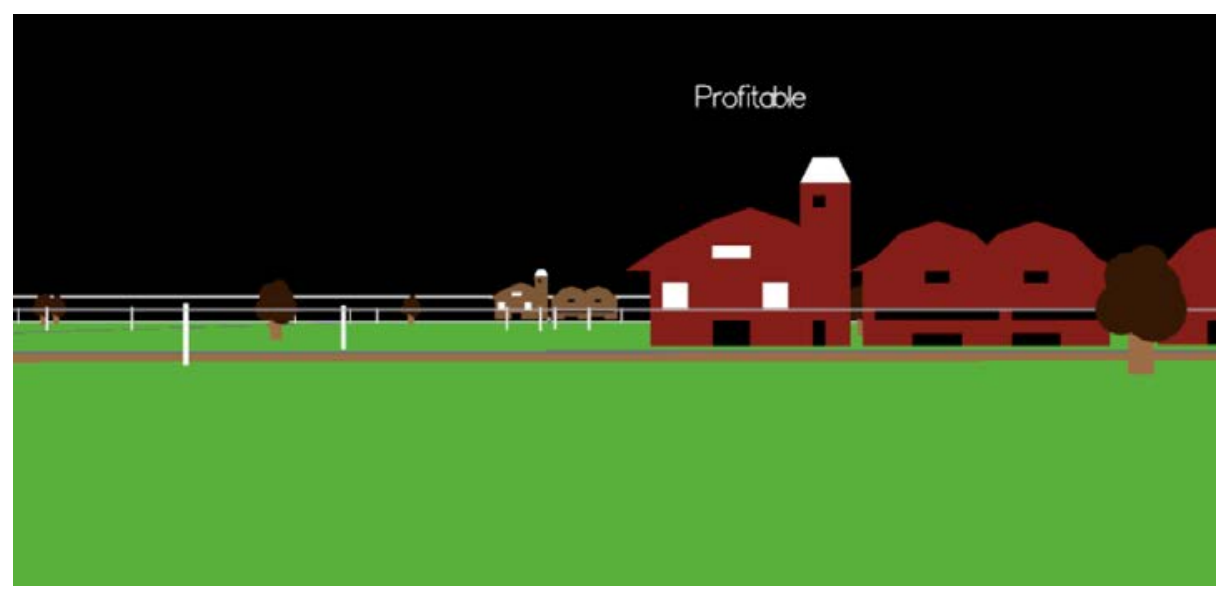

Figure 5.31: The profitability status is labeled above the farm of interest after 10,979 iterations. In this illustration, the NPV over the planning horizon is greater than zero.

Based on these simulation results, we can infer the importance of not only considering the influences of climatological conditions on the primary inputs of production but also economic motivation or incentives in order to enhance sustainable production within a spatially correlated industry. In fact, the revenue received from carbon offsets under the cap-and-trade system is a function of the manure management technique as well as market price (Key and Sneeringer, 2011). Thus, carbon price is a key determinant of profitability of a diversified enterprise. However, for small PBB businesses in Appalachia, the profitability of adopting an anaerobic digester to diversify a pasture based enterprise within a region might take major importance when a combination of carbon price with a cost-share program is taken into account. The benefit of an industry is intensified when clustering systems are developed and the indirect effects of adjacent farms with respect to the farm of interest are captured augmenting renewable energy production, reducing $\mathrm{CO}_{2}$ equivalent emissions compared to their baseline and improving profitability when policy instruments are employed. BET results show that a significant NPV would not take place without considering a carbon offset price and cost share program combination. 
Based on the data used in our ABM, no combination comprised of a carbon price of \$13 or below along with a cost share program lower than or equal to 20 percent toward the anaerobic digester will motivate the specialized business to switch to a more diversified enterprise. However, results also show that a combination of 50 percent share cost with a carbon price of $\$ 13$ presents great possibilities for the diversified enterprise to become a reality. This will permit the farm of interest to reduce approximately 176 to $308 \mathrm{CO}_{2} \mathrm{e}$ emissions from a baseline of 184 to $321 \mathrm{CO}_{2} \mathrm{e}$ tons emissions produced from manure and generate approximately 12 to $20 \mathrm{MWh}$ while providing 35,000 Kg of high quality beef to the region under certainty. This allows the diversified enterprise to obtain a NPV range of $\$ 39,000$ to $\$ 45,000$ over 15 years when considering from zero to up to two participants in the clustering system obtaining a higher profitability than focusing on grass-based beef production only $(\$ 38,500)$. On the other hand, even though the diversified business might bring some social and environmental benefits through the same carbon price and cost share percentage combination under an uncertain situation, it will generate a NPV range of \$33,000 under stochastic conditions. Since the specialized business will generate a NPV of approximately $\$ 44,500$, the farm of interest would not have an economic stimulus for this new business venture.

Furthermore, deterministic results show that a combination of 50 percent cost share along with a \$26 carbon price will build up a financial basis to diversify the sources of income on a PBB farm assuming that up to five participants have agreed to become part of the cluster. Under this scenario, the farm of interest will obtain a NPV of $\$ 62,000$ to $\$ 85,000$ over the planning horizon. It will also be able to produce on average 35,000 Kg of grass-based beef, while between 12 to 33 MWh of energy will be produced and 176 to $505 \mathrm{CO}_{2} \mathrm{e}$ emissions reduction or 96 percent of baseline can be achieved. 
On the other hand, stochastic results show that a combination of 50 percent cost share along with a \$26 carbon price will produce approximately 12 to $34 \mathrm{MWh}$ of renewable energy, more or less $37,000 \mathrm{~kg}$ of beef and capture approximately a range of 180 to $516 \mathrm{CO}_{2} \mathrm{e}$ tons of emissions. This will allow the diversified PBB business to obtain a NPV of $\$ 48,000$ to $\$ 87,000$ against a NPV of $\$ 43,000$ to $\$ 45,000$ for a specialized enterprise.

Although the carbon prices used on this study are hypothetical as a futuristic approach, it is fundamental to point out some of the most recent and projected values found in the literature reviewed. For instance, Shih et. al (2006) express that by 2006 the carbon price was approximately $\$ 30$ per $\mathrm{CO}_{2} \mathrm{e}$ ton under the E.U. Emissions Exchange System. On the other hand, FOE (2008) illustrates that the public sector tends to use this price based on the social cost of carbon (societal cost per ton of emission), thus this price was around $\$ 41.87$ by July 2008 . Furthermore, Baylis and Paulson (2011) point out that historical carbon prices in the European Union ETS floated around $\$ 21.15$ per $\mathrm{CO}_{2} \mathrm{e}$ by 2010. Alternatively, Olso (2009) envisions that this price will be around 37 and 50 per $\mathrm{CO}_{2} \mathrm{e}$ emissions reduced by 2013 and 2016, respectively. 


\section{CHAPTER VI: POLICY RECOMMENDATIONS}

The outcomes from BET are fundamental in order to address our third objective or provide a basis for policy recommendations. Our experimental simulation shows that the emergent patterns in physical and time spaces can be developed through the interaction between agents and the surrounding environment (Lijun, 2009). In fact, the implementation of these management techniques as a form of optimizing beef farmers' profitability enhances clustering among locations by intensifying the benefits from sustainable practices. Thus, the use of multifunctional land attributes enables us to address climate-related issues as well as to expand sustainable techniques across space. From the multiple interactions between the diversified industry, agents, and the surrounding ecosystem we have found potential environmental benefits as well as profitability. We can infer that the primary agent (i.e., the farm of interest) focuses on the achievement of higher profits by utilizing available inputs within a region for the production of outputs in concert with environmental protection objectives; however, in order to achieve these objectives a carbon market as well as cost share programs are crucial for this emerging industry to become a reality.

Our results imply that for an average grass-fed beef enterprise with 93 acres of pastureland (as is typical of Appalachia) as the primary resource surrounded by nearby cow/calf farms within an approximate 20 mile radius, will need to rely on a minimum of $\$ 13$ per ton $\mathrm{CO}_{2} \mathrm{e}$ reduced along with a cost share program willing to share the risk of no less than half of the capital investment associated with an anaerobic digester within a clustering system of up to two participants in order to economically justify diversification of business bringing environmental and economic development to the region under certainty. Alternatively, a policy combination of 50 percent cost share with a \$26 carbon price not only will enhance environmental improvement 
but also improve profitability under unexpected as well as certain weather conditions. Current federal cost-share programs such as, the Environmental Quality Incentives Program (EQIP) under the USDA offer cost share up to 75 percent of the total capital investment (USDA, 2012). We can infer from our results that a diversified farm can benefit from lower cost-share percentages than currently provided if carbon markerts are available.

Furthermore, since we are creating a new market for manure as a raw material for energy production (while capturing $\mathrm{CO}_{2} \mathrm{e}$ emissions) and its eventual use as fertilizer in the form of digested manure, this market asset would have some implications toward surrounding farms and given certain market mechanisms to compensate for their willingness to participate in a manure collection program within a clustering system. Our model assumes that adjacent farms collaborating in the emerging clustering systems will benefit from the price (cost) of manure sold to the farm of interest as well as from the sales of harvested silage which also depends on the climatological and topographical conditions of the region. The interaction among these agents driven by the goal of improving quality of life while bringing economic development to the region illustrates the necessity of developing appropriate policy instruments (especially during periods where issues dealing with energy independence, climate change and human health are taking on a renewed sense of urgency at the global level) that not only bring innovative technology but also a more sustainable industry to Appalachia.

We can also infer from our results overall benefits to the Appalachian region if the proposed policy instruments are implemented as an approach to motivate the introduction of a diversified PBB industry in West Virginia. Examples of such benefits include:

i. More local and nutritive meat production for the Appalachian community supporting local farming practices which create local jobs and increases food 
security. The creation of clustering systems within a more diversified industry would enhance economic activity not only through the elements required in the beef livestock supply and demand chain but also power utility companies as well as the transportation sector in charge of the mobility of resources within the region. Thus, the implementation of clusters in the region would permit farmers to provide a healthy meat diet, more energy independence and improved and protected natural resources as a tool that eventually enhances economic growth and social improvement locally.

ii. Enhance the use of environmentally friendly techniques for niche products within the agricultural sector that might expand to other local industries. By virtue of inter-industry linkages, the use of innovative technologies that might contribute in the optimization of agricultural resources while bringing some social benefits at the county level could stimulate other parts of the agricultural sector in Appalachia. Local government in conjunction with federal agencies might be able to encourage agricultural entrepreneurs to explore achieving the above-noted outcomes or envision similar interconnected applications (waste treatment, energy production and GHG emissions reduction) that can be economically achievable and advantageous. The public sector could support this "green technology" to be employed in farms by providing guidance and information for better planning, waste management logistics and economic incentives on capital investment (RELU, 2011). Furthermore, incentives that stimulate adjacent cow/calf enterprises in manure collection could help in the development of clustering systems. 
iii. Greenhouse gas emissions reduction. The capture of methane to be used for renewable energy production allows for emissions reduction (EPA, 1999, S.E.C.O., Undated). In fact, the incorporation of the anaerobic digester and creation of clustering systems in the Appalachian region would contribute significantly in reducing the GHG emissions generated (through manure) from the PBB industry while bringing profits to Appalachian farmers.

iv. $\quad$ Promote the expansion or development of markets. A diversified PBB industry would stimulate the establishment of new markets within the region. For instance, an emerging manure market would occur not only because it is the primary input for energy production and carbon offset but also a substitute for inorganic fertilizers that could be utilized in the farming sector and green areas within the region. In addition, the possibility of achieving substantial profitability and environmental benefits by diversifying products through better resource allocation and utilization. As a result, the ability of generating several products within one industry would eventually contribute in the development of emerging markets through each niche product.

v. Maximize resources available as a form of reducing the extraction of natural resources. Local economic activities in the rural sector might increase negative externalities in the area. However, an increase of renewable resources available in the region would lead to decreased necessity of extracting local natural resources in order to satisfy the demand of inputs used in the farming sector which might reduce the negative effects associated with these economic activities. One way to encourage this strategy is through guidelines developed and monitored by local 
authorities. The government could provide incentives to support the mobilization of wastes from one location to the centralized digester as a measure to decrease the use of inorganic fertilizers while generating renewable energy (RELU, 2011, Horowitz and Gottlieb, 2010). 


\section{CHAPTER VII: SUMMARY AND CONCLUSIONS}

\subsection{Summary and Conclusions}

Our simulation model shows the difficulty associated with a small pasture-based beef farm to reach the economies of scale desirable in order to meet the expenses associated with the anaerobic digester capital investment (Baylis and Paulson, 2011, Key and Sneeringer, 2011) and operational costs associated with profitable manure collection. Thus, results are highly sensitive to the price of carbon offset and cost-share programs to make this multi-product business profitable while providing environmental and economic benefits to surrounding communities in the Appalachian region. Although anaerobic digestion systems contribute significantly to reducing the greenhouse effect since it is captured methane, known to be around 25 times more harmful than $\mathrm{CO}_{2}$ (Baylis and Paulson, 2011, EPA, 2004, Key and Sneeringer, 2011, Forster et. al, 2007, EPA, 1999), and utilized it as a renewable energy source, the absence of a carbon price would not allow to adopt this technology. In fact, Key and Sneeringer (2011) identified that carbon prices play a crucial role in making anaerobic digestion systems more profitable for businesses that sell carbon offsets. They also found that a carbon price of $\$ 13$ per $\mathrm{CO}_{2} \mathrm{e}$ ton would make the adoption of this technology profitable in large operations located in states, like for example, Texas, Wisconsin, New York and California. Although their analysis did not incorporate the effect of cost-share subsidies, they suggest that these programs will contribute in adopting anaerobic digesters (Key and Sneeringer, 2011). On the other hand, Leur, Hyde and Richard (2008) found that even though that this technology would bring environmental improvements, the absence of carbon prices would bring negative profits making the adoption of the technology unprofitable and requiring the need of policy development. 
The BET model is a tool that allows us to evaluate an innovative approach to simulate an emerging industry using NetLogo platform in which the resources available in a given region can be spatially optimized. Thus, the optimal utilization of the natural resources available in a region helps to develop clustering systems within an industry that eventually bring some agglomeration economies in the area.

The ABM approach using the NetLogo platform for our experimental inter-temporal spatial simulation permits showing a sustainable emerging industry using an innovative computer program. NetLogo has seemingly infinitive capabilities able to develop dynamic simulations within an interactive setting in order to reflect potential agent behaviors in an intertemporal world based on theory, data, equations and language programming. For example, our model allows simulating climatological influences toward production and the effects of optimizing spatially distributed resources in order to achieve profitable and social goals in a predetermined area. In fact, BET shows the importance of incorporating multiple products in bio-economic modeling (Standiford and Howitt, 1992) as an approach for possible considerations in a real PBB enterprise and associated external resources needed to attain these goals. Results indicate that cost-share policies and carbon prices might stimulate diversified PBB farms under deterministic and uncertain situations. Overall, the investment in anaerobic digesters when a combination of carbon price and cost-share programs exists not only brings environmental benefits to the Appalachian region but also profitability to PBB entrepreneurs.

From a sustainability perspective, it is fundamental to implement farm practices that would bring benefits not only to the private sector but also to society since it would be socially inappropriate to endorse practices that maximize private interests at the cost of society and the environment. When the use of a natural resource would promise highest present value to the 
private sector compared to conserving it as natural for the wellbeing of society, it is very likely to experience divergence between the two sectors (Krutilla, 1967). However, the PBB industry promises an alternative that would contribute in a sustainable way to meet present needs without compromising future necessities. The combination of appropriate use of land for sustainable production, proper waste management practices and clustering among firms would maintain the required nutrients for a high quality soil as well as improved water and air quality; so, firms are able to obtain a premium from their high quality products while enhancing a better ecosystem which eventually has a positive effect on society when past events as well as uncertainty are taken into consideration. We recognize that the development of this emerging industry might not reduce all the environmental problems we encounter on a daily basis in the Appalachian region; but it has the potential to make a significant contribution to farmers' profitability, our quality of life and the basis to bring some change in future generations.

\subsection{Policy Implications}

Based on BET results and the policy discussion addressed in Chapter VI, incentive programs such as cost-share programs, carbon price and renewable energy sales have an effect toward the existence of a carbon market since they not only might bring profitability but also GHG emission reductions in livestock operations (Key and Sneeringer, 2011). As we have observed, policies that contribute in reducing GHG emissions while diversifying energy supply are able to generate additional income to PBB producers in the Appalachian region. It must be recognized, however, that business profitability as well as social benefits will also be influenced by topographical and weather factors and surrounding agricultural enterprises that might have an economic motivation to join a clustering system. The clustering system also contributes in achieving a more efficient methane digester and economy of scales and scope at the regional level; however, it would 
increases operational costs through costs associated with transporting manure from individual farms to the centralized technology (Ghafoori and Flynn, 2006). This occurs due to the fact that the adoption of anaerobic digesters for small-scale farms might not be profitable as compared to larger-scale enterprises (Key and Sneeringer, 2011). On the other hand, manure supplemented by food waste products from crops, for example, might be an alternative for small farmers to accomplish a more efficient scale, although additional governing requirements associated with managing solid waste could raise costs (MDA, 2005). Overall, if policymakers demonstrate interest on renewable energy sources derived from anaerobic digesters utilized in the PBB industry in Appalachia, then economic incentives such as grants must be considered to stimulate the investment on environmentally friendly technologies.

\subsection{Model Limitations and Future Research}

There are several points associated with our ABM that might be visualized as future research goals. It is fundamental to point out that our approach does not consider the nonmarket benefits that the diversified industry might bring not only to the farmer but also to communities such as air contamination reduction, odor control and polluted water reduction as well as revenues from bedding and digested manure sales to agricultural and non-agricultural adjacent locations when the amount of the digested manure is above the required fertilizer applications in the contracting farm. For instance, the potential income generated from any digested manure applied on the contracting farm pasture is not reflected in our approach. The exclusion of these benefits in our experimental ABM underestimates the overall benefits accruing to society and entrepreneurs. Our model also relies on the assumption of the existence of a carbon market; however, there are other possible incentives such as the renewable portfolio standard in WV. It basically considers 
the production of renewable energy and reduction of $\mathrm{CO}_{2}$, using innovative technologies, like for example, anaerobic digesters allowing for more policy development.

Other limitations in our approach that might be considered for a future extension of the model is livestock prices employed and the profitability measure. In our approach we used annual average livestock prices; however, livestock prices are seasonal and tend to be higher during the spring season compared to fall. Thus, seasonality of each scenario, the specialized operation with its fall sale of livestock and the diversified operation with its spring sale of livestock, are not reflected in these analyses. Additionally, we computed the NPV for only the farm of interest from both diversified and specialized perspectives and did not measure profitability on the other farms in the spatial domain. Thus, the social outcomes across farms from a profitability stand of point are not measured.

Moreover, BET is programmed to run on a yearly basis (365 days) over 15 years allowing the farm of interest to fit better as a stocker farm only that depends on the resources within a predetermined spatial domain. Nevertheless, BET would bring more flexibility to potential users if it would have the capability to switch from a stocker to cow/calf or vice versa as the farm of interest allowing more practical applications depending on the area of interest. Likewise, since our model is programmed to optimize the resources available within the spatial domain identified, it does not consider any external resource such as additional pasturelands outside of the world. The possibility of extending those model capabilities would allow for more flexibility to potential researchers.

Moreover, our model only takes into account the total amount of $\mathrm{CO}_{2} \mathrm{e}$ emissions generated through manure as the baseline assuming that total amount of manure on a yearly basis is deposited into manure ponds or lagoons. However, it is fundamental to point out that besides 
the greenhouse emissions generated through cattle manure; ruminants also produce methane through belching due to microbial breakdown of carbohydrates in the rumen (Chase, 2010, Arthur, Herd and Basarab, 2010, Baylis and Paulson, 2011). The total methane emited by cattle is derived from manure and enteric emissions. In fact, 26 percent out of all rumen gases generated corresponds to methane. Manure produces approximately 7 percent out of the 26 percent of methane generated by cattle while enteric fermentation is responsible for approaximently 19 percent (Ishler, 2008, Sniffen and Herdt, 1991). Our model only considers methane reductions based on manure generation and excludes enteric emissions for simplication purposes.

Other elements that our model does not explicitly consider but it is important to be aware is the emissions generated as well as fuel consumption by hauling truck trips from nearby farms to the farm of interest as part of the clustering system developed in a region. Although the anaerobic digester might help capturing methane generated by animals to produce renewable energy, pollution can be induced by hauling trucks transporting manure from adjacent farms to the farm of interest and its magnitude will depend on distance and transportation frequency. In other words, the greater the number of members that join the clustering system as well as the longer the distance between nearby farms and the farm of interest, the more fuel is consumed and the more $\mathrm{CO}_{2}$ emissions are released into the atmosphere. For instance, a clustering system composed of five members might generate approximately 900 pounds of $\mathrm{CO}_{2}$ or 0.45 tons and would consume over 230 gallons of gasoline (8504 KWh) on a yearly basis as a result of manure transportation (EPA, 2000). After subtracting the equivalence of the values previously mentioned, we identify a net energy production of 24,000 KWh annually. However, BET does not take into account these components derived from the transportation sector. 
Furthermore, another possible extension for this model is to simulate the dynamics of prices (energy, beef and carbon offset) over time under uncertainty. BET measures the trends of prices through the passage of time in a deterministic manner, thus they tend to vary depending on historical trends. However, an extension would be to forecast prices stochastically allowing prices to fluctuate as a closer approach to reality. In terms of carbon offset prices, BET utilizes the most commonly used prices in the literature; but uncertain prices would reflect unpredictable response of a carbon offset market.

Moreover, our approach uses OLS to obtain the costs of investment associated with the anaerobic digester for energy and carbon offset production. Another alternative would be to explore the possibility of using a spatial econometric model such the Spatial Autocorrelation Model (SAR). The possibility of employing SAR in NetLogo would allow us to obtain the parameters associated with the capital investment of this technology taking into consideration spatial autocorrelation that is not captured through OLS regression.

Notwithstanding these limitations, this analysis shows the advantages of using agentbased modeling in agricultural/natural resource applications, especially those with the potential to generate payoffs to both private and public entities while contributing to the solution of "wicked problems." 


\section{REFERENCES}

Allergy and Asthma Foundation of America [AAFA]. (2011). The Top 10 Worst Cities in the U.S. to Live in with Asthma. Des Moines, Allergy and Asthma Foundation of America. Retrieved from http://www.asthmacapitals.com/.

American Grass-Fed Association [AGA]. ( 2011). What is GrassFed? Retrieved from http://www.americangrassfed.org/about-us/faq/\#1.

Anthes, G. (2003) Agent-Based Modeling of Complex, Adaptive Systems. Computerworld. Retrieved from http://www.computerworld.com/s/article/77858/FAQ_Agent_based_modeling_of_compl $\underline{\text { ex_adaptive_systems }}$

Arthur, P.F., Herd, R.M. and Basarab, J.A. (2010). "The Role of Cattle Genetically Efficient in Feed Utilization in an Australian Carbon Trading Environment.” AFBM Journal.. Vol 7, No 2. Charles Sturt University.

Axelrod, R. (1997) Resources for Agent-Based Modeling. Princeton, NJ, Princeton University Press, pp. 20.

Bagi, F.S., R.J. Reeder, and S.D. Calhoun. (2002). Federal Funding in Appalachia and Its Three Subregions. Rural America 17(4). pp. 31-37.

Bakshy, E., \& Wilensky, U. (2007). Turtle Histories and Alternate Universes; Exploratory Modeling with NetLogo and Mathematica. In M. J. North, C. M. Macal \& D. L. Sallach (Eds.), Proceedings of the Agent 2007 Conference on Complex Interaction and Social Emergence (pp. 147-158). IL: Argonne National Laboratory and Northwestern University. 
Balsam, J. and Ryan, D. (2006). "Anaerobic Digestor of Animal Wastes: Factors to Consider."National Center for Approproate Technology-ATTRA. Retrieved from http://www.wcasfmra.org/biogas_docs/ATTRA\%20anaerobic.pdf.

Barker C. J. (2001). "Methane Fuel Gas from Livestock Wastes a Summary." Water Quality \& Waste Management. North Carolina State Univerity. Published Num.: EBAE 071-80. March 14, 2001.Retrieved from http://www.bae.ncsu.edu/programs/extension/publicat/wqwm/ebae071_80.html

Baylis, K. and Paulson, N. (2011). Potential for Carbon Offsets from Anaerobic Digesters in Livestock Production. Animal Feed Science and Technology. Vol. 166, pp. 446- 456. doi:10.1016/j.anifeedsci.2011.04.032.

Beddoes, J.C., Bracmort, K.S., Burns, R.T. and Lazarus, W.F. (2007). An Analysis of Energy Production Costs from Anaerobic Digestion Systems on U.S. Livestock Production Facilities. Technical Note No. 1. Retrieved from http://www.biogas.psu.edu/pdfs/TechNote1BiogasEconomics.pdf

Business Dictionary.Com [BDC]. (2012). Best Management Practice (BMP). Business Dictionay.Com. Retrieved from http://www.businessdictionary.com/definition/bestmanagement-practice-BMP.html

Bhattacharyya, S.C. (2011). Energy Economics: Concepts, Issues, Markets and Governance.1 ed. New York: Springer. pp. 1-55, 107-119.

Blaser, R.E., Hammes, R.C., Fontenot, J.P., Bryant, H.T., Polan, C.E., Wolf, D.D., McClaugherty, F.S., Kline, R.G. and Moore, J.S. (1986). Forage-Animal Management Systems.Virginia Agricultural Experiment Station, Virginia Polytechnic Institute and State University Research Division Bulletin No. 86-7. 
Bowles Rice McDavid Graff and Love [BRMGL] (2007). Soil Organic Matter and N Cycling. The Leading Edge Journal of No-Till Agricultur. Vol. 2(1). Views \& Visions. Spring 2007. $\quad$ Retrieved from $\quad$ http://www.wvresearch.org/wpcontent/uploads/2011/11/views_and_visions_spring_2007.pdf

Burt, O.R. (1981). Level Economics of Soil Conservation in the Palouse Area of the Northwest. American Journal of Agricultural Economics, 63(1), pp. 83-92.

Business Environmental Leadership Council [BELC]. (Undated). Carbon Sequestration and Offsets Solutions. Pew Center on Global Climate Change. Retrieved from http://www.c2es.org/business/belc/climate-energy-strategies/sequestration.

Brock, W., and Xepapadeas.A. (2009). The Emergence of Optimal Control Agglomeration in Dynamic Economics. University of Wisconsin-Department of Economics and Athens University of Economics-Department of International and European Economic Studies. Retrieved from http://www.ssc.wisc.edu/ wbrock/Brock_Xepapadeas_Optimal_Agglomeration.pdf

Cacho, O.J. (1998) Solving Bioeconomic Optimal Control Models Numerically. In J. Gooday (Ed), Proceedings of the Bioeconomic Workshop, Australian Agricultural and Resource Economics Society Conference, 22 January, Armidale, ABARE, Canberra. University of New England, Armidale, ABARE Bioeconomic Workshop pp. 13-26.

Conservation Breeding Specialist Group [CBSG]. (2008). Proceedings of the Appalachian Salamander Conservation. Conservation and Research Center, Smithsonian's National Zoological Park, Front Royal, Virginia. Retrieved from http://nationalzoo.si.edu/SCBI/SpeciesSurvival/AmphibianConservation/AppalachianSal amanderReport.pdf 
Chase, L.E. (2010). How Much Gas Do Cows Produce? Department of Animal Science, Cornell Universtiy. Retrieved from http://vivo.cornell.edu/display/individual5509

Chi, H. 2000. "Computer Simulation Models for Sustainability." Interanational Journal of Sustainability in Higher Education 1(2): pp.154-167.

Chiang, A.C., ed. (2000). Elements of Dynamic Optimization. $2^{\text {nd }}$ edn., Illinois: Vaveland Press, Inc. pp. 161-176.

Chidester, B. (2010). Rising Pollution and Private Development Threaten the Appalachian Trail.

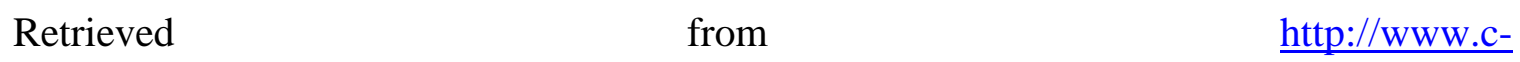
ville.com/index.php?cat=121304062461064\&ShowArticle_ID $=11800305104201494$

Costanza, V. and Neuman, C.E. (1997). Managing Cattle Grazing under Degraded Forests: An Optimal Control Approach. Ecological Economics 21(2): pp. 123-139.

Cuellar, A.D., and Webber, M.E. (2008). Cow Power: The Energy and Emmissions Benefits of Converting Manure to Biogas. Environmental Research Letters:1-10. doi:10.1088/1748$\underline{9326 / 3 / 3 / 034002 .}$

Dearlove, D. (2001) The Cluster Effect: Can Europe Clone Silicon Valley?, vol. 3th Quarter New York, NY, Booz \& Company.

Dorfman, R. (1969). An Economic Interpretation of Optimal Control Theory. The American Economic Review, 59(5), pp. 817-831.

D'Souza, G.E. (2010). "A Portfolio of Economic Driven Strategies for Obesity Prevention in Appalachia." West Virginia University.

Eberly, E. and Groover, G. (2011). 2011 Virginia Farm Business Management Livestock Budgets. Virginia Cooperative Extesion, Virginia Tech. Publication 446-048. Retrieved from http://pubs.ext.vt.edu/446/446-048/446-048.html 
Evanylo, G. and Peterson, P. (2000). Availability of N in Biosolids for Tall Grass Hay Production. Final Report to the T. M. Helper Endowment Committee, Virginia Tech. pp. 9.

Evans, J., D'Souza, G.E., Brown, C., Collins, A., Rayburn, E.B. and Sperow, M. (2007). Determining Consumer Perceptions of and Willingness to Pay for Appalachian Grass-fed Beef: An Experimental Approach. (Doctoral Dissertation). Retrieved from http://wvuscholar.wvu.edu:8881//exlibris/dtl/d3_1/apache_media/L2V4bGlicmlzL2R0bC 9kM18xL2FwYWNoZV9tZWRpYS8xMzg4MQ==.pdf

Evans, J., Sperow, M., D'Souza, G.E. and Rayburn, E.B. (2007). Stochastic Simulation of Pasture-Raised Beef Production Systems and Implications for the Appalachian Cow-Calf Sector. Journal of Sustainable Agriculture. 30(4): pp. 27-51.

Ferreira, W.N. (2001). BUDSYS: A New Tool for Farm Enterprise Analysis. Cooperative Extesion Service, Clemson Universtiy. EER 195. Retrieved from http://cherokee.agecon.clemson.edu/budgets/BudSys.htm

Follett, R.F., Kimble, J.M. and Lal, R., eds. (2001). The Potential of U.S. Grazing Lands to Sequester Carbon and Mitigate the Greenhouse Effect. Boca Raton, Florida, USA, Lewis Publishers, CRC Press. pp. 422.

Food and Agriculture Organization of the United Nations [FAO]. (2010). Grassland Carbon Sequestration: Management, Policy and Economics. Proceedings of the Workshop on the Role of Grassland Carbon Sequestration in the Mitigation of Climate Change. Integrated Crop Management. (11)2010. pp. 2-13, 92-93.

Forster, P., V. Ramaswamy, P. Artaxo, T. Berntsen, R. Betts, D.W. Fahey, J. Haywood, J. Lean, D.C. Lowe, G. Myhre, J. Nganga, R. Prinn, G. Raga, M. Schulz and R. Van Dorland. 
(2007) Changes in Atmospheric Constituents and in Radiative Forcing. In: Climate Change 2007: The Physical Science Basis. Contribution of Working Group I to the Fourth Assessment Report of the Intergovernmental Panel on Climate Change [Solomon, S., D. Qin, M. Manning, Z. Chen, M. Marquis, K.B. Averyt, M.Tignor and H.L. Miller (eds.)]. Cambridge University Press, Cambridge, United Kingdom and New York, NY, USA.

Friends of the Earth [FOE]. (2008). The Price of Carbon: What Should it Be and Why? Seminar, Mercer Suite, Royal Society, $8^{\text {th }}$ July 2008. Friends of the Earth. pp. 4. Retrieved from http://www.foe.co.uk/resource/reports/carbon_price_seminar_2008.pdf

Fulhage, C.D., D. Sievers, and J.R. Fischer. (1993). Generating Methane Gas from Manure. University of Missouri Extension, Department of Agricultural Engineering. http://extension.missouri.edu/publications/DisplayPub.aspx?P=G1881

Ghafoori, E. and Flynn, P. (2006). Optimizing the Size of Anaerobic Digesters. Presented at the Canadian Society for Bioengineering (SCBE/SCGAB) Annual Conference, Edmonton, Alberta, Canada. July 16-19, 2006.

Hahn, W.F. (2012). Meat Price Spreads. Economic Research Service. Retrived from http://www.ers.usda.gov/data/meatpricespreads/

Heckman, E., Hinds, S., Johnson, K., Perkins, J., Shelton, V. and Zupancic, R. (2007). Management-Intensive Grazing in Indiana. Purdue University-Purdue Extension. AY328. pp. 5. Retrieved from http://www.extension.purdue.edu/extmedia/AY/ay-328.pdf

Hemert, J.V., and J. Holmes. (2008). Healthy Food Systems: Putting Sustainable Community Development in Context: A Look at the Food System. The Rocky Mountain Land Use Institute, University of Denver. pp. 1-11. Retrieved from 
http://law.du.edu/images/uploads/rmlui/rmlui-sustainable-HealthyFoodSystems.pdf

Hennessy, D. A.; J. Roosen, and H. H. Jensen. (2005). Infectious Disease, Productivity, and Scale in Open and Closed Animal Production Systems. American Journal of Agricultural Economics. 87(November 2005): pp. 900-917.

Holechek, J.L. (1988). An Approach for Setting the Stocking Rate. Ragelands. 10(1): pp. 10-14.

Holmes, T.P., J.C. Bergstrom, E. Huszar, S.B. Kask, and F. Orr III. 2004. Contingent Valuation, Net Marginal Benefits, and the Scale of Riparian Ecosystem Restoration. Ecological Economics 49: pp. 19-30.

Horowitz, J. and Gottlieb, J. (2010). The Role of Agriculture in Reducing Greenhouse Gas Emissions.Economic Research Service. Economic Brief No. (EB-15) 8. Retrieved from http://www.ers.usda.gov/Publications/EB15/EB15.pdf.

Ishler, V. (2008). Carbon, Methane Emissions and the Dairy Cow. PennState University. Dairy and Animal Science. 08-127. Retrieved from http://www.das.psu.edu/researchextension/dairy/pdf/carbonanddairy.pdf

Joandet, G.E. and Cartwright. T.C. (1975). Modeling Beef Production Systems. Journal of Animal Science. 41(4): pp. 1238-1246.

Judy, G. (2011). The Economics of High Density Grazing, in Proceeding of the Appalachian Grazing Conference, March 4-5, 2011, Morgantown, WV.

Keating, B.A. and Carberry, P.S. (2008). Emerging Opportunities for Australian Agriculture? Australian Society of Agronomy. Global Issues Paddock Action. Proceedings of the 14th Australian Agronomy Conference. September 2008, Adelaide South Australia, Australia. Retrieved from $\quad$ http://www.regional.org.au/au/asa/2008/plenary/emergingopportunities/5923_keatingb.htm. 
Key, N., and S. Sneeringer. (2011). Climate Change Policy and the Adoption of Methane Digesters on Livestock Operations . U.S.D.A.-Economic Research Service Report (111). Retrieved from http://www.ers.usda.gov/Publications/ERR111/ERR111.pdf

Krueger, C.R. ed. (1998). Grazing in the Northeast: Assesing Current Technologiez, Research Directions, and Education Needs. NRAES-113, in Proceeding from the Grazing in the Northeast Workshop, March 25-26, 1998, Camp Hill, Pennsylvania.

Krutilla, J.V. (1967). Conservation Reconsidered. The American Economic Review 57(4): pp. 777-786.

Laca, E.C. (2000). Modelling Spatial Aspects of Plant Animal Interactions. Grassland Ecophysiology and Grazing Ecology: pp. 209-231. New York, CAB Interational. d.o.i. 10.1079/9780851994529.0209.

LaSalle, T.J. (2009). In Defense of the Cow: How Eating Meat Could Help Slow Climate Change. TreeHugger. Rerieved from http://www.treehugger.com/green-food/in-defenseof-the-cow-how-eating-meat-could-help-slow-climate-change.html.

Lee, J., D. Nezamutinova, and T. Paul (2005). From Mid-East Oil to London Broil: A Comparison of Energy Inputs in Feedlot verssus Grass-Fed Beef. Acres USA Magazine. $\begin{array}{lll}\text { November } & 2005 . & \text { Retrieved }\end{array}$ http://www.acresusa.com/magazines/archives/1105Inputs.htm

Lee, R., Boyer, D.G. and Dickerson, W.H. (1979). Global Radiation in West Virginia. Agricultural and Forestry Experiment Station, West Virginia University: Bulletin 665T.

Leuer, E.R., Hyde, J. and Richard, T.L. (2008). Investing in Methane Digesters on Pennsylvania Dairy Farms: Implications of Scale Economies and Environmental Programs. 
Agricultural and Resource Economics Review. Northeastern Agricultural and Resource Economics Association. October 2008. pp. 188-203.

Macal, C., and M. North. (2010). Tutorial on Agent Based Modelling and Simulation. Journal of Simulation 4: pp. 151-162.

Mathews, K.H.J., and K.E. McConnell. (2011). U.S. Cattle and Beef Industry, 2002-2010. U.S.D.A. Economic Research Service. Retrieved from http://webarchives.cdlib.org/sw1db7wq09/http://ers.usda.gov/News/BSECoverage.htm

MATRIC (2010). Appalachian Land Restoration Center. South Charleston, WV, Mid-Atlantic Technology, Research and Innovative Center.

Mazereeuw, B. (2005). Urban Agriculture Report. Region of Waterloo Growth Management Strategy (Doc. \# 168595): pp. 28.

McConnell, K.E. 1983. "An Economic Model of Soil Conservation." American Journal of Agricultural Economics 65(1): pp. 83-89.

Minnesota Department of Agriculture (MDA). (2005). Opportunities, Constraints, and Research Needs for Co-digestion of Alternative Waste Streams with Livestock Manure in Minnesota. Agricultural Resources Management and Development Division. Retrieved from http://www.mnproject.org/e-intro.html .

Moseley, B. (2009). Intensive Grazing and Grass Fed Beef Workshop Held in Fairfield. U.S. Natural Resources Conservation Service. Retrieved from http://www.tx.nrcs.usda.gov/news/lonestarlink/archives/09/grazing_ws.html

Natural Resources Conservation Service [NRCS]. (2011). Section-4 Manure Production. Retrieved from http://www.wy.nrcs.usda.gov/technical/wycnmp/sec4.html 
Oslo, N. (2009). Carbon Trading Price Rise Predicted. Renewable Energy World.Com. Retrieved from http://www.renewableenergyworld.com/rea/news/article/2009/06/carbon-tradingprice-rise-predicted.

Paine, L., P. Reedy, R. Skora, and J. Swenson. (2009). A Consumer's Guide to Grass-Fed Beef. UW Cooperative Extension, University of Wisconsin-Madison: pp. 1-12. Retrieved from http://www.wisconsinlocalfood.com/recipes/CGGFB.pdf

Pang, H., Makarechian, .M., Basarab, J.A., and Berg, R.T. (1999). Structure of a Dynamic Simulation Model for Beef Cattle Production Systems.” Canadian Journal of Animal Science. pp. 409-417. d.o.i. 10.4141/A99-020.

Parsch, L.D., Popp, M.P. and Loewer, O. J. (1997). Stocking Rate Risk for Pasture-Fed Steers under Weather Uncertainty. Journal of Range Management, 50(5): pp. 541-549.

Perman, R., Y. Ma, J. McGilvray, and M. Common. (2003). Natural Resource and Environmental Economics. $3^{\text {rd }}$ ed: pp. 364-375. Pearson Education Limited. Gosport.

Peter. (2010). New Zealand Adopts Cap and Trade for Livestock. The Ostrich Head. Retrieved from $\quad$ http://theostrichhead.typepad.com/index/2010/04/new-zealand-adopts-cap-andtrade-for-livestock.html.

Pillars, R. (2003). Farm-Based Anaerobic Digesters, Manure Technologies Fact Sheet, Michigan $\begin{array}{llll}\text { State } & \text { University, } & \text { Retrieved } & \text { from }\end{array}$ http://www.agmrc.org/media/cms/FinalAnearobicDigestionFactsheet_2E11FAB524961.p df.

Pimentel, D. and Pimentel, M. (2008). Food, Energy and Society, $3^{\text {rd }}$ edn. pp. 67-75, 277-310. CRC Press, Taylor and Francis Group, Boca Raton, FL. 
Portelli, J. (2008). Home, Home on the Feedlot: A Study of the Sustainability of Grass-Fed and Grain-Fed Beef Production. Working Paper for ENVS 664 Sustainable Design: pp. 1-11. Retrieved from http://www.greendesignetc.net/GreenProducts_08_(pdf)/Portelli_JoeGrass_fed_beef(paper).pdf

Porter, M.E. (1990). The Competitive Advantage of Nations. Harvard Business Review-Harvard University. Free Press. May 1990. Retrieved from http://kkozak.wz.cz/Porter.pdf

Raine, M. 2001. “In Search of the Perfect Rotation”. The Western Producer.

Rayburn, E. (2003). Forage Production Risk in the Northeast. Extension Service, West Virginia University.

Rayburn, E. (2005). Pasture Management for Pasture-Finished Beef. Extesion Service, West $\begin{array}{lll}\text { Virginia } & \text { Universtiy. } & \text { Retrieved }\end{array}$ http://www.wvu.edu/ agexten/forglvst/pasturemang.pdf

Rayburn, E., ed. (2006). Managing and Marketing for Pasture-Based Livestock Production. Natural Resource, Agriculture, and Engineering Service-NRAES-174, Ithaca, New York. pp. 27-51.

Rayburn, E., ed. (2008). Animal Production Systems for Pasture-Based Livestock Production. Natural Resource, Agriculture, and Engineering Service-NRAES-171, Ithaca, New York. pp. 28-78, 205.

Rayburn, E. and Lozier, J. (2002). Pasture-Based Beef Systems for Appalachia Preliminary Report of a Nationwide Survey. Retrieved from http://www.wvu.edu/ agexten/forglvst/PFBPrpt.pdf 
Rayburn, E., Hall, M., Murphy, W. and Vough, L. (1998). Pasture Production. Northeast Regional Agricultural Engineering Service. Proceedings from the Grazing in the Northeast Workshop, March 25-26, 1998, Camp Hill, Pennsylvania. pp. 13-50.

Rayburn, E., Hall, M., Murphy, W. and Vough, L. (2006). Forage Production for Pasture-Based Livestock Production. Natural Resource, Agriculture, and Engineering Service-NRAES172, Ithaca, New York. pp. 7-60.

Redfearn, D.D. and Bidwell, T.G. (2009). Stocking Rate:The Key to Successful Livestock Production. Oklahoma Cooperative Extension Service. Oklahoma State University. PSS$\begin{array}{llll}\text { 2871. } & \text { Retrieved } & \text { February } & \text { 6, 2012, }\end{array}$ http://pods.dasnr.okstate.edu/docushare/dsweb/Get/Document-2050/PSS-2871web.pdf

Reynolds, C. (1999). Individual-Based Models. Retrieved from http://www.red3d.com/cwr/ibm.html

Ribaudo, M., Gollehon, N., Aillery, M., Kaplan, J. Johansson, R., Agapoff, J., Christensen, L., Breneman, V. and Peters, M. (2003). Manure Management for Water Quality: Costs to Animal Feeding Operations of Applying Manure Nutrients to Land. AER-824. Retrieved from http://www.ers.usda.gov/publications/aer824/ .

Rith, C. and Dubberly, H. (2006).Why Horst W. J. Rittel Matters. Design Issues, 22(4).

Robinson, J. (2002). "Pasture Perfect." Mother Earth News. pp. 46-51.

Rural Economy and Land Use Programme (RELU). (2011). Farm Diversification into Energy Production by Anaerobic Digestion. Centre for Rural Economy School of Agricutlture, Food and Rural Development, Newcastl University. Note No. 26. February 2011. $\begin{array}{ll}\text { Retrieved } & \text { from }\end{array}$ 
http://www.relu.ac.uk/news/policy\%20and\%20practice\%20notes/26\%20Banks/PPN26.p

df.

Saliba, C. (1985). Soil Productivity and Farmer's Erosion Control Incentives-A Dynamic Modeling Approach. Western Journal of Agricultural Economics 10(2): pp. 354-364.

Scaglia, G., Swecker, W.S., Fontenot, J.P., Fiske, D., Fike, J.H., Abaye, A.O., Peterson, P.R., Clapham, W. and Hall, J.B. (2008). Forage Systems for Cow-Calf Production in the Appalachian Region. Journal of Animal Sciences. 86: pp. 2032-2042. DOI: 10.2527/jas.2007-0407.

Schuster, D., Undersander, D., Schaefer, D., Klemme, R. M., Siemens, M. and Smith, L. (2001). Stocker Enterprise Budgets for Grass-based Systems. A3718. UW-Extesnion. University of Wisconsin. Retrieved from http://learningstore.uwex.edu/assets/pdfs/A3718.pdf

Shih, J., Burtraw, D., Palmer, K., Sukiyaki, J. (2006). Air Emissions of Ammonia and Methane from Livestock Operations: Valuation and Policy Options. Discussion Paper No. 06-11, Resources for the Future, Washington, D.C.

Shubert, N.E. (2010). No Farm, No Food: Organizing Appalachian Family Farms around the Politics of 'Good Food'. (Doctoral Dissertation). Retrieved from http://etd.ohiolink.edu/view.cgi/Shubert\%20Natalie\%20E.pdf?ohiou1272911792

Sollenberger, L.E. and Vanzant, E.S. (2011). Interrelationships among Forage Nutritive Value and Quantity and Individual Animal Performance. Crop Science. 51(2). pp. 420-432.

Sniffen, C.J. and Herdt, H.H. (1991). Dairy Nutrition Management. The Veterinary Clinics of North America. Food Animal Practice. 7(2). pp. 311-632. Philadelphia, PA: W.B. Saunders Company. 
Standiford, R.B., and R.E. Howitt. (1992). Solving Empirical Bioeconomic Models: A Rangeland Management Application. American Agricultural Economics Association: pp. 421-433.

State Energy Conservation Office [SECO]. (Undated). Biomass Energy: Manure for Fuel. State Energy Conservation Office (Texas): pp. 1-7. Retrieved from http://www.seco.cpa.state.tx.us/re_biomass-manure.htm

Stevens, P., and J. Deal (2010). An End-of-the Decade Checkup on the Wellbeing of our Region. Charlottesville, VA, Appalachian Voices.

Stonehouse, D.P. and Bohl, M. (1990). Canadian Public Policy / Analyse de Politiques. 16(4). pp. 418-431. University of Toronto Press Retrieved from http://www.jstor.org/discover/10.2307/3550856?uid=3739968\&uid=2129\&uid=2\&uid=7 $\underline{0 \text { \&uid }=4 \& \text { uid }=3739256 \& \text { sid }=56252264273}$

Subler, S. (2006). Carbon Credits in Animal Agriculture. USDA-Agricutural Air Quality Task Force. Environmental Credit Corporation, Harrisburg, PA. Retrived from http://www.nrcs.usda.gov/Internet/FSE_DOCUMENTS/nrcs143_008725.pdf

Sundermeier, A., Reeder, R. and Lal, R. (2005). Soil Carbon Sequestration Fundamentals. Ohio State University Fact Sheet, AEX 510-05. Retrieved from http://ohioline.osu.edu/aexfact/0510.html

Tanzania Traditional Energy Developement and Environmental Organization [TaTEDO]. (Undated). Biogas Technology: Construction, Utilization and Operation Manual. Retrieved from http://www.tatedo.org/cms/index.php .

Thom, W.O., H.B. Rice, D. Adams, C. May, and C. Absher. (1990). "Beef Cattle Production on Surface-Minded Land in Central Appalachia." ID-96. Retrieved from 
http://www.uky.edu/Ag/AnimalSciences/pubs/id96.pdf

Thornley, J.H.M. and France J. (2007). Mathematical Models in Agriculture: Quantitative Methods for the Plant, Animal and Ecological Sciences. 2 edn. pp. 2-54. Cromwell Press, Trowbridge, UK.

Thiele J.C. and Grimm V. (2010). NetLogo meets R: Linking agent-based models with a toolbox for their analysis. Environmental Modeling and Software. 25(8): pp. 972 - 974. [DOI: 10.1016/j.envsoft.2010.02.008].

Torell, L.A., Lyon, K.S. and Godfrey, E.B. (1991). Long-Run Versus Short-Run Planning Horizons and the Rangeland Stocking Rate Decision. American Agricultural Economics Association: pp.795-807.

US Department of Agricutlure [USDA]. (2009). Web Soil Survey. Natural Resource Conservation Service. Retrived from http://websoilsurvey.nrcs.usda.gov/app/WebSoilSurvey.aspx.

US Department of Agricutlure [USDA]. (2012). Environmental Quality Incentives Program (EQIP). Natural Resource Conservation Service. Retrieved from http://www.nh.nrcs.usda.gov/programs/Farm_Bill/EQIP/EQIP.html

US Department of Energy [DOE]. (2010). How Much Electricity Does a U.S. Home Use? : U.S.D.O.E.-U.S. Energy Information Administration. Retrieved from http://www.eia.gov/tools/faqs/

US Department of Labor-Bureau of Labor Statictics [DOL]. (2012). Databases, Tables and Calculators by Subject: CPI Inflation Calculator. US Department of Labor. Retrieved from http://www.bls.gov/data/inflation_calculator.htm 
US Energy Information Administration ([EIA]. (2012). Electricity: Detailed State Data. US Department of Energy. Retrieved from http://www.eia.gov/electricity/data/state/. US Environmental Protection Agency [EPA]. (1999). Livestock Manure Management. Retrieved from http://epa.gov/methane/projections.html

US Environmental Protection Agency [EPA]. (2000). Emission Facts: Average Annual Emissions and Fuel Consumption for Passenger Cars and Light Trucks. Retrieved from http://www.epa.gov/oms/consumer/f00013.pdf

US Environmental Protection Agency [EPA]. (2004). Market Opportunities for Biogas Recovery Systems: A Guide to Identifying Candidates for On-Farm and Centralized Systems. The AgStar Program, U.S. Environmental Protection Agency. pp. 1-34.

Wang, F.S. (2001). Deterministic and Stochastic Simulations for Solid Waste Collection Systems-A SWIM Approach. Environmental Modeling and Assessment. 6: pp. 249-260.

Ward, R. (2003). Soil Organic Matter and N Cycling. The Leading Edge Journal of No-Till. Agriculture. 2(1). Retrieved from http://www.notill.org

Weinheimer, B. (2008). Value of Manure from Beef Cattle Feedyards. Texas Cattle Feeders Association. Retrieved from http://www.tcfa.org.

West Virginia Department of Agriculture (WVDA). (2012). State Beef Producers Marketing Father's Day with Luncheon at Governor's Mansion. News Release. Retrieved from http://www.wvagriculture.org/news_releases/2012/6-7-12.html.

Wilensky, U. (1999). NetLogo. http://ccl.northwestern.edu/netlogo/. Center for Connected Learning and Computer-Based Modeling, Northwestern University, Evanston, IL. 
Wilensky, U. (2005). NetLogo Wolf Sheep Predation (docked) model. http://ccl.northwestern.edu/netlogo/models/WolfSheepPredation(docked). Center for Connected Learning and Computer-Based Modeling, Northwestern University, Evanston, IL.

Wilensky, U. (2005). NetLogo Wolf Sheep Predation (System Dynamics) model. http://ccl.northwestern.edu/netlogo/models/WolfSheepPredation(SystemDynamics).

Center for Connected Learning and Computer-Based Modeling, Northwestern University, Evanston, IL.

William, J.C. and Hall, M.H. (1994). Four Steps to Rotational Grazing. Cooperative Extesion Service, The Pennsylvania State University: Agronomy Facts 43. Retrieved from $\underline{\text { http://www.forages.psu.edu/agfacts/agfact43.pdf }}$

World Commission on Environment and Development (WCED). (1987). Our Common Future. Oxford: Oxford University Press. Retrieved from http://conspect.nl/pdf/Our_Common_Future-Brundtland_Report_1987.pdf

U S Department of Agriculture [USDA]. 2011. On-Farm Renewable Energy Production Shows $\begin{array}{llll}\text { Tremendous } & \text { Growth. } & \text { Charleston. } & \text { Retrieved }\end{array}$ http://www.usda.gov/wps/portal/usda/usdamediafb?contentid=2011/02/0079.xml\&printa $\underline{\text { ble=true\&contentidonly=true }}$

Virginia Forage Research Station [VAFS]. (1969). Managing Forages for Animal Production: 1949-1969. History and Research Findings. Virginia Forage Research Station, Virginia Polytechnic Institute-Research Division Bulletin No. 45. 
Yohn, C. and Rayburn, E. (2000). The Production of Rationally Grazed Pasture in Jefferson County. Extesion Service, West Virginia Universtiy. http://www.wvu.edu/ agexten/forglvst/product.PDF

Zipper, C.E. and Skousen, J.G. (Undated). Income Opportunities on Reclaimed Surface Mine Lands in Central Appalachia. Green Lands. Retrieved from http://anr.ext.wvu.edu/r/download/44893

ZoBell, D., Burrell, C. and Bagley, C. (1999). Raising Beef Cattle on Few Acres. Extension Service. Utah State University. 


\section{APPENDIX}

\begin{tabular}{|ccc|}
\hline \multicolumn{2}{|l|}{ Table A-1: Energy Data } & \\
\hline \hline Description & Data & Source \\
Price of Energy Sold & $\$ /$ KWh & EIA, 2012 \\
Cost of Maintaining and Operating Digester & $\$ 0.034 / \mathrm{KWh}$ & Baylis and Paulson, 2011, Key and Sneeringer 2011 \\
Cost of Anaerobic Digester & $\$ /$ Head & Key and Sneeringer, 2011, Beddoes et. al 2007 \\
& & \\
\end{tabular}

\begin{tabular}{|cc|}
\hline Table A-2: Climatological and WV County Data* \\
\hline Description & Data \\
\hline Precipitation & Inches \\
\hline Temperature & Low and High $\left({ }^{\circ} \mathrm{F}\right)$ \\
\hline Coordinates & Latitude and Longitude \\
\hline Average Slopes & Percentage \\
\hline *Data are obtained from NOAA (30 years: 1971-2000) and Soil Web Survey, 2009. \\
\hline
\end{tabular}

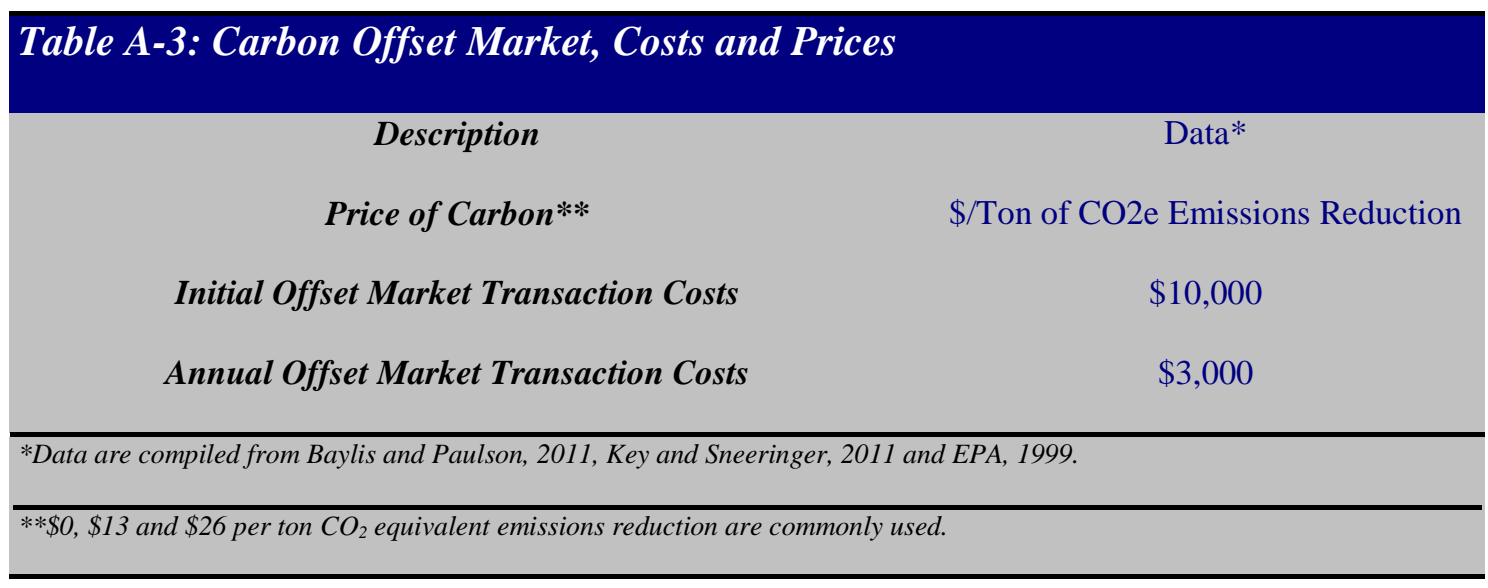




\begin{tabular}{llll}
\hline \multicolumn{5}{l}{ Table A-4: Steer Sold Price (\$ per $\mathrm{cwt}$ ) } \\
\hline \multicolumn{1}{c}{ Year } & Price* & Year & Price* \\
2013 & $\$ 114.82$ & 2021 & $\$ 134.76$ \\
2014 & $\$ 105.76$ & 2022 & $\$ 139.17$ \\
2015 & $\$ 112.36$ & 2023 & $\$ 149.18$ \\
2016 & $\$ 118.96$ & 2024 & $\$ 149.61$ \\
2017 & $\$ 123.96$ & 2025 & $\$ 132.58$ \\
2018 & $\$ 113.48$ & 2026 & $\$ 150.02$ \\
2019 & $\$ 137.13$ & 2027 & $\$ 174.07$ \\
2020 & $\$ 137.22$ & & \\
\hline *Prices are annual averages prices based on years 2006-2011 (Hahn, 2012, Rayburn, 2006). \\
\hline *The above prices have been adjusted to inflation based on DOL, 2012. \\
\hline
\end{tabular}

\section{Table A-5: Other Beef Production Costs per Head**}

\begin{tabular}{llll} 
Year & Cost-Diversified (Specialized)* & Year & Cost-Diversified (Specialized)* \\
2013 & $\$ 134.74(119.63)$ & 2021 & $\$ 153.45(132.25)$ \\
2014 & $\$ 139.52(119.28)$ & 2022 & $\$ 158.02(133.19)$ \\
2015 & $\$ 139.08(120.83)$ & 2023 & $\$ 159.19(137.06)$ \\
2016 & $\$ 141.17(123.56)$ & 2024 & $\$ 164.90(136.64)$ \\
2017 & $\$ 145.35(124.42)$ & 2025 & $\$ 164.37(138.49)$ \\
2018 & $\$ 146.42(127.97)$ & 2026 & $\$ 166.87(141.73)$ \\
2019 & $\$ 151.65(127.58)$ & 2027 & $\$ 171.87(142.77)$ \\
2020 & $\$ 151.16(129.28)$ & & \\
\hline
\end{tabular}

*Costs are based on Eberly and Groover, 2011, Schuster et al., 2001 and have been adjusted to inflation based on DOL, 2012.

**These costs associated costs to beef production are defined as: costs of pasture grazed, labor, veterinary fees and medication, salts and minerals, fly control ear tags, interest and insurance, repair and maintenance, depreciation, marketing costs, miscellaneous and management costs. 
Table A-6: Energy Prices in Cents (KWh)

\begin{tabular}{|c|c|c|c|}
\hline Year & Price* & Year & Price* \\
\hline 2013 & $\$ 0.0943$ & 2021 & $\$ 0.0918$ \\
\hline 2014 & $\$ 0.0926$ & 2022 & $\$ 0.0918$ \\
\hline 2015 & $\$ 0.0921$ & 2023 & $\$ 0.0918$ \\
\hline 2016 & \$0.0919 & 2024 & $\$ 0.0918$ \\
\hline 2017 & $\$ 0.0918$ & 2025 & $\$ 0.0918$ \\
\hline 2018 & $\$ 0.0918$ & 2026 & $\$ 0.0918$ \\
\hline 2019 & \$0.0918 & 2027 & $\$ 0.0918$ \\
\hline 2020 & $\$ 0.0918$ & & \\
\hline
\end{tabular}

\begin{tabular}{|c|c|c|c|}
\hline \multicolumn{4}{|c|}{ Table A-7: Steer Purchasing Price (\$ per cwt) } \\
\hline Year & Price* & Year & Price* \\
\hline 2013 & $\$ 125.95$ & 2021 & $\$ 147.82$ \\
\hline 2014 & $\$ 116.01$ & 2022 & $\$ 152.65$ \\
\hline 2015 & $\$ 123.25$ & 2023 & $\$ 163.64$ \\
\hline 2016 & $\$ 130.49$ & 2024 & $\$ 164.11$ \\
\hline 2017 & $\$ 135.98$ & 2025 & $\$ 145.43$ \\
\hline 2018 & $\$ 124.48$ & 2026 & $\$ 164.56$ \\
\hline 2019 & $\$ 150.42$ & 2027 & $\$ 190.94$ \\
\hline 2020 & $\$ 150.52$ & & \\
\hline 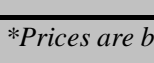 & 11 & D06). & \\
\hline
\end{tabular}




\begin{tabular}{|c|c|c|c|}
\hline \multicolumn{4}{|c|}{ Table A-8: Hauling Manure Costs Ton Per Mile } \\
\hline Year & Costs* & Year & Costs* \\
\hline 2013 & $\$ 0.35$ & 2021 & $\$ 0.61$ \\
\hline 2014 & $\$ 0.38$ & 2022 & $\$ 0.65$ \\
\hline 2015 & $\$ 0.42$ & 2023 & $\$ 0.68$ \\
\hline 2016 & $\$ 0.454$ & 2024 & $\$ 0.718$ \\
\hline 2017 & $\$ 0.487$ & 2025 & $\$ 0.751$ \\
\hline 2018 & $\$ 0.520$ & 2026 & $\$ 0.784$ \\
\hline 2019 & $\$ 0.553$ & 2027 & $\$ 0.817$ \\
\hline 2020 & $\$ 0.586$ & & \\
\hline
\end{tabular}

\begin{tabular}{|c|c|c|c|}
\hline \multicolumn{4}{|c|}{ Table A-9: Manure Base Charge per Ton } \\
\hline Year & Costs* & Year & Costs* \\
\hline 2013 & $\$ 3.66$ & 2021 & $\$ 4.17$ \\
\hline 2014 & $\$ 3.64$ & 2022 & $\$ 4.20$ \\
\hline 2015 & $\$ 3.71$ & 2023 & $\$ 4.36$ \\
\hline 2016 & $\$ 3.82$ & 2024 & $\$ 4.34$ \\
\hline 2017 & $\$ 3.85$ & 2025 & $\$ 4.42$ \\
\hline 2018 & $\$ 3.99$ & 2026 & $\$ 4.55$ \\
\hline 2019 & $\$ 3.98$ & 2027 & $\$ 4.59$ \\
\hline 2020 & $\$ 4.05$ & & \\
\hline
\end{tabular}




\begin{tabular}{|c|c|c|c|}
\hline \multicolumn{4}{|c|}{ Table A-10: Costs of Manure per Ton } \\
\hline Year & Costs* & Year & Costs* \\
\hline 2013 & $\$ 2.09$ & 2021 & $\$ 2.38$ \\
\hline 2014 & $\$ 2.08$ & 2022 & $\$ 2.40$ \\
\hline 2015 & $\$ 2.12$ & 2023 & $\$ 2.49$ \\
\hline 2016 & $\$ 2.18$ & 2024 & $\$ 2.48$ \\
\hline 2017 & $\$ 2.20$ & 2025 & $\$ 2.52$ \\
\hline 2018 & $\$ 2.28$ & 2026 & $\$ 2.60$ \\
\hline 2019 & $\$ 2.28$ & 2027 & $\$ 2.62$ \\
\hline 2020 & $\$ 2.31$ & & \\
\hline
\end{tabular}

\section{Table A-11: Capital Costs of Anaerobic Digester as a Function of Operation Size}

Dependent Variable: Capital Ln(capital)

$\begin{array}{lc}\text { Intercept } & * 10.1994(0.5749) \\ \text { Ln(heads) } & * 0.3977(0.0888)\end{array}$

Num. of Observations

10

Standard errors depicted in parenthesis, significant at 99 percent level with R-squared .71.

\begin{tabular}{|c|c|c|c|}
\hline Year & Diversified (Specialized)* & Year & Diversified (Specialized)* \\
\hline 2013 & $\$ 7,610.90(\$ 6,085.95)$ & 2021 & $\$ 1,984.90(\$ 6,637.01)$ \\
\hline 2014 & $\$ 1,576(\$ 5,269.86)$ & 2022 & $\$ 2,051.40(6,859.34)$ \\
\hline 2015 & $\$ 1,628.80(\$ 5,446.40)$ & 2023 & $\$ 3,492.20(8,461.22)$ \\
\hline 2016 & $\$ 1,683.40(\$ 5,628.85)$ & 2024 & $\$ 2,191.20(\$ 7,326.62)$ \\
\hline 2017 & $\$ 1,739.80(\$ 5,817.42)$ & 2025 & $\$ 2,264.60(\$ 7,572.06)$ \\
\hline 2018 & $\$ 2,961.80(\$ 7,175.97)$ & 2026 & $\$ 2,340.40(\$ 7,825.72)$ \\
\hline 2019 & $\$ 1,858.30(\$ 6,213.71)$ & 2027 & $\$ 2,418.80(\$ 8,087.89)$ \\
\hline 2020 & \multicolumn{3}{|l|}{$\$ 1,920.60(\$ 6,421.87)$} \\
\hline \multicolumn{4}{|c|}{ *Costs are based on Schuster et al., 2001, Eberly and Groover, 2011 and have been adjusted to inflation based on DOL, 2012.} \\
\hline
\end{tabular}


;; ; ; ; ; Farmer 8 Adjacent;;;;;;;;;

if timer-loop-sequence $=500$ and ticks > 5490 [ask farmers7 [setxy -1546 set goal patch -733 face goal $\mathrm{fd} .1$ ]

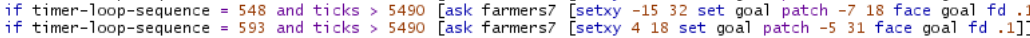

if timer-loop-sequence $=639.5$ and ticks $>5490$ [ask farmers7 [setxy 445 set goal patch 433 face goal fd. 1 . 1 ]

if timer-loop-sequence $=683$ and ticks $>5490$ [ask farmers7 [setxy 618 set goal patch 1531 face goal fd.1]]
if timer-loop-sequence $=728$ and ticks $>5490$ [ask farmers7 [setxy 1533 set goal patch 1545 face goal $\mathrm{fd}$. 1] ]
if timer-loop-sequence $>>773$ and timer-loop-sequence $\langle=1046$ and ticks $>5490$ [ask farmers7 [setxy 8 47]]

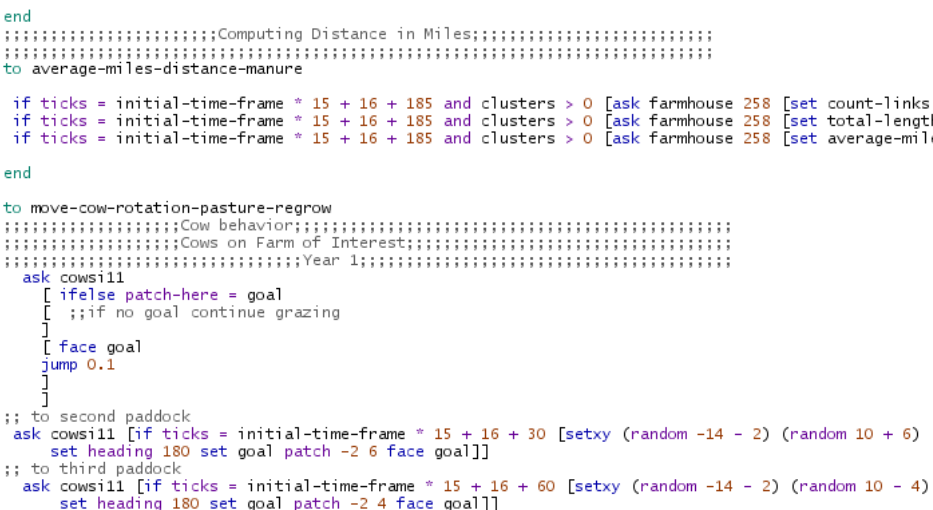

Figure A-1: Through language programming coded in the procedure tab, BET is able to measure the mean miles among the agents within the clustering system as well as to simulate the cattle interaction with the natural environment.

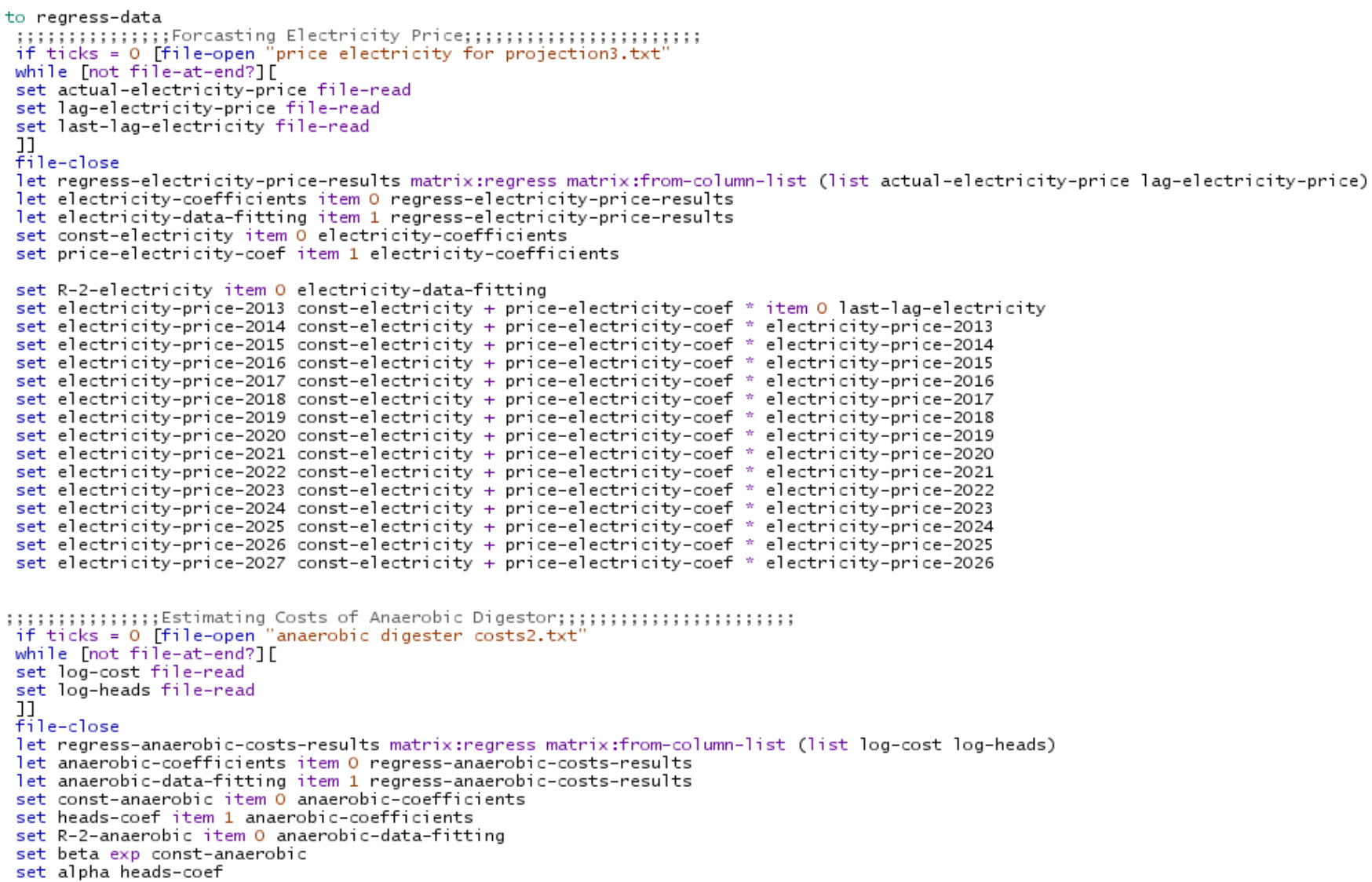

Figure A-2: BET also is programmed to conduct ordinary least square to estimate parameters used during the simulation. The code illustrated above has been developed to predict the trend of electricity prices (upper) and the capital cost of anaerobic digesters (lower). 


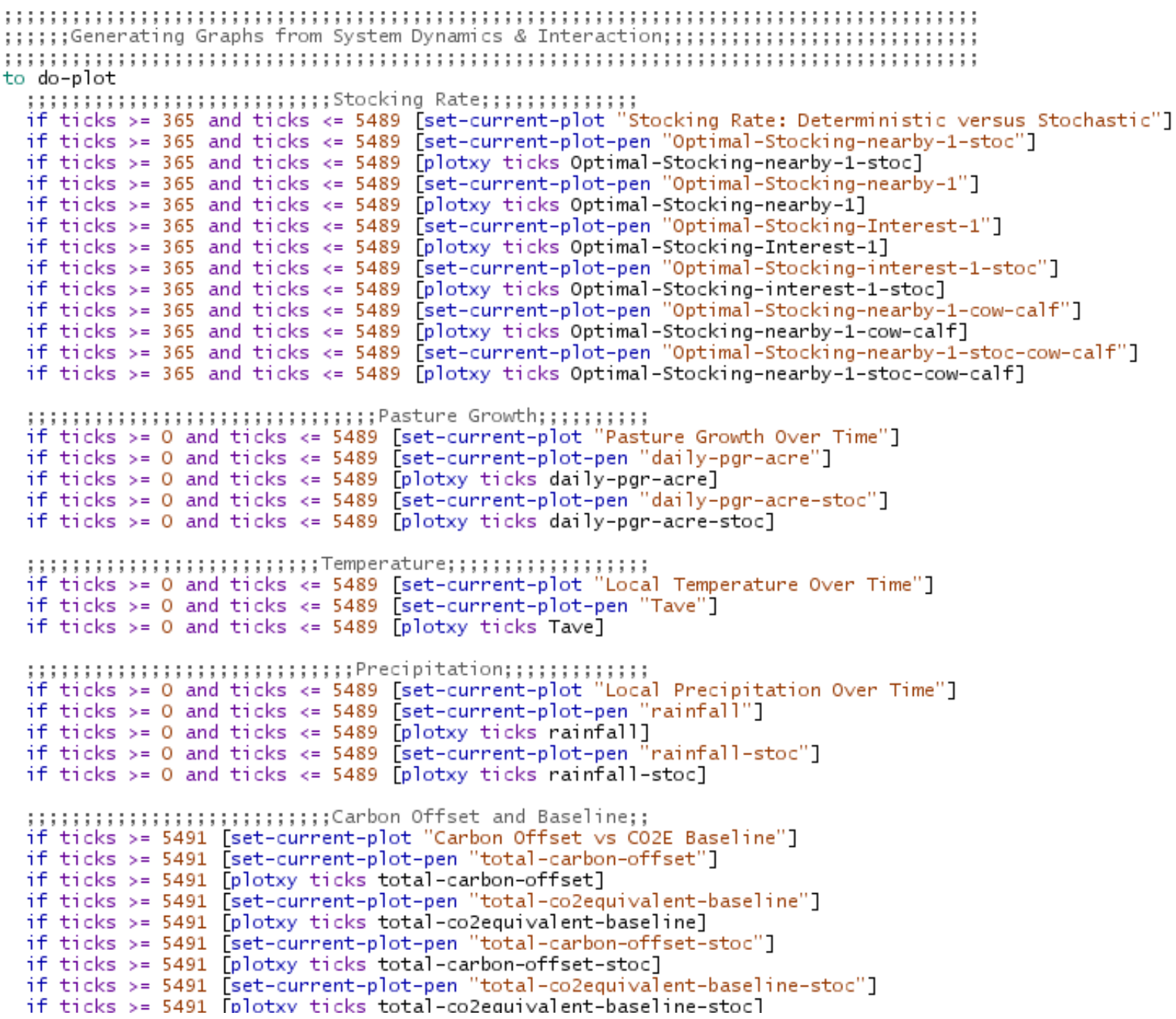

Figure A-3: In order to provide a graphical representation of the pre-interaction and interaction stages, plots (as known in NetLogo) are developed in the procedure tab through code and must be synchronized with the interface view. 


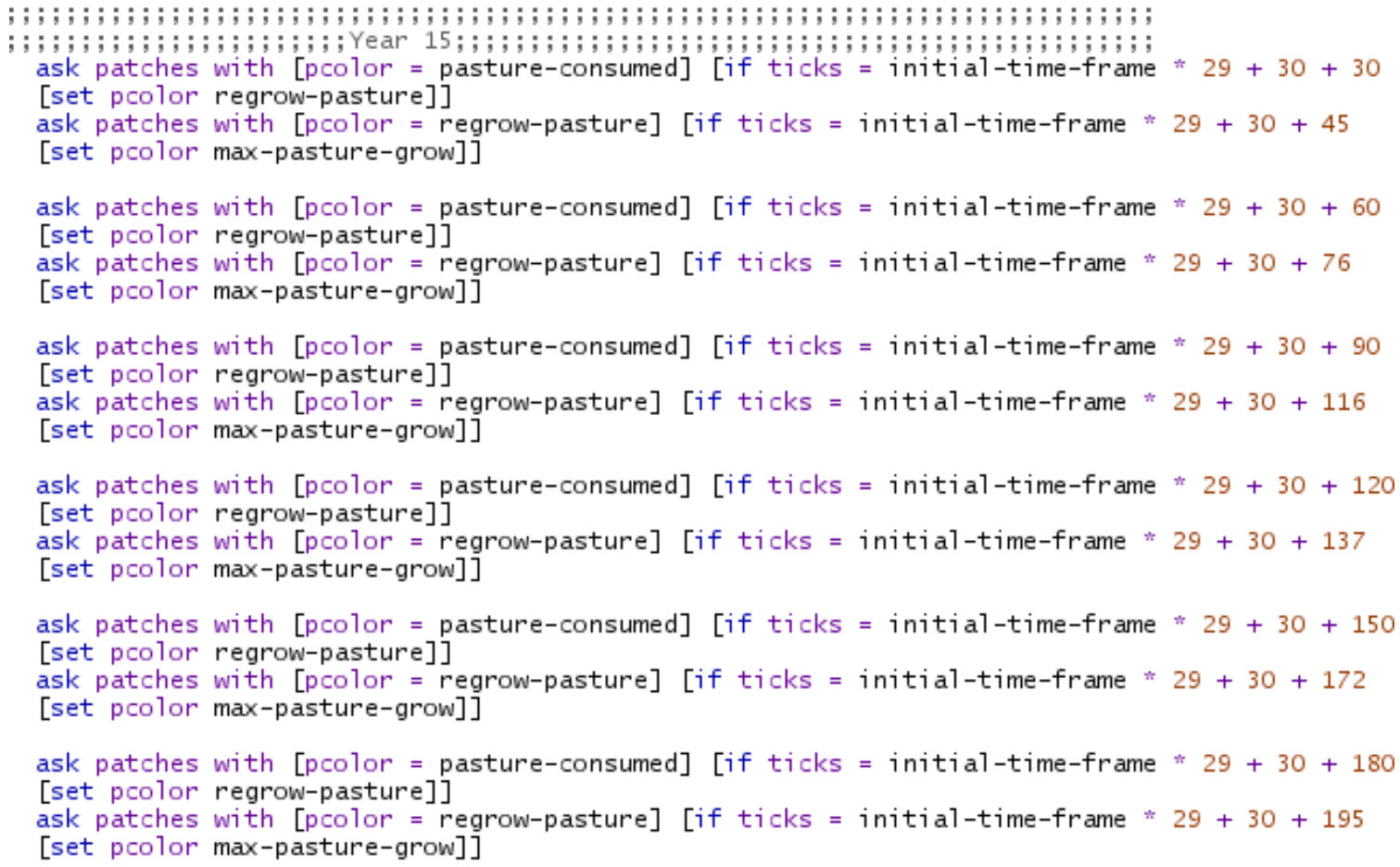

Figure A-4: Patches play an important role at yearly basis in the model since they simulate forage allowance on the interacting farms. Language programming has also been developed to represent the interaction between maximum pasture available for and consumed by animals as well as forage in the regrowing process. 